Universidade de São Paulo

\title{
Faculdade de Medicina de Ribeirão Preto
}

\section{Polianna Delfino Pereira}

\section{A influência da estimulação olfatória no desenvolvimento de crises límbicas em ratos Wistar}

Ribeirão Preto 



\title{
Polianna Delfino Pereira
}

\section{A influência da estimulação olfatória no desenvolvimento de crises límbicas em ratos Wistar}

\author{
Dissertação de Mestrado apresentada ao Departamento de \\ Neurociências e Ciências do Comportamento, Faculdade de \\ Medicina de Ribeirão Preto, Universidade São Paulo, para \\ aquisição do título de Mestre em Ciências Médicas.
}

Área de concentração: Neurologia

Opção: Neurociências

Orientador: Prof. Dr. Norberto Garcia-Cairasco

Ribeirão Preto 
AUTORIZO A REPRODUÇÃo E DIVULGAÇÃo TOTAL OU PARCIAL DESTE

TRABALHO, POR QUALQUER MEIO, CONVENCIONAL OU ELETRÔNICO, EXCLUSIVAMENTE PARA FINS NÃO COMERCIAIS, DE ESTUDO, PESQUISA OU DIVULGAÇÃO CIENTÍFICA, DESDE QUE CITADA A FONTE.

\section{Ficha Catalográfica}

Pereira, Polianna Delfino

A influência da estimulação olfatória no desenvolvimento de crises límbicas em ratos Wistar. Ribeirão Preto, 2015.

pp. 146.

Dissertação de Mestrado, apresentada à Faculdade de Medicina de Ribeirão Preto/USP- Área de concentração: Neurologia; Opção: Neurociências.

Orientador: Garcia-Cairasco, Norberto. 


\title{
FOLHA DE APROVAÇÃo
}

\section{Polianna Delfino Pereira}

\section{A influência da estimulação olfatória no desenvolvimento de crises límbicas em ratos Wistar}

\begin{abstract}
Dissertação de Mestrado apresentada ao Departamento de Neurociências e Ciências do Comportamento, Faculdade de Medicina de Ribeirão Preto, Universidade São Paulo, para obtenção do título de Mestre em Ciências Médicas.
\end{abstract}

Aprovada em:

\section{Banca examinadora}

Prof. Dr. Norberto Garcia Cairasco (Orientador e Presidente da Banca) Instituição: FMRP-USP Assinatura:

Profa. Dra. Kátia Lin

Instituição: UFSC

Assinatura:

Prof. Dr. Lauro Wichert Ana

Instituição: FMRP-USP Assinatura: 



\section{DEDICATÓRIA}

À minha família. 



\section{AgradeCIMENTOS}

Primeiramente agradeço a Deus, por ter me inspirado, me protegido, me guiado nessa importante e árdua etapa.

À minha família, em especial à minha mãe, pelo amor incondicional, doação e paciência. Sem vocês certamente não teria conseguido chegar à conclusão desse sonho. Obrigada por se fazerem presentes em todos os momentos, me apoiando, me dando força que muitas vezes faltava, a coragem para não desistir e o carinho expressado por vezes em palavras, mas sentido com a ternura de um abraço. Amo vocês!

Ao meu orientador Prof. Dr. Norberto Garcia-Cairasco pela oportunidade que tive em fazer ciência, pelo conhecimento e experiências vividas. E também pela confiança que me impulsionou a superar desafios.

Aos meus colaboradores pela paciência e dedicação para a realização desse trabalho, com auxílios nas técnicas, discussões, sugestões e correções. Certamente sem a assistência de vocês esse estudo não teria sido concluído.

Aos demais membros do LNNE por todo auxílio nesse período.

Aos meus queridos amigos pela companhia fundamental nessa etapa, pelas conversas inspiradoras, pela cumplicidade, pelas risadas, enfim, pelos momentos vividos que serão lembrados com muito carinho!

À Universidade de São Paulo (USP).

À Faculdade de Medicina de Ribeirão Preto (FMRP).

Ao Departamento de Neurociências e Ciências do Comportamento (FMRP-USP).

Ao Departamento de Fisiologia (FMRP-USP).

Ao Núcleo de Pesquisa em Produtos Naturais e Sintéticos (NPPNS-USP), em especial ao Prof. Dr. Norberto Peporine Lopes e a Izabel Cristina Casanova Turatti.

Ao Núcleo de Neurociências (NNC-UFMG), principalmente ao Prof. Dr. Márcio Flávio Dutra Moraes e ao Dr. Daniel de Castro Medeiros.

À Universidade Federal dos Vales do Jequitinhonha e Mucuri (UFVJM), em especial aos mestres e à $10^{\circ}$ Turma de Fisioterapia.

Ao Grupo Epilepsia Externamente Modificada (EpExMo).

Finalmente a todos que contribuíram direta ou indiretamente para a conclusão do presente estudo. 
Este trabalho foi desenvolvido no Laboratório de Neurofisiologia e Neuroetologia Experimental (LNNE) pela Faculdade de Medicina de Ribeirão Preto (FMRP) da Universidade de São Paulo (USP). Com apoio financeiro das seguintes agências de fomento:

Fundação de Amparo à Pesquisa do Estado de São Paulo - FAPESP;

Conselho Nacional de Desenvolvimento Científico e Tecnológico - CNPq;

Coordenação de Aperfeiçoamento de Pessoal de Nível Superior - CAPES;

Fundação de Apoio ao Ensino, Pesquisa e Assistência - FAEPA;

Cooperação Interinstitucional de Apoio a Pesquisas sobre o Cérebro - FAPESP-Cinapce.

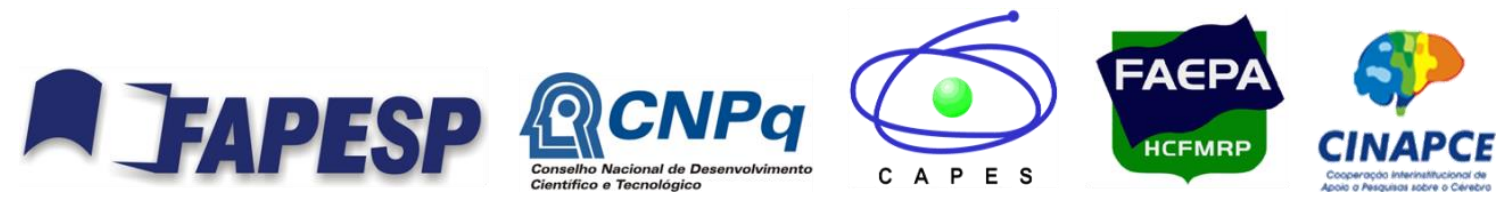




\section{RESUMO}

Um dos modelos experimentais mais utilizados para estudar a epilepsia do lobo temporal (ELT) é o abrasamento (kindling) por estimulação elétrica diária da amígdala, o abrasamento elétrico convencional. Uma alternativa rápida e eficaz a esse modelo é o abrasamento elétrico rápido, também capaz de gerar crises límbicas, porém com 10 estímulos elétricos aplicados ao dia, por 2 dias. No $3^{\circ}$ dia é aplicado um estímulo elétrico adicional, o $21^{\circ}$ estímulo, quando podem ser testadas drogas antiepilépticas ou estudados mecanismos de plasticidade ou memória. Entre as principais áreas ativadas nas crises límbicas encontram-se o complexo amigdalóide, a formação hipocampal, o córtex piriforme e neocórtices adjacentes. O envolvimento de estruturas olfatórias na ELT é antigo e estudos indicam que a exposição a um estímulo olfatório é capaz de suprimir, inibir ou induzir a ocorrência de crises. Todas as evidências clínicas e experimentais dão suporte científico para a hipótese de que a estimulação olfatória com o 2,5-Dihydro-2,4,5-trimethylthiazoline (TMT), uma potente substância química, derivada das fezes de raposa e que biologicamente representa o "cheiro de predador" pode influenciar no processo de crises evocadas por estimulação elétrica da amígdala. O objetivo geral do presente estudo foi avaliar a influência da apresentação do estímulo olfatório com TMT nas crises epilépticas de ratos Wistar, submetidos ao abrasamento elétrico rápido da amígdala. Para tanto, os parâmetros químicos do TMT foram avaliados, bem como as respostas comportamentais de ratos Wistar machos naives submetidos ao estímulo olfatório com diferentes doses de TMT. Na sequência, um novo grupo de ratos Wistar machos naives foi submetido ao protocolo de abrasamento elétrico rápido da amígdala com a aquisição dos registros eletrencefalográficos (EEGráficos) do córtex piriforme, formação hipocampal além do complexo amigdalóide. Após abrasados os animais foram expostos ao TMT ou água destilada, previamente ao $21^{\circ}$ estímulo elétrico. Posteriormente o tecido cerebral foi processado (perfundido, crioprotegido, congelado e cortado) e então foram feitas as técnicas histoquímicas de: Nissl e Fluoro-Jade C (FJC, marcador de neurodegeneração). As respostas comportamentais foram analisadas mediante o uso do Índice de Gravidade para Crises Límbicas e da neuroetologia. Adicionalmente foi avaliada a expressão EEGráfica do $1^{\circ}, 20^{\circ}$ e $21^{\circ}$ estímulos e verificada a presença/ausência de neurodegeneração em regiões do sistema límbico. Os resultados da análise comportamental obtidos nesse estudo foram comparados com os obtidos no protocolo de estimulação olfatória com TMT nas crises audiogênicas agudas de ratos da cepa WAR. O TMT desencadeou reações de medo e modificou as sequências comportamentais, reduziu a atividade motora e os comportamentos de autolimpeza. Dados qualitativos da cromatografia gasosa e algoritmos matemáticos possibilitaram estabelecer as concentrações na câmara para as diferentes doses de TMT. Além disso, a cromatografia gasosa identificou que 30 minutos é o tempo necessário para saturação e dessaturação da câmara ao TMT, e indicou uma saturação homogênea do interior dessa câmara. O TMT puro no abrasamento elétrico rápido em ratos Wistar foi capaz de reduzir significativamente o Índice de Gravidade para Crises Límbicas comparado à água, corroborando os dados neuroetológicos que indicam o efeito supressor do TMT nas crises, tanto para o modelo de abrasamento elétrico rápido quanto para as crises audiogênicas agudas. Os resultados da duração da pós-descarga EEGráfica primária no $21^{\circ}$ estímulo foram inconclusivos, sendo necessárias outras análises empregando diferentes métodos analíticos. Com a técnica de FJC não foi possível verificar morte celular por necrose em qualquer região cerebral avaliada.

Palavras-chave: ELT; Abrasamento Elétrico Rápido; Eletrencefalograma (EEG); Olfação; TMT; Amígdala; Hipocampo; Córtex Piriforme. 


\section{Abstract}

One of the most widely used experimental models to study temporal lobe epilepsy (TLE) is the kindling by electrical daily stimulation of the amygdala, the conventional kindling. A rapid and effective alternative to this model is rapid electrical kindling, also capable of generating limbic seizures, but with 10 electrical stimuli applied per day for 2 days. On the 3rd day an additional electrical stimulus is applied, the 21st stimulus, when antiepileptic drugs can be tested or mechanisms of plasticity and memory can be studied. Among the main areas activated in limbic seizures are the amygdaloid complex, the hippocampal formation, piriform cortex and adjacent neocortices. The involvement of the olfactory structures in TLE is old and studies indicate that exposure to an olfactory stimulus is capable to suppress or inhibit or induce the occurrence of seizures. All the clinical and experimental evidences provide scientific support for the hypothesis that the olfactory stimulation with 2,5-Dihydro-2,4,5-trimethylthiazoline (TMT), a powerful chemical substance derived from fox feces which biologically represents the "predator smell" can influence the seizures process evoked by electrical stimulation of the amygdala. The overall objective of this study was to evaluate the influence of olfactory stimulation with TMT in seizures of Wistar rats subjected to rapid electrical kindling of the amygdala. Therefore, the chemical parameters of TMT were evaluated, as well as behavioral responses of naive male Wistar rats exposed to the olfactory stimulus with different concentrations of TMT. Other group of rats was electrically stimulated in the amygdaloid complex, following the protocol of rapid electrical kindling and the electroencephalographic recordings (EEGraphic) obtained from the piriform cortex, hippocampal formation in addition to the amygdaloid complex. After scorched the animals were exposed to TMT or distilled water, prior to the 21st electrical stimulation. Subsequently the cerebral tissue was processed (perfused, cryoprotected, frozen and sliced) and then processed for Nissl and Fluoro-Jade C histochemistry (FJC, a marker of neurodegeneration). The behavioral responses were analyzed by using the Severity Index for Limbic Seizures and neuroethology. In addition to EEG, reviewed after the 1st, 20th and 21th stimuli we also examined the presence/absence of neurodegeneration in regions of the limbic system. The results obtained in this study were compared with those obtained in the protocol of olfactory stimulation with TMT on acute audiogenic seizures of rats from the WAR strain. The TMT triggered fear reactions and modified the behavioral sequences, reduced motor activity and grooming behavior. Qualitative data from gas chromatography and mathematical algorithms made possible to establish the concentrations in the camera for the different doses of TMT. In addition, the gas chromatography helped to identify that 30 minutes is the time required for saturation and desaturation of the camera to TMT and indicated a homogeneous saturation of the interior of such camera. The pure TMT in rapid electrical kindling in Wistar rats was able to significantly reduce the Severity Index for Limbic Seizures, compared to water, corroborating the data of the neuroethology method indicating the suppressive effect of TMT in seizures, in both, the model of rapid electrical kindling as well as the acute audiogenic seizures. However, the results of the duration of the EEGraphic primary after-discharge at the 21th stimulus were inconclusive, requiring further analysis using different analytical methods. With the technique of FJC it was not observed necrotic cell death in any studied brain region.

Keywords: TLE; Rapid Electrical Kindling; Electroencephalogram (EEG); Olfaction;

TMT; Amygdala; Hippocampus; Piriform Cortex. 


\section{LISTA DE ILUSTRAÇÕES}

Figura 1. Esquema do sistema olfatório e seus subsistemas (A) em corte sagital da cabeça de rato, com: sistema olfatório principal composto pelo EOP (bege) e BOP (bege); sistema olfativo acessório formado pelo OV (vermelho e roxo) e BOA (rosa e verde); além do OSM (azul) e GG (amarelo). E as conexões do sistema olfatório principal com: Amígdala (Ami), Hipocampo (Hip), Núcleo Olfatório (NOP), Piriforme (Pir) e Tubérculo Olfatório (TO) (Figura adaptada de GUTIYAMA, 2013).

Figura 2. Estrutura química do TMT (FENDT et al., 2005).

Figura 3. Representação esquemática resumida do protocolo utilizado para análise cromatográfica acoplada a um espectrômetro de massas.

Figura 4. Desenho experimental: esquema resumido dos grupos de animais e protocolos experimentais da curva Dose-Resposta ao TMT.

Figura 5. Câmara utilizada durante os protocolos experimentais: curva Dose-Resposta ao TMT e $21^{\circ}$ estímulo elétrico. Em (A) Câmara, (B) Sistema de controle e (C) Sistema de exaustão (idealizada pelo nosso grupo, LNNE).

Figura 6. Padrão de calibração para confecção dos fluxogramas (GARCIA-CAIRASCO et al., 1992). Cada retângulo representa um comportamento. A altura dos retângulos simboliza a frequiência de ocorrência, e a base, a duração média do comportamento durante a observação. As setas representam valores estatísticos $\left(\mathrm{X}^{2} \geq 3,841\right.$; $\left.\log \mathrm{X}^{2} \geq 0,25 ; \mathrm{p}<0,05\right)$ que indicam a probabilidade de um segundo comportamento ocorrer após um dado comportamento. A cor do retângulo tem o objetivo de identificar qualitativamente a classe comportamental. A cor das setas representa o ponto de partida das mesmas ao acompanhar a cor do retângulo que origina a interação entre pares comportamentais.

Figura 7. Fluxograma da resposta comportamental de medo induzidas pela Salina versus TMT na concentração de 300 nMol. Notamos a presença de comportamentos como: ALER, CG, SCR e SOB (círculos vermelhos). Alteração da duração dos comportamentos exploratórios de: caminhar (CM) e parar (PR) (círculos roxos). Bem como a interação estatística (seta) presente entre estes dois comportamentos (CM e PR, círculo verde) no Grupo TMT 300 nMol, e nas demais concentrações. Retângulos, setas e cores (Figura 6), siglas (Tabela Complementar 1).

Figura 8. Fluxograma da resposta comportamental de medo induzidas pela TMT na concentração de $300 \mathrm{nMol}$ versus TMT na concentração de 1000 nMol. Notamos a presença de comportamentos como: ALER, BC, CG, SCR e SOB (círculos vermelhos). Retângulos, setas e cores (Figura 6), siglas (Tabela Complementar 1). 53 Figura 9. Fluxograma da resposta comportamental de medo induzidas pela TMT na concentração de $1000 \mathrm{nMol}$ versus TMT na concentração de 10000 nMol. Notamos a presença de comportamentos como: ALER, BC, CG e SCR (círculos vermelhos). Redução na quantidade de comportamentos expressos no grupo TMT na concentração de $10000 \mathrm{nMol}$ comparado ao grupo TMT na concentração de $1000 \mathrm{nMol}$, como também do menor número de interações estatísticas entre díades (setas). Retângulos, setas e cores (Figura 6), siglas (Tabela Complementar 1).

Figura 10. Fluxograma da resposta comportamental de medo induzidas pela TMT na concentração de 10000 nMol versus TMT Puro. Notamos a presença dos mesmos comportamentos em ambos os grupos, como: BC, CG e SCR (círculos vermelhos). Redução no número de interações estatísticas entre pares comportamentais no 
grupo TMT Puro, apesar dos animais expostos ao TMT na concentração de 10000 nMol apresentarem menor número de comportamentos de autolimpeza como: autolimpeza a direita (ALD) e esquerda (ALE), autolimpeza de genitais (ALG), LCB, LG, LVF, limpar a garra posterior direita $\left(\mathrm{LGD}_{2}\right)$ e esquerda $\left(\mathrm{LGE}_{2}\right)$. Retângulos, setas e cores (Figura 6), siglas (Tabela Complementar 1).

Figura 11. Frequência dos itens comportamentais de medo expressados pelo grupo salina e pelos grupos com diferentes concentrações de TMT (300 nMol, 1000 nMol, 10000 nMol e Puro). Anova One way, Kruskal-Wallis, $* \mathrm{p}<0,05$.

Figura 12. Duração (segundos) dos itens comportamentais de medo expressados pelo grupo salina e pelos grupos com diferentes concentrações de TMT (300 nMol, 1000 nMol, 10000 nMol e Puro). Anova One way, Kruskal-Wallis, ${ }^{*} \mathrm{p}<0,05$.

Figura 13. Espectro de massas do TMT (valores dados em m/z). No eixo x representa o tempo de retenção, e em y a concentração dos íons.

Figura 14. Curva cromatográfica da concentração interna da câmara nas diferentes doses de TMT (TMT 300 nMol - marron; TMT 1000 nMol - azul; TMT 10000 nMol - rosa e TMT Puro - preto): representação qualitativa da concentração interna da câmara. Eixo $\mathrm{X}$ indica o tempo de retenção, e $\mathrm{Y}$ a concentração total de íons em cada dose. Parâmetros utilizados: volume de $5 \mu \mathrm{L}$ na concentração a ser testada de TMT, com modo de aquisição SIM e injeção Split.

Figura 15. Desenho experimental: esquema resumido dos grupos e protocolos experimentais do modelo de abrasamento elétrico rápido.

Figura 16. Desenho esquemático do rato implantado com os eletrodos após a cirurgia, no canto superior à direita. E a ampliação desta área, no desenho central (adaptado de TILELLI, 2003).

Figura 17. Esquema ilustrativo do sistema de estimulação elétrica.

Figura 18. Diagrama esquemático do sistema de registro de EEG (18.0, 18.1, 18.3 e 18.4) e estímulo (18.0, 18.1, 18.2 e 18.4).

Figura 19. Padrão de calibração para confecção dos fluxogramas (GARCIA-CAIRASCO et al., 1992). Cada retângulo representa um comportamento. A altura dos retângulos simboliza a frequência de ocorrência, e a base, a duração média do comportamento durante a observação. As setas representam valores estatísticos $(\mathrm{X} 2 \geq 3,841$; $\log \mathrm{X} 2 \geq 0,25 ; \mathrm{p}<0,05)$ que indicam a probabilidade de um segundo comportamento ocorrer após um dado comportamento. As cores utilizadas nos retângulos têm o objetivo de identificar qualitativamente classes relacionadas de comportamentos. A cor das setas representa o ponto de partida das mesmas ao acompanhar a cor do retângulo que origina a interação entre pares comportamentais.

Figura 20. Dados gerais do posicionamento dos eletrodos, nos grupos: Sem Estímulo e Água, Estímulo e Água, Sem Estímulo e TMT, e Estímulo e TMT, com desenho esquemático nas seguintes áreas: córtex piriforme (A), complexo amigdalóide (B) e formação hipocampal (C), todos no hemisfério esquerdo dos 60 animais que foram implantados com eletrodos na cirurgia extereotáxica. Sendo representado em círculos fechados com diferentes cores: vermelho o animal com acerto em apenas umas das áreas cerebrais acima descrita; amarelo o animal com acerto em duas áreas cerebrais (piriforme, complexo amigdalóide e/ou formação hipocampal); em azul o animal com eletrodo posicionado no piriforme, complexo amigdalóide e/ou formação hipocampal; e finalmente em verde o animal com o posicionamento no córtex piriforme, BLA e hilus do giro denteado. *amarelo representa 
um eletrodo do grupo Estímulo e Água posicionado na área correspondente da prancha inferior, mas que devido a organização da Figura foi representado na prancha do grupo Sem Estímulo e Água.

Figura 21. Tecido corados pela técnica de Nissl com posicionamento de eletrodos: (A) córtex piriforme, (B) BLA, (C) hilus do giro denteado no hipocampo, todos no hemisfério esquerdo (lado direito). Esquema do atlas de Paxinos \& Watson (2005) com indicação do posicionamento na área desejada (lado esquerdo). Barra de calibração de $1000 \mu \mathrm{m}$.

Figura 22. Classificação comportamental de crises observadas durante a evolução do abrasamento elétrico rápido, estímulo a estímulo, dos animais de ambos os grupos Estimulados $(\mathrm{N}=20)$. No eixo $\mathrm{Y}$ estão às médias do Índice de Gravidade para Crises Límbicas segundo Racine (1972) alcançado em cada estímulo indicado pelo eixo X. Anova One Way, Friedman test, Dunn's post test, ${ }^{*} \mathrm{p}<0,05$; **p $<0,01$ e p $<0,001$.

Figura 23. Classificação comportamental de crises observadas durante a evolução do abrasamento elétrico rápido, estímulo a estímulo, dos animais do grupo Estímulo e Água (linha e círculos pretos preenchidos, N=8), e do grupo Estímulo e TMT (linha e quadrados vermelhos preenchidos, $\mathrm{N}=12$ ). No eixo $\mathrm{Y}$ estão às médias do Índice de Gravidade para Crises Límbicas segundo Racine (1972) alcançado em cada estímulo, indicado pelo eixo X. Two-way ANOVA, com diferença entre os grupos de $\mathrm{p}<0,01$, diferença entre os estímulos de $\mathrm{p}<0,001$.

Figura 24. Comparação das médias obtidas pelo Índice de Gravidade para Crises Límbicas observadas no $21^{\circ}$ estímulo elétrico, com a intervenção prévia da água no grupo Estímulo e Água (A, N=8), versus TMT no grupo Estímulo e TMT (B, N=12). No eixo Y estão às médias do Índice de Gravidade para Crises Límbicas segundo Racine (1972) alcançado em cada grupo indicado pelo eixo X. Teste t Student não pareado, *p<0,05.

Figura 25. Fluxogramas ilustrando o efeito comportamental da Água (A) e do TMT (B), com as sequências comportamentais da simulação do $21^{\circ}$ estímulo elétrico dos grupos Sem Estímulo e Água (A), e Sem Estímulo e TMT (B), ambos com 5 animais por grupo. Sendo apresentado na primeira célula de cada estímulo, o período pré de estimulação olfatória (1) de 20 segundos; na célula intermediária (2) o período de simulação do "estímulo" elétrico por 10 segundos; e finalmente na última célula (3) o período pós estímulação, com duração de 05 minutos. Retângulos, setas e cores (Figura 19), siglas (Tabela Complementar 1).

Figura 26. Fluxogramas da somatória das sequências comportamentais registradas no $1^{\circ}$ (A) e $20^{\circ}$ estímulos elétricos (B) de 10 animais de ambos os grupos estimulados (Estímulo e Água, e Estímulo e TMT). Sendo (1) período pré estimulação elétrica de 5 minutos; (2) período de estimulação elétrica de 10 segundos e (3) período pós-estimulação elétrica, com duração de 05 minutos. Retângulos, setas e cores (Figura 19), siglas (Tabela Complementar 1).

Figura 27. Fluxogramas das sequências comportamentais do $21^{\circ}$ estímulo do grupo Estímulo e Água (A, N=5), e Estímulo e TMT (B, N=5). Os números representam os períodos: (1) pré estimulação elétrica de 20 segundos; (2) estimulação de 10 segundos e (3) pós-estimulação, com duração de 05 minutos. Retângulos, setas e cores (Figura 19), siglas (Tabela Complementar 1).

Figura 28. Média dos Índices de Gravidade para Crises Límbicas observadas durante a evolução do abrasamento elétrico rápido, estímulo a estímulo, dos animais do grupo Estímulo e TMT selecionados aleatoriamente para a análise neuroetológica ( $\mathrm{A}, \mathrm{N}=5)$ versus grupo Estímulo e TMT (B, N=12). Em C e D estão representadas as médias dos Índices de Gravidade para Crises Límbicas dos animais do grupo Estímulo e Água analisados pela neuroetologia $(\mathrm{C}, \mathrm{N}=5)$ versus grupo Estímulo e Água $(\mathrm{D}, \mathrm{N}=8)$. No eixo $\mathrm{Y}$ estão as médias do Índice de 
Gravidade para Crises Límbicas alcançadas em cada estímulo indicado pelo eixo X. Teste Friedman, com $* \mathrm{p}<0,05$ e $* * \mathrm{p}<0,01$.

Figura 29. Duração da pós descarga primária no $1^{\circ}, 20^{\circ}$ e $21^{\circ}$ estímulos, das áreas: Piriforme, Complexo Amígdalóide e Formação Hipocampal, para o Grupo Estímulo e Água (N=8, linha preta) versus Estímulo e TMT $(\mathrm{N}=12$, linha vermelha). Two-way ANOVA, $* \mathrm{p}<0,05 ; * * * \mathrm{p}<0,001$.

Figura 30. Duração da pós descarga primária no $21^{\circ}$ estímulo, das áreas: Piriforme, Complexo Amígdalóide e Formação Hipocampal, para o Grupo Estímulo e Água ( $\mathrm{N}=8$, coluna preta) versus Estímulo e $\mathrm{TMT}$ (N=12, coluna vermelha). Teste $t$ Student não pareado, $\mathrm{p}>0,05$.

Figura 31. Registro EEGráfico do $1^{\circ}(\mathrm{A}), 20^{\circ}$ (B) e $21^{\circ}$ (C) estímulos de um animal escolhido aleatoriamente do grupo Estímulo e Água, com escala de aumento de 40 segundos/divisão em A e B, e 15 segundos/divisão em C. Períodos pré estímulo (atividade basal), estímulo e pós estímulo estão representados pelos algarismos romanos I, II e III, respectivamente. A barra horizontal indica o tempo (segundos) e a barra vertical à esquerda estão indicados os três canais de registro: em verde o córtex piriforme, rosa a formação hipocampal e em cinza o complexo amigdalóide. E na barra do lado direito o ganho de cada canal, correspondendo os intervalos 2 volts (V), ao valor de $1 \mathrm{mV}$, dado o ganho do sistema igual a 2000 vezes. Nessa figura está também representada a presença de pós-descarga primárias indicada pelas setas pretas e a pós-descarga secundária indicada pelas setas vermelhas, indicando um aumento da duração da pós descarga primária, entre $1^{\circ}$ e $20^{\circ}$ estímulos. E no $21^{\circ}$ Estímulo presença da pós descarga primária.

108

Figura 32. Registro EEGráfico do $1^{\circ}(\mathrm{A}), 20^{\circ}$ (B) e $21^{\circ}$ (C) estímulos de um animal escolhido aleatoriamente do grupo Estímulo e TMT, com escala de aumento de 40 segundos/divisão em A e B, e 15 segundos/divisão em C. Períodos pré estímulo (atividade basal), estímulo e pós estímulo estão representados pelos algarismos romanos I, II e III, respectivamente. A barra horizontal indica o tempo (segundos) e a barra vertical à esquerda estão indicados os três canais de registro: em verde o córtex piriforme, rosa a formação hipocampal e em cinza o complexo amigdalóide. E na barra do lado direito o ganho de cada canal, correspondendo os intervalos 2 volts (V), ao valor de $1 \mathrm{mV}$, dado o ganho do sistema igual a 2000 vezes. Nessa figura está também representada a presença de pós-descarga primárias indicada pelas setas pretas e a pós-descarga secundária indicada pelas setas vermelhas, indicando um aumento e redução da duração da pós descarga primária, entre $1^{\circ}$ e $20^{\circ}$ estímulos, e $20^{\circ}$ e $21^{\circ}$ estímulos, respectivamente.

Figura 33. Histoquímica de FJC: (A) Hilus do giro denteado do controle positivo (animal submetido ao SE i.p.), (B) Hilus do giro denteado, (C) Complexo amigdalóide e (D) Córtex piriforme, sendo em (B-D) animal escolhido aleatoriamente do grupo Estímulo e TMT. Podemos notar que em (A) os animais submetidos ao SE tiveram marcação para neurodeneração no Hilus, evidenciado no inset (aumento digital de 4x) pela coloração verde. E em B-D indica a ausência de marcação para essa técnica, notado pelo inset (aumento digital de 4x) em B. Todos os quatro tecidos foram submetidos à mesma bateria de realização da histoquímica. Barra de calibração de $150 \mu \mathrm{m}$.

Figura 34. Influência do TMT no desenvolvimento de crises audiogênicas agudas.

Figura 35. Evidências neuroetológicas do efeito anticonvulsivante do TMT nas crises audiogênicas agudas. Diferentes respostas comportamentais de medo foram induzidas pelo TMT/s (B) versus SAL/s (A), como: ALER, BC, CG e SCR (B, círculos vermelhos). O possível efeito anticonvulsivo é reforçado pelo aumento da frequência e das interações entre os comportamentos procursivos (corridas, COR; giros, GID e GIE; pulos, PU; e 
quedas, QT; em amarelo) nos TMT/som (D, círculo verde) versus SAL/som (C). E e F representam os animais que tiveram um perfil diferente de crises, com (E) ou sem (F) comportamentos de CVT (círculo verde). $\quad 117$ 



\section{Lista DE TABELAS}

Tabela 1. Respostas comportamentais nas diferentes concentrações. 45

Tabela 2. Diferentes tempos de exposição ao TMT. 46

Tabela 3. Respostas comportamentais e endócrinas induzidas pelo TMT. 61

Tabela 4. Metodologias diferentes geram respostas diferentes. $\quad 62$

Tabela 5. Índice de Gravidade para Crises Límbicas. $\quad 77$

Tabela 6. Índice de Gravidade para Crises Mesencefálicas. $\quad 80$

Tabela 7. Valor-p durante a evolução do abrasamento elétrico rápido da Figura 22.

Tabela 8. Avaliação dos índices de gravidade de crises segundo Racine (1972), do grupo Estímulo e TMT analisados pela neuroetologia.

Tabela 9. Avaliação dos índices de severidade de crises segundo Racine (1972), do grupo Estímulo e Água analisados pela neuroetologia.

Tabela 10. Alterações celulares e moleculares presentes no tecido cerebral de animais submetidos ao modelo de abrasamento elétrico rápido.

Tabela 11. Efeitos do TMT na modulação do sistema olfatório principal.

Tabela 12. Efeitos do TMT na modulação de diferentes estruturas cerebrais centrais. 



\section{LISTA DE SIGLAS}

$\begin{array}{ll}\text { AMPc } & \text { Adenosina monofosfato cíclico } \\ \text { AP } & \text { Ântero-posterior } \\ \text { BLA } & \text { Núcleo basolateral do complexo amigdalóide } \\ \text { BOA } & \text { Bulbo olfatório acessório } \\ \text { BOP } & \text { Bulbo olfatório principal }\end{array}$

CA Corno de Ammon

CRE Crises recorrentes espontâneas

dB Decibéis

d.C. Depois de Cristo

DV Dorso-ventral

EEG Eletrencefalograma

EEGráfica Eletrencefalográfica

ELT Epilepsia de Lobo Temporal

EOP Epitélio olfatório principal

fets Transistores de efeito de campo

FFT Transformada de Fourier

FJC Fluoro-Jade C

FMRP Faculdade de Medicina de Ribeirão Preto

GG Gânglio Grueneberg

$\mathrm{Hz} \quad \mathrm{Hertz}$

ISc Índice de Gravidade para crises Mesencefálicas

ILAE Comission International League Against Epilepsy

i.p. Intra peritoneal

LNNE Laboratório de Neurofisiologia e Neuroetologia Experimental

ML Médio-lateral

$m / z \quad$ Razão massa/carga

NE Norepinefrina

NIH/NINDS National Institutes of Health/National Institute of Neurological

Disorders and Stroke

NPPNS Núcleo de Pesquisa em Produtos Naturais e Sintéticos

OSM Órgão septal de Masera

OV Órgão vomeronasal 


$\begin{array}{ll}\text { PAG } & \text { Substância cinzenta periaquedutal } \\ \text { PBS } & \text { Tampão Fosfato Salina } \\ \text { PFA } & \text { Paraformaldeído } \\ \text { ppb } & \text { Partes por bilhão } \\ \text { ppm } & \text { Partes por milhão } \\ \text { PTZ } & \text { Pentilenotetrazol } \\ \text { SAL/s } & \text { Grupo Sem Som exposto a salina } \\ \text { SAL/som } & \text { Grupo Com Som submetido por 20 segundos a salina } \\ \text { SSM } & \text { Órgão septal de Masera } \\ \text { SE } & \text { Status Epilepticus } \\ \text { SNA } & \text { Sistema Nervoso Autônomo } \\ \text { SCAN } & \text { Análise por varredura } \\ \text { SCP } & \text { Substância cinzenta periaquedutal } \\ \text { SIM } & \text { Selected Ion Monitoring } \\ \text { SPME } & \text { Solid Phase Micro Extration } \\ \text { TMT } & \text { 2,5-Dihydro-2,4,5-Trimethylthiazoline } \\ \text { TMT/s } & \text { Grupo Sem Som exposto ao TMT } \\ \text { TMT/som } & \text { Grupo Com Som submetido por 20 segundos ao TMT } \\ \text { UFMG } & \text { Universidade Federal de Minas Gerais } \\ \text { USP } & \text { Universidade de São Paulo } \\ \text { vídeo-EEG } & \text { Vídeo-eletrencefalograma } \\ \text { ZE } & \text { Zona epileptogênica } \\ \text { WAR } & \text { Wistar Audiogenic Rats } \\ \text { WDS } & \text { Wet dog shake } \\ & \end{array}$

Para lista de siglas referentes aos itens comportamentais apresentados nos fluxogramas, ver TABELA COMPLEMENTAR 1. 


\section{SUMÁRIO}

1 INTRODUÇÃO

1.1 Epilepsia $\quad 25$

1.2 Modelos Experimentais $\quad 26$

1.2.1 Abrasamento Elétrico 28

1.3 Epilepsia e Olfação 29

1.4 Olfação e Circuitaria Cerebral 30

1.5 Medo e 2,5-Dihydro-2,4,5-Trimethylthiazoline (TMT) 33

2 JUSTIFICATIVA

3 HIPÓTESE 38

4 OBJETIVO GERAL 38

5 CAPÍTULO I: PARÂMETROS QUÍMICOS E CARACTERIZAÇÃO NEUROETOLÓGICA DOS EFEITOS DA EXPOSIÇÃO AO ESTÍMULO OLFATÓRIO COM TMT EM RATOS WISTAR 39

5.1 Objetivos Específicos $\quad 39$

5.2 Material e Métodos $\quad 40$

5.2.1 Delineamento Experimental $\quad 40$

5.2.2 Análise Química do TMT 40

5.2.3 Dose-resposta do TMT 42

5.2.3.1 Escolha das Concentrações do TMT 45

5.2.3.2 Tempo de Exposição ao TMT 46

5.2.4 Perfusão, Crioproteção e Congelamento 46

$\begin{array}{lll}\text { 5.2.5 Registro e Análise Comportamental } & 47\end{array}$

5.3 Resultados e Discussão

5.3.1 Escolha do TMT 49

5.3.2 Caracterização dos Efeitos da Exposição ao Estímulo Olfatório com TMT em Ratos Wistar 51

5.3.3 Análise Química do TMT

6 CAPÍTULO II: INFLUÊNCIA DA ESTIMULAÇÃO OLFATÓRIA COM TMT NO MODELO DE ABRASAMENTO ELÉTRICO RÁPIDO DA AMÍGDALA 67

6.1 Objetivos Específicos 
$\begin{array}{llr}\text { 6.2 } & \text { Material e Métodos } & 68\end{array}$

$\begin{array}{lll}\text { 6.2.1 } & \text { Grupos Experimentais } & 68\end{array}$

$\begin{array}{lll}6.2 .2 & \text { Anestesia } & 70\end{array}$

$\begin{array}{lll}\text { 6.2.3 Cirurgia Estereotáxica } & 70\end{array}$

$\begin{array}{lll}6.2 .4 & \text { Estimulação Elétrica } & 72\end{array}$

6.2.5 Indução de Crises Epilépticas 73

$\begin{array}{lll}\text { 6.2.6 Estimulação Olfatória } & 74\end{array}$

6.2.7 Perfusão, Crioproteção e Congelamento 74

$\begin{array}{lll}6.2 .8 & \text { Histoquímica de Nissl } & 75\end{array}$

6.2.9 Histoquímica de FJC 76

6.2.10 Registro e Análise Comportamental 76

6.2.11 Estimulação Olfatória em Animais WAR 79

$\begin{array}{llr}\text { 6.3 } & \text { Resultados e Discussão } & 80\end{array}$

$\begin{array}{lll}\text { 6.3.1 } & \text { Confirmação Histológica } & 80\end{array}$

6.3.2 Índice de Gravidade para Crises Epilépticas 83

$\begin{array}{lll}\text { 6.3.3 Caracterização Neuroetológica } & 89\end{array}$

$\begin{array}{lll}\text { 6.3.4 Análise EEGráfica } & 101\end{array}$

6.3.5 Morte Neuronal Induzida pelo Abrasamento Elétrico Rápido 110

6.3.6 Caracterização Neuroetológica dos Efeitos da Exposição ao Estímulo Olfatório com TMT

Nas Crises Audiogênicas Agudas $\quad 115$

7 DISCUSSÃO GERAL 119

8 CONCLUSÃO 127

9 REFERÊNCIAS BIBLIOGRÁFICAS 131

10 ANOTAÇÕES 141 


\section{INTRODUÇÃOO}

\subsection{EPILEPSIA}

A epilepsia pode ser definida como uma importante alteração neurológica crônica, caracterizada pela persistente predisposição a geração de crises epilépticas recorrentes espontâneas (CRE; FISHER et al., 2005), convulsivas ou não e normalmente autolimitadas (ENGEL, 1995). Pode acarretar consequências neurobiológicas, psicológicas, cognitivas e sociais ao indivíduo acometido. Entretanto, dentre os elementos que devem ser considerados para o diagnóstico de epilepsia inclui-se a presença de pelo menos uma crise epiléptica, que cause alteração cerebral permanente, resultando no quadro transitório de sinais/sintomas, dada à hiperexcitabilidade e à hipersincronicidade anormais de substratos neurais (FISHER et al., 2005).

Essa alteração neurológica pode resultar de diferentes causas, sendo classificadas como epilepsia idiopáticas ou primárias aquelas sem substrato lesional, relacionadas à predisposição genética, e epilepsia adquiridas ou secundárias quando estão associadas a algum tipo de insulto ou disfunção neurológica adquirida, tais como: trauma, tumor, infecção, febre, dentre outros (ENGEL, 2001).

Segundo a International League Against Epilepsy (ILAE Commission, 1981), as crises parciais ocorrem quando o início envolve regiões neuronais específicas e restritas a um hemisfério cerebral podendo propagar para outras áreas cerebrais. Tais crises podem também ser subclassificadas em relação ao comprometimento ou manutenção da consciência, sendo denominadas crises complexas ou simples, respectivamente. Já as crises generalizadas o início é simultâneo em ambos os hemisférios cerebrais podendo ser convulsivas ou não (ILAE Commission). Em 2010, Berg e colaboradores revisaram e redefiniram alguns dos principais termos utilizados para caracterizar a epilepsia, nessa nova proposta crises generalizadas incluem a propagação para redes neurais bilaterais - podendo incluir estruturas corticais e subcorticais, mas não necessariamente todo o córtex. Já as crises epilépticas parciais tem origem numa rede neural limitada a um dos hemisférios cerebrais, ou em estruturas subcorticais.

Além disso, as crises podem ter manifestações sintomáticas (ENGEL, 2001), como alterações autonômicas, motoras, sensoriais, cognitivas, comportamentais, além de poder afetar a consciência, a memória, a cognição e o estado emocional. Entretanto, nem todas as 
crises apresentam todas essas manifestações, mas pelo menos uma alteração está presente em uma crise. E finalmente, é possível associar a manifestação clínica com uma alteração eletrofisiológica característica de crises epilépticas (FISHER et al., 2005).

Segundo McNamara (1999), a epilepsia acomete 1 a 2\% da população mundial; destes, aproximadamente um terço apresentam Epilepsia de Lobo Temporal (ELT - estruturas predominantemente acometidas: hipocampo, complexo amigdalóide e córtices adjacentes) caracterizando o tipo mais comum de epilepsia. Sua ocorrência é precedida de um insulto inicial seguido de um período variado de latência, período esse que ocorrem as alterações epileptogênicas, que irão cursar posteriormente com a presença de CRE (McNAMARA, 1999). Cerca $30 \%$ dos indivíduos com ELT são resistentes aos tratamentos farmacológicos atuais (FONG et al., 2011; WHO, 2010), e embora a remoção do foco epileptogênico seja um procedimento importante para tais pacientes, os critérios necessários para esse procedimento nem sempre legitimam todos os candidatos. Além disso, a provável instalação de sequelas pós cirúrgicas e o índice de recidivas em alguns centros (FONG et al., 2011) representam pontos desfavoráveis da abordagem cirúrgica. Desta forma, a busca por novas intervenções terapêuticas mostra-se como um importante desafio no estudo da epilepsia, afim de desenvolver estratégias que minimizem a ocorrência de CRE e que induzam eventuais respostas neuroprotetoras (PITKÄNEN, 2010).

\subsection{MODELOS EXPERIMENTAIS}

Os modelos experimentais podem ser definidos como métodos que possibilitam mimetizar ou reproduzir em animais de laboratório determinadas características de certos tipos de doenças, bem como testar a resposta fisiológica dos animais a diferentes drogas e estímulos, sendo amplamente utilizados com o objetivo de entender os diversos mecanismos envolvidos no fenômeno estudado. Além disso, tais modelos viabilizam o uso de ferramentas que por motivos éticos não poderiam ser aplicadas diretamente em pesquisas clínicas, mas por outro lado, possuem como desvantagens principalmente o uso de animais de experimentação, muito questionado na sociedade atual, além de peculiaridades anatômicas inerentes à espécie escolhida para estudo (FISHER, 1989). Entretanto, não existe um modelo experimental que mimetize completamente o quadro clínico de epilepsia, logo todos os modelos predizem uma resposta clínica (KANDRATAVICIUS et al., 2014), o que em suma permite grosseiramente generalizar que o melhor modelo que reproduz a epilepsia clínica é o humano. 
Assim a escolha do modelo experimental reflete a pergunta da pesquisa, a conveniência e a familiaridade do experimentador ao modelo. Esses estudos diferem quanto ao número de estímulos indutores de crises epilépticas, sendo o modelo agudo ou crônico; ou em relação à preparação do tecido, podendo ser in vivo, in vitro ou in sílico, e finalmente quanto aos métodos utilizados para o desenvolvimento de crises epilépticas (FISHER, 1989).

Como exemplo, em alguns modelos genéticos são necessários além da predisposição genética inata à crise, um segundo fator denominado de iniciador ou gatilho, como estímulos exógenos incluindo: luz, som, e outros. Neste sentido, um dos modelos genéticos que vem sendo estudado há mais de 25 anos é o da cepa Wistar Audiogenic Rats (WAR), que apresenta crises epilépticas de origem mesencefálica deflagradas por meio de estímulos sonoros de alta intensidade (DORETTO et al., 2003; GARCIA-CAIRASCO, 2002; GARCIA-CAIRASCO et al., 1996; KANDRATAVICIUS et al., 2014). Esta cepa é proveniente de seleção desenvolvida no nosso Laboratório de Neurofisiologia e Neuroetologia Eperimental (LNNE) a partir do cruzamento endogâmico dos animais da linhagem Wistar, que apresentavam predisposição a desenvolver crises tônico-clônicas generalizadas, quando expostos ao som de uma campainha elétrica, com intensidade sonora equivalente a 120 decibéis (dB; DORETTO et al., 2003).

Para modelos químicos ou farmacológicos, é necessária a administração de drogas que provoquem crises, como ácido caínico (BEN-ARI et al., 1978; FISHER, 1989; KANDRATAVICIUS et al., 2014), pilocarpina (CAVALHEIRO., 1995; CASTRO et al., 2011; FISHER, 1989; FURTADO et al., 2002, 2011; KANDRATAVICIUS et al., 2014; TURSKI et al., 1983) e outras. Essas drogas podem ser administradas tanto por via sistêmica, como por injeção intracerebral.

Já a estimulação elétrica de determinadas áreas cerebrais caracteriza os modelos elétricos. Essa estimulação pode ser contínua (FISHER, 1989; KANDRATAVICIUS et al., 2014; TILELLI et al., 2005) levando ao desenvolvimento de Status Epilepticus (SE, descrito como crises contínuas ou repetidas sem recuperação entre elas, por no mínimo 30 minutos CASTRO et al., 2011; FISHER, 1989; TILELLI et al., 2005; TURSKI et al., 1983) ou intermitente, como no abrasamento (kindling) - modelo esse que foi utilizado no presente estudo (BERTRAM, 2007; EBERT; LÖSCHER, 1995; FISHER, 1989; FORESTI et al., 2008; GODDARD, 1983; LÖSCHER; BRANDT, 2010; KANDRATAVICIUS et al., 2014; LÖSCHER; EBERT, 1996; SAYIN et al., 2003). 


\subsubsection{AbraSAMENTo ELÉTRICO}

O modelo experimental de abrasamento elétrico consiste na indução de crises epilépticas evocadas por estimulação elétrica repetida e de baixa intensidade (sublimiares) que culmina com progressivas alterações estruturais, eletrofisiológicas e comportamentais (BERTRAM, 2007; EBERT; LÖSCHER, 1995; FISHER, 1989; FORESTI et al., 2008; GODDARD, 1983; LÖSCHER; BRANDT, 2010; LOTHMAN et al., 1985; LÖSCHER; EBERT, 1996; SAYIN et al., 2003). É descrito como um importante modelo de ELT, que mimetiza o quadro clínico de epilepsia parcial complexa (BERTRAM, 2007; EBERT; LÖSCHER, 1995; FISHER, 1989; LÖSCHER; BRANDT, 2010; KANDRATAVICIUS et al., 2014; LÖSCHER; EBERT, 1996; LOTHMAN et al., 1985; McNAMARA et al., 1980). Entre as principais áreas ativadas nas crises límbicas encontram-se o complexo amigdalóide, a formação hipocampal, o córtex piriforme e neocórtices adjacentes (BERTRAM, 2007; EBERT; LÖSCHER, 1995; FISHER, 1989; GODDARD; MCINTYRE; LEECH, 1969; GODDARD, 1967, 1983; LÖSCHER; BRANDT, 2010; LÖSCHER; EBERT, 1996; LÖSCHER et al., 1995; LOTHMAN et al., 1985; McNAMARA et al., 1980). Para tal modelo, a indução também pode ser realizada por estimulação sensorial ou química - além da elétrica (FISHER, 1989; GODDARD, 1983).

A primeira descrição desse modelo data de 1961, quando Delgado e Sevillano observaram a intensificação progressiva da crise quando administrada corrente elétrica em baixos níveis de forma repetida no hipocampo (apud McNAMARA et al., 1980). Posteriormente, outros pesquisadores observaram uma diminuição da latência para crises, com o progressivo agravamento comportamental (GODDARD; MCINTYRE; LEECH, 1969; GODDARD, 1967). Assim, ao longo de mais de 50 anos muitas investigações foram realizadas utilizando esse modelo no estudo da epileptogênese e também dos mecanismos de plasticidade e memória (FISHER, 1989; GODDARD; MCINTYRE; LEECH, 1969; GODDARD, 1967). Dentro das alterações epileptogênicas descritas nesse modelo experimental, incluem-se: a morte celular por apoptose e necrose (LÖSCHER; BRANDT, 2010; LÖSCHER; EBERT, 1996; SAYIN et al., 2003).

Conhecer a data do início das crises, as diferentes conexões neurais dependendo da localização dos eletrodos implantados, controlar a intensidade da corrente indutora de crises, e identificar os efeitos da estimulação repetida no cérebro, são algumas das vantagens em utilizar tal modelo (BERTRAM, 2007). 
Dentre os protocolos de abrasamento elétrico descritos na literatura, podemos citar duas abordagens diferentes: o abrasamento elétrico convencional e o abrasamento elétrico rápido. Nos modelos de abrasamento elétrico convencional são aplicados 1 a 2 estímulos por dia, durante aproximadamente duas semanas para o desenvolvimento do abrasamento, enquanto no abrasamento elétrico rápido descrito por alguns estudos (FORESTI et al., 2008; LÖSCHER et al., 1995; LOTHMAN et al., 1985; RACINE et al., 1973) são aplicados 20 estímulos elétricos durante 2 dias, ou seja, 10 estímulos ao dia. E no $3^{\circ}$ dia é aplicado um estímulo adicional.

Logo, o abrasamento elétrico rápido apresenta algumas vantagens em relação ao convencional, como: a prevenção de infecções ou outras alterações fisiológicas causadas pelo implante crônico de eletrodos, além do desenvolvimento de CRE dentro de poucos dias. Ademais, a abreviação do período de experimentação gera uma redução dos gastos com a manutenção do animal, o que também representa uma vantagem desse modelo (EBERT; LÖSCHER, 1995; FORESTI, 2008).

\subsection{EPILEPSIA E OlfaÇÃo}

Em pacientes com ELT, é comum a ocorrência de auras, que são breves (duram segundos) sintomas subjetivos, que geralmente indicam o início da crise ao paciente (LÜDERS et al., 1998), sendo a aura epigástrica, caracterizada por uma "sensação de vazio ou náusea na região epigástrica, de caráter ascendente pela região torácica" a mais frequentemente relatada pelos pacientes (DANTAS et al., 1998). Também pode ocorrer, porém em menor frequência, a aura olfativa, caracterizadas por sensações olfatórias subjetivas. Entretanto, para as últimas crises a utilização de estímulo olfatório pode prevenir ou suprimir crises (BETTS, 2003; EFRON, 1956, 1957; JASEJA, 2008).

Efron (1956) descreveu o caso de uma paciente com ELT, que apresentava crises epilépticas precedidas de auras, inibidas por estimulação sensorial com jasmim (odor semelhante ao da aura). Em outro trabalho, o autor relata a memorização desse cheiro com a concomitante associação a um acessório, que após tal condicionamento, a paciente conseguia impedir a expressão das crises com a simples evocação da memória olfatória (EFRON, 1957). Sugerindo que, a ativação de circuitos para o processamento desse odorante pode ser importante no controle de crises.

Em algumas partes do mundo como a Índia, tem testemunhado desde tempos remotos a utilização do cheiro de shoe-smell, ou seja, o popular "chulé" como técnica de primeiros 
socorros anticonvulsivante. A persistência desse exótico método tem compelido estudos que buscam entender suas bases científicas (JASEJA, 2008).

No trabalho desenvolvido por Betts e colaboradores (2003), foi utilizado o tratamento não farmacológico, conhecido como aromaterapia. Os autores descrevem que após esse tratamento os indivíduos conseguiram suprimir suas crises, demonstrando que a aromoterapia pode ajudar no controle da epilepsia em indivíduos que apresentam auras olfatórias, corroborando aos dados publicados por Efron (1956, 1957) e Jaseja (2008).

Em modelo animal de ELT por abrasamento elétrico da amígdala, a estimulação olfatória intensa com Tolueno (C7H8 - PM 92,14 - Merck Indústria Química Rio de Janeiro, Brasil) suprimiu as crises na maioria dos ratos, mesmo com estímulo elétrico $20 \%$ acima do necessário para deflagrar uma crise (EBERT; LÖSCHER, 2000). Segundo os autores, o córtex piriforme estaria "ocupado", processando a informação olfatória, o que dificultaria a propagação da crise (EBERT; LÖSCHER, 2000).

Finalmente, a estimulação olfatória também com Tolueno foi efetiva em animais da cepa WAR submetidos ao abrasamento audiogênico e a um único estímulo acústico, bloqueando ou reduzindo substancialmente a expressão comportamental de crises nesses animais (BERTTI et al., 2010, 2011, 2013), em consonância aos estudos supracitados.

Considerando as evidências clínicas e experimentais sobre a exposição olfatória no controle de crises, pouco se sabe sobre tais mecanismos, logo, entender tais paradigmas, e possivelmente no futuro poder fornecer outra opção de tratamento além das opções atualmente disponíveis, representa um importante desafio.

\subsection{Olfação e Circuitaria Cerebral}

Todos os seres vivos estão constantemente expostos às moléculas odoríferas sejam elas dissolvidas na água ou no ar (SU; MENUZ; CARLSON, 2009). Essas moléculas têm um papel fundamental para a sobrevivência das espécies, motivando comportamentos sexuais, comportamentos de ingestão de água e alimentos, além dos comportamentos sociais (agressão, submissão ou aproximação) (SU; MENUZ; CARLSON, 2009). A detecção e posterior discriminação do odorante são realizadas pelo sistema olfatório (BUCK; AXEL, 1991; ISAACSON, 2010; SU; MENUZ; CARLSON, 2009).

A olfação corresponde a um dos três sentidos químicos, além da gustação e da somestesia química, e embora seja menos acurado em humanos que em outros animais, sua 
organização morfofuncional é bastante semelhante entre os diferentes organismos (GUTIYAMA, 2013; MALNIC, 2008).

O sistema olfatório é composto por vários subsistemas denominados: sistema olfatório principal, sistema olfatório acessório, órgão septal de Masera (OSM) e o gânglio Grueneberg (GG). Mas as pesquisas atuais envolvendo o olfato baseiam-se, fundamentalmente no sistema olfatório principal e sistema olfatório acessório (SU; MENUZ; CARLSON, 2009).

O sistema olfatório principal é composto pelo epitélio olfatório principal (EOP) e o bulbo olfatório principal (BOP). O EOP localizam na cavidade nasal superior dorsal e é constituído por neurônios sensoriais olfatórios, células progenitoras basais, e as células de sustentação (ARISI et al., 2012; BUCK; AXEL, 1991; GUTIYAMA, 2013; ISAACSON, 2010; MALNIC, 2008, 2007; SU; MENUZ; CARLSON, 2009).

Os neurônios olfatórios são células bipolares com dendritos voltados para a cavidade nasal, nos quais localizam-se cerca de 10-30 cílios por neurônio, e são responsáveis pelo reconhecimento e transdução do sinal olfatório. Seus axônios ascendem em filetes, correspondendo ao $1^{\circ}$ par de Nervo Craniano - o Olfatório, ultrapassando a placa crivosa do osso etmóide, e fazendo sinapse diretamente com o BOP, por via direta extra-talâmica (ARISI et al., 2012; BUCK; AXEL, 1991; GUTIYAMA, 2013; ISAACSON, 2010; MALNIC, 2008, 2007; SU; MENUZ; CARLSON, 2009).

Do BOP partem os axônios que formam o trato olfatório lateral, e projetam diretamente para diferentes áreas corticais e subcorticais, como: tubérculo olfatório, núcleo olfatório, córtex entorrinal, amígdala e córtex piriforme que corresponde à principal área do córtex olfatório (ARISI et al., 2012; BUCK; AXEL, 1991; ISAACSON, 2010; MALNIC, 2007; SU; MENUZ; CARLSON, 2009) (Figura 1). Tais áreas processam as informações olfatórias, resultando na percepção e discriminação dos cheiros (BUCK; AXEL, 1991; MALNIC, 2008, 2007; GUTIYAMA, 2013).

De uma forma sucinta, o nariz é o órgão que canaliza e conduz o ar aos pulmões, e consequentemente permite a ligação das moléculas voláteis de maneira específica aos seus respectivos receptores olfatórios presentes nos cílios dos neurônios olfatórios (BUCK; AXEL, 1991; GUTIYAMA，2013; ISAACSON，2010; MALNIC，2008，2007; SU; MENUZ; CARLSON, 2009). Com a interação do odorante ao seu receptor olfatório, ocorre a ativação da proteína Golf, que é a proteína $\mathrm{G}$ específica dessas células, que na sequência ativa a adenilil ciclase responsável pela síntese de adenosina monofosfato cíclico (AMPc). E com o aumento das concentrações intracelulares de AMPc ocorrem a abertura de canais com a 
consequente entrada intracelular de sódio e cálcio, despolarizando a membrana e ativando o neurônio olfatório (BUCK; AXEL, 1991; GUTIYAMA, 2013; MALNIC, 2008).

Estudos demonstraram que um odorante pode ativar diferentes receptores olfatórios, assim como um receptor pode ser estimulado por diferentes odorantes. Dessa forma cada odorante interage de maneira específica com o receptor que apresenta características químicas compatíveis com as suas propriedades. Logo existe uma espécie de "código combinatorial" para cada odorante (BUCK; AXEL, 1991; GUTIYAMA, 2013; MALNIC, 2008, 2007).

Acredita-se que o ser humano tenha aproximadamente 400 receptores olfatórios (cerca de 1/3 a menos que os ratos), cada neurônio apresenta um único tipo de receptor, essa combinação de receptores ativados resulta na capacidade de identificar até 10.000 odores diferentes (GUTIYAMA, 2013; MALNIC, 2008) Entretanto ao longo da evolução, a aquisição da postura ereta afastando o nariz da vasta gama de odorantes dispersos no solo, somado ao surgimento da visão tricromática refletiu no quanto cada espécie depende desse sentido para sua sobrevivência e reprodução (GUTIYAMA, 2013). Essa diferença na sensibilidade reflete-se na anatomia do sistema olfatório, com maior tamanho dessas áreas nos animais com importante capacidade olfatória como o rato e cachorro por exemplo, em comparação ao homem. Mas por outro lado, as estruturas de processamento central, tanto límbicas como corticais no homem, possibilitam um maior processamento dessa informação, permitindo correlacionar um dado odorante a um contexto emocional, e as memórias emotivas, conhecidos como experiências proustianas (GUTIYAMA, 2013; MALNIC, 2008).

Além do sistema olfatório principal o sistema olfatório também é composto pelo sistema olfatório acessório formado pelo órgão vomeronasal (OV) em roedores, o que corresponde ao órgão vestigial de Jacobson no homem (Figura 1). Essa estrutura envia projeções para o bulbo olfatório acessório (BOA; ARISI et al., 2012; GUTIYAMA, 2013; MALNIC, 2008; SU; MENUZ; CARLSON, 2009), e então envia aferências principalmente para a amígdala (ARISI et al., 2012), sendo responsável pela detecção de feromônios (ARISI et al., 2012; GUTIYAMA, 2013; SU; MENUZ; CARLSON, 2009). E finalmente formado pelo GG e o OSM com funções fisiológicas não completamente conhecidas, que se localizam anterior ao EOP (para maiores detalhes ver Figura 1) (GUTIYAMA, 2013). 


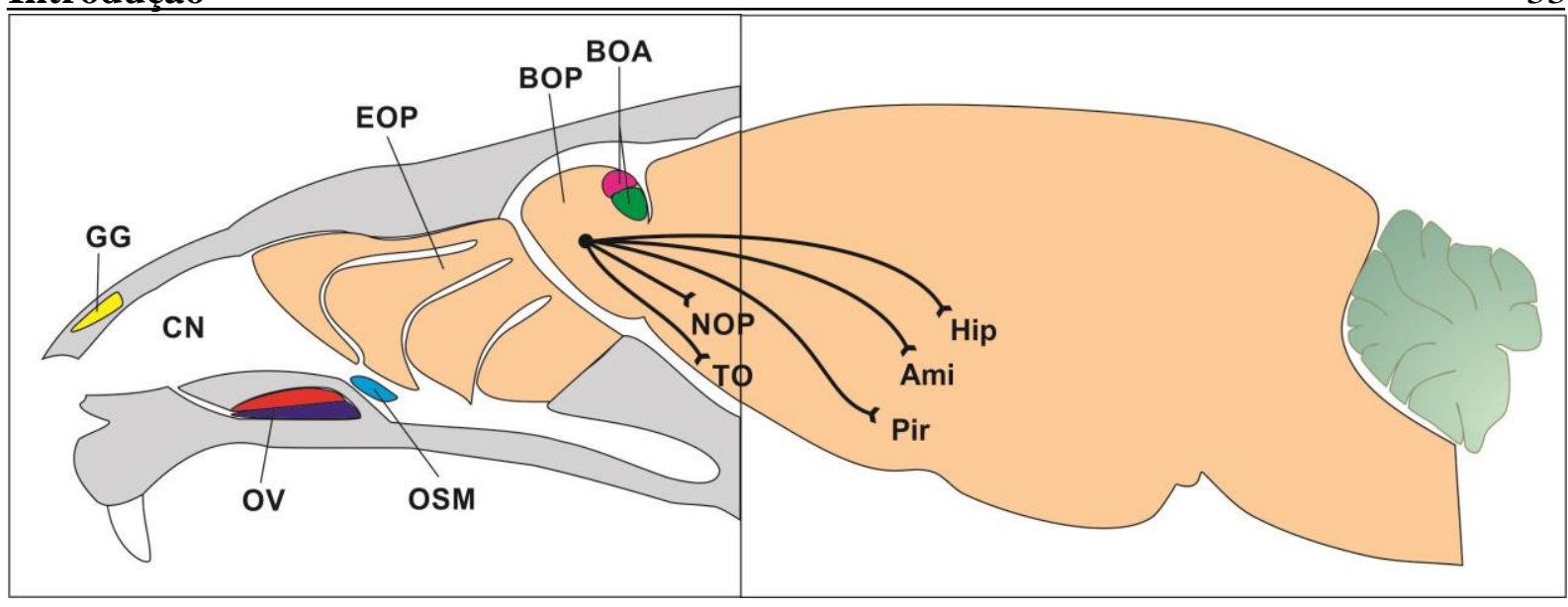

Figura 1. Esquema do sistema olfatório e seus subsistemas (A) em corte sagital da cabeça de rato, com: sistema olfatório principal composto pelo EOP (bege) e BOP (bege); sistema olfativo acessório formado pelo OV (vermelho e roxo) e BOA (rosa e verde); além do OSM (azul) e GG (amarelo). E as conexões do sistema olfatório principal com: Amígdala (Ami), Hipocampo (Hip), Núcleo Olfatório (NOP), Piriforme (Pir) e Tubérculo Olfatório (TO) (Figura adaptada de GUTIYAMA, 2013).

\subsection{MEdO E 2,5-DIHYDRO-2,4,5-TRIMETHYLTHIAZOLINE (TMT)}

As presas possuem diferentes adaptações para se defender de seus predadores, que podem ser morfológicas (através de espinhos, dentes e outros), fisiológicos (venenos ou toxinas), ou comportamentais (comportamento de luta, fuga, submissão ou congelamento; FENDT et al., 2005). As formas para avaliar o risco de predação necessariamente incluem as vias sensoriais como as vias auditiva, visual e olfatória (HACQUEMAND et al., 2013).

Através do olfato os animais são capazes de reconhecer sinais químicos presentes no ambiente, detectando por exemplo, a proximidade ou a presença de um predador. Essa detecção precoce, localização, identificação e a consequente resposta da presa frente ao predador é uma característica importante do comportamento de defesa, fundamental para a sobrevivência das espécies (BLANCHARD; BLANCHARD; ROSEN, 2008).

Nesse sentido o uso das pistas olfatórias é particularmente relevante no ambiente natural, por ser às vezes a única informação disponível para presas que estão se escondendo, ou são incapazes de detectar visualmente a fonte de ameaça (TAKAHASHI, 2014) em especial para os animais com hábitos noturnos (BLANCHARD et al., 2001).

Segundo Gross \& Canteras (2012), o medo é uma resposta neurobiológica, que surge frente a uma ameaça que comprometa a sobrevivência do animal. As respostas de medo decorrentes da ameaça iminente necessariamente dependem do envolvimento do sistema nervoso autônomo (SNA), resultando em uma cascata de reações bioquímicas e fisiológicas responsáveis por preparar o indivíduo para lidar com a ameaça. Essas respostas de medo podem ser divididas em medo condicionado e incondicionado. O medo condicionado é 
estabelecido quando um estímulo aversivo é pareado a um estímulo neutro ou a um contexto específico, sendo que após algumas exposições o indivíduo passa a responder com medo mesmo na ausência do estímulo aversivo, ou seja, basta o estímulo neutro para deflagrar a resposta.

Já o medo incondicionado, também chamado de medo inato, corresponde a uma resposta a um estímulo intrinsecamente ameaçador (GROSS; CANTERAS, 2012), ou seja, não é necessário que haja uma experiência prévia para o reconhecimento de um determinado estímulo como ameaçador ou perigoso, logo, as respostas de medo surgem na primeira exposição.

Para os roedores, seus principais predadores são carnívoros, incluindo cães, gatos, lobos e raposas (FENDT et al., 2005). Em 1980, Vernet-Maury relatou o TMT (Figura 2), como o constituinte das fezes da raposa vermelha que melhor induz respostas de medo incondicionado (apud FENDT et al., 2005).

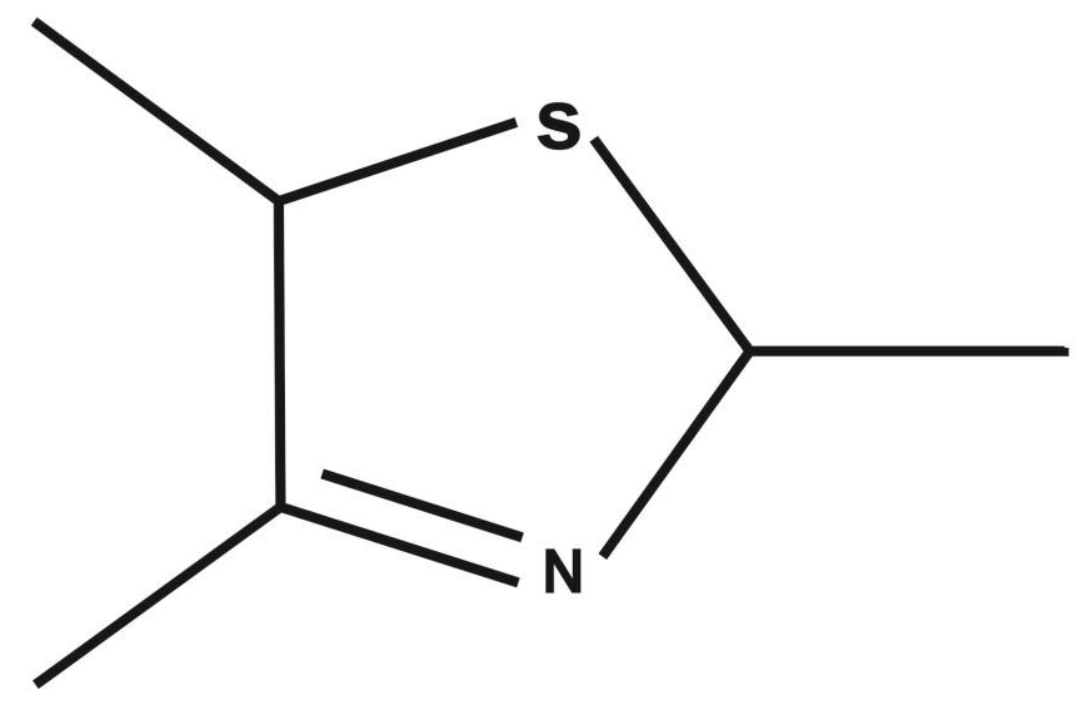

Figura 2. Estrutura química do TMT (FENDT et al., 2005).

Do ponto de vista neurofisiológico, o TMT ativa o SNA simpático (BRANDÃO et al., 2004; HORII et al., 2010; ROSEN et al., 2008; TAKAHASHI, 2014). Comportamentalmente, estudos mostram diferentes respostas dos animais à exposição com o TMT como: congelamento ou freezing (APFELBACH et al., 2005; AYERS et al., 2013; BLANCHARD et al., 2003; BRANDÃO et al., 2004; FENDT et al., 2005; HACQUEMAND; JACQUOT; BRAND, 2010; HORII et al., 2010; LASKA et al., 2005; NIKAIDO; NAKASHIMA, 2009; ROSEN et al., 2008; THOMAS; URBAN; PETERSON, 2006; WALLACE; ROSEN, 2000), 
redução da atividade motora (APFELBACH et al., 2005; BRANDÃO et al., 2004; ENDRES; APFELBACH; FENDT, 2005; HACQUEMAND; JACQUOT; BRAND, 2010; ROSEN et al., 2008; THOMAS; URBAN; PETERSON, 2006), redução dos comportamentos de autolimpeza ( BRANDÃO et al., 2004; FENDT et al., 2005; ROSEN et al., 2008; WALLACE; ROSEN, 2000) e outros.

É bem descrito na literatura que o complexo amigdalóide desempenha um papel central no medo (FENDT et al., 2005; GROSS; CANTERAS, 2012; HACQUEMAND; JACQUOT; BRAND, 2010; TAKAHASHI, 2014), reunindo distintas entradas aferentes que carregam informações sobre as ameaças ambientais e canalizando-os ao longo de distintas vias eferentes. Além disso, o TMT ativa o hipocampo ventral (DAY; MASINI; CAMPEAU, 2004; TAKAHASHI, 2014), e o córtex piriforme. Assim, todas essas informações são projetadas para o hipotálamo medial e para a substância cinzenta periaquedutal (PAG; GROSS; CANTERAS, 2012). 



\section{JUSTIFICATIVA}

Esse estudo baseia-se em evidências clínicas e experimentais que fornecem um escopo científico demonstrando que a estimulação olfatória pode influenciar o processo de crise, interferindo na resposta molecular, comportamental e eletrencefalográfica (EEGráfica).

Entretanto, pouco se sabe sobre o paradigma de ELT com eventual controle por estimulação olfatória. Embora a supressão ou inibição de crises utilizando o Tolueno seja efetivo, os efeitos adversos do uso dessa substância tóxica surgirá seja a curto, médio, ou longo prazo.

O TMT uma substância que representa biologicamente o "cheiro de predador", surge como um eventual supressor ou bloqueador de crises evocadas por estimulação elétrica da amígdala, dado o envolvimento de estruturas como complexo amigdalóide, a formação hipocampal, o córtex piriforme tanto durante as respostas de medo induzidas pelo TMT, quanto nas crises límbicas.

Ademais, não é o intuito desse estudo indicar uma substância que promova uma sensação desagradável como o medo, mas estudar possíveis mecanismos básicos desse controle e sugerir com base no conhecimento adquirido novos estudos com outros odorantes. Sejam por exemplo, odorantes provenientes de fêmeas no cio, ou de uma substância com cheiro agradável, ou outros.

Assim, esse estudo usa do conhecimento clínico para tentar entender o controle olfatório sobre as crises. E o TMT surge como uma opção interessante, que como qualquer outro odorante possui ação direta no sistema nervoso central, com resposta rápida, sem apresentar absorção sistêmica. Logo, entende-se que é o TMT é uma alternativa para a construção desse conhecimento.

Além disso, o esforço por novas opções terapêuticas se faz necessário principalmente para os pacientes que não respondem aos tratamentos farmacológicos atuais, e para os que buscam por uma terapia com menos reação adversa. 


\section{HIPÓTESE}

A exposição olfatória ao TMT deverá induzir o aumento do limiar de crises em ratos Wistar submetidos ao abrasamento elétrico rápido da amígdala. Natural consequência deste fenômeno será a ausência ou redução de marcação para morte celular por necrose (neurodegeneração) em circuitos epileptogênicos, bem como a supressão ou inibição dos efeitos comportamentais e EEGráficos característicos do modelo de abrasamento elétrico rápido da amígdala.

\section{ObJeTivo GeraL}

Avaliar a influência da apresentação do estímulo olfatório nas crises epilépticas de ratos Wistar, submetidos ao abrasamento elétrico rápido da amígdala. 


\subsection{OBJETIVOS ESPECÍfICOS}

$\rightarrow$ Verificar a concentração de TMT capaz de induzir comportamentos de medo em ratos Wistar.

$\rightarrow$ Quantificar a saturação odorífera dentro da câmara (exposição ao odor) nas diferentes concentrações de TMT.

$\rightarrow$ Verificar o tempo necessário para saturação e dessaturação da câmara ao TMT.

$\rightarrow$ Avaliar se a saturação interna da câmara é homogênea. 


\subsection{Material E MÉTOdoS}

Esse protocolo foi aprovado pelo Comitê de Ética em Pesquisa Animal da Faculdade de Medicina de Ribeirão Preto (FMRP) - Universidade de São Paulo (USP; número da licença: 200/2011).

\subsubsection{DELINEAMENTO EXPERIMENTAL}

Inicialmente foi realizada uma revisão na literatura afim de verificar qual a concentração necessária para induzir respostas de medo em ratos, quando submetidos a estimulação olfatória com TMT.

Assim, para que pudéssemos prosseguir com os experimentos, precisávamos verificar a concentração ou dose de TMT capaz de produzir alterações comportamentais significativas em ratos Wistar. Entretanto, era necessário estabelecer previamente alguns parâmetros da câmara que seria utilizada para os experimentos como o tempo necessário para saturação e dessaturação ao TMT e avaliar se a saturação era homogênea dentro dessa câmara.

Dessa forma, foram realizados inicialmente tais experimentos envolvendo a curva Dose-Resposta de TMT para cumprir com o primeiro objetivo e análises cromatográficas para verificar os demais objetivos dessa primeira parte. Para que fosse possível prosseguir com os protocolos subsequentes envolvendo o TMT na vigência de crises (Capítulo II).

\subsubsection{ANÁlise QuíMICA do TMT}

Todos os experimentos descritos nessa seç̧ão foram realizados com a colaboração do Núcleo de Pesquisa em Produtos Naturais e Sintéticos (NPPNS), coordenado pelo Prof. Dr. Norberto Peporine Lopes na Faculdade de Ciências Farmacêuticas de Ribeirão Preto, e executado pela técnica Izabel Cristina Casanova Turatti.

A cromatografia em fase gasosa é um método físico-químico de separação, fundamentada na migração diferencial dos componentes de uma mistura, baseando primariamente nos diferentes pontos de ebulição (método comparado à destilação fracionada, mas em microescala (COLLINS et al., 2003).

Essa técnica objetiva separar diversos componentes de uma mistura, quantificar sustâncias químicas e identificar compostos principalmente quando acoplada a um espectrômetro de massas (COLLINS et al., 2003). 
Para nosso estudo essa metodologia foi aplicada afim de, verificar através de curva analítica a saturação odorífera à qual o rato seria exposto nas diferentes concentrações de TMT utilizando o sistema Solid Phase Micro Extration (SPME) para o sequestro do ativo e após quantificar o índice de saturação utilizando algoritmos matemáticos para a concentração na câmara nas diferentes doses de TMT, dado seu volume. Além disso, foi possível também verificar o tempo necessário para a saturação e dessaturação completa da câmara, e finalmente avaliar se a saturação dentro da câmara era homogênea.

A cromatografia em fase gasosa é composta por duas fases imiscíveis, "uma fase permanece estacionária, enquanto a outra se move através dela" (COLLINS et al., 2003). Resumidamente após colocar o TMT na câmara, a fibra (PDMS, 100 $\mu \mathrm{L}$ ) foi exposta a amostra contida no ambiente saturado dessa câmara por um determinado tempo, e imediatamente após a dessorção pelo sistema SPME, a fibra foi inserida no injetor do cromatógrafo em fase gasosa (Shimadzu, GCMS-QP2010 série C704643). Então o analito foi termicamente dessorvido devido à alta temperatura do injetor $\left(230^{\circ} \mathrm{C}\right)$, e introduzido na entrada da coluna contendo a fase estacionária (parede recoberta com 5\% difenildimetilsiloxano). O gás inerte carreador (Hélio) arrastou (fase móvel) a amostra vaporizada através da coluna contendo a fase estacionária a um fluxo constante de 1,1 milímetros/minuto, onde ocorreu à movimentação inibida pela adsorção (fixação) entre as duas fases imiscíveis, a fase móvel e a fase estacionária. Logo, a separação da mistura ocorreu com diferentes taxas de progressão na coluna, baseando nas propriedades físico-química do TMT e da fase estacionária. Ao final o detector monitorou o fluxo de saída e identificou os compostos pelo tempo de retenção, registrando esse sinal graficamente através do cromatograma (Protocolo para análise cromatográfica acoplada ao espectrômetro de massa, Figura 3) (COLLINS et al., 2003).

Para esses experimentos utilizamos o método baseado na coluna de capilares; com volume, comprimento, diâmetro interno e espessura do filme de: $1 \mu \mathrm{L}, 30 \mathrm{~m}, 0,025 \mathrm{~mm}, 0,25$ $\mu \mathrm{m}$, respectivamente. Além do uso do detector de espectrômetro de massas com modo de ionização por impacto de elétrons. A temperatura da coluna inicial aplicada foi de $40^{\circ} \mathrm{C}$ que aumentava linearmente $3^{\circ} \mathrm{C}$ a cada minuto até alcançar $115^{\circ} \mathrm{C}$ (programação de temperatura). $\mathrm{Na}$ fonte de ionização a temperatura foi de $250^{\circ} \mathrm{C}$ e na interface de $260^{\circ} \mathrm{C}$. Com modo de aquisição incialmente por análise por varredura (SCAN), e após por Selected Ion Monitoring (SIM). E injeção Splitless ou Split (1:10). 


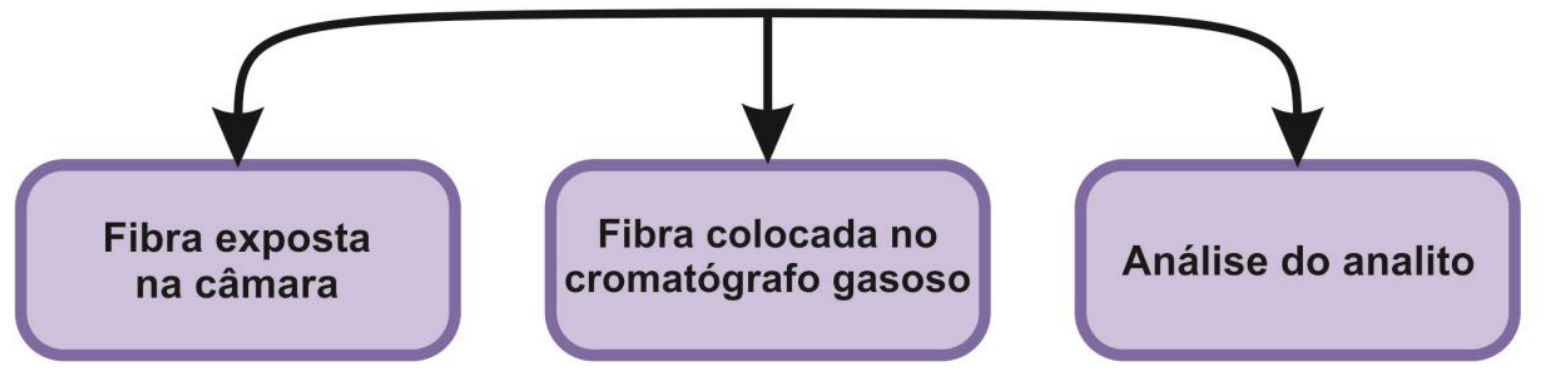

Figura 3. Representação esquemática resumida do protocolo utilizado para análise cromatográfica acoplada a um espectrômetro de massas.

Para as análises iniciais do TMT foi preparado uma solução de $500 \mu \mathrm{L}$ na concentração de $300 \mathrm{nMol}$ afim de determinar o perfil cromatográfico, ou seja, os íons pela razão massa/carga $(\mathrm{m} / \mathrm{z})$ característicos dessa substância (Experimento 1).

Após, foi realizado o Experimento 2, utilizando o protocolo para análise cromatográfica acoplada ao espectrômetro de massa (Figura 3), com $500 \mu \mathrm{L}$ de TMT na concentração de $300 \mathrm{nMol}$. Entretanto para esse experimento o tempo de exposição da fibra ao TMT na câmara variou entre 1-30 minutos. Para inicialmente determinar a duração necessária para saturar a câmara, e em um segundo momento, para identificar o tempo de retirada do odorante da câmara, ou seja, dessaturar.

Além disso, foi verificado se a modificação do posicionamento da fibra dentro da câmara poderia alterar a captação do TMT, utilizando a mesma metodologia do experimento anterior, exceto quanto ao posicionamento da fibra (Experimento 3).

E finalmente foi realizado o Experimento 4 para construção da curva analítica da saturação odorífera na câmara nas diferentes concentrações de TMT, com o mesmo protocolo ilustrado na Figura 3, utilizando o volume de $5 \mu \mathrm{L}$ - adotado como volume padrão nesse estudo - da dose ser testada de TMT. Após foi realizado cálculos através de algoritmos matemáticos a fim de verificar a saturação de TMT na câmara para as diferentes concentrações.

Todos os experimentos foram realizados em triplicatas. Para tanto alguns cuidados foram tomados evitando a contaminação e perdas da amostra.

Em seguida foi realizado o protocolo para identificação da concentração capaz de produzir respostas comportamentais de medo em ratos Wistar.

\subsubsection{DOSE-RESPOSTA DO TMT}

Como citado anteriormente, durante a revisão da literatura foi observada certa inconsistência entre os estudos quanto à concentração de TMT necessária para deflagrar 
e caracterização neuroetológica dos efeitos da exposição ao estímulo olfatório com TMT em ratos Wistar respostas de medo. Diante desse impasse, surgiu então a necessidade de realizar a curva DoseResposta de TMT.

Para esse protocolo de exclusiva estimulação olfatória foram utilizados ratos Wistar, machos, naives, adultos, 280-300 gramas, provenientes do Serviço de Biotério do Campus de Ribeirão Preto da Universidade de São Paulo.

Os animais foram submetidos a um ciclo claro-escuro de 12/12 horas, sob temperatura controlada de $21^{\circ} \mathrm{C}$, com água e ração ad libitum. Foram armazenados em caixas de polietileno com tampa de ferro cromado $(40,5 \times 33,5 \times 21 \mathrm{~cm})$, em grupos de no máximo 6 ratos por caixa no período anterior ao dia do experimento. E após os animais foram mantidos em caixas individuais.

Inicialmente os ratos foram habituados ao experimentador, a sala de experimentação e ao trajeto do biotério para sala, durante 3 dias consecutivos anteriores ao dia de experimentação, afim de minimizar qualquer variável que pudesse interferir nos resultados desse estudo - já que é sabido que o ambiente novo pode induzir mudanças endócrinas e comportamentais (HORII et al., 2010; NIKAIDO; NAKASHIMA, 2009; ROSEN et al., 2008).

No quarto dia, os animais foram distribuídos aleatoriamente em um dos cinco grupos experimentais conforme protocolo representado na Figura 4, e expostos ao estímulo olfativo com solução salina $(\mathrm{NaCl}$ 0,9\%) ou a uma das diferentes concentrações de TMT.

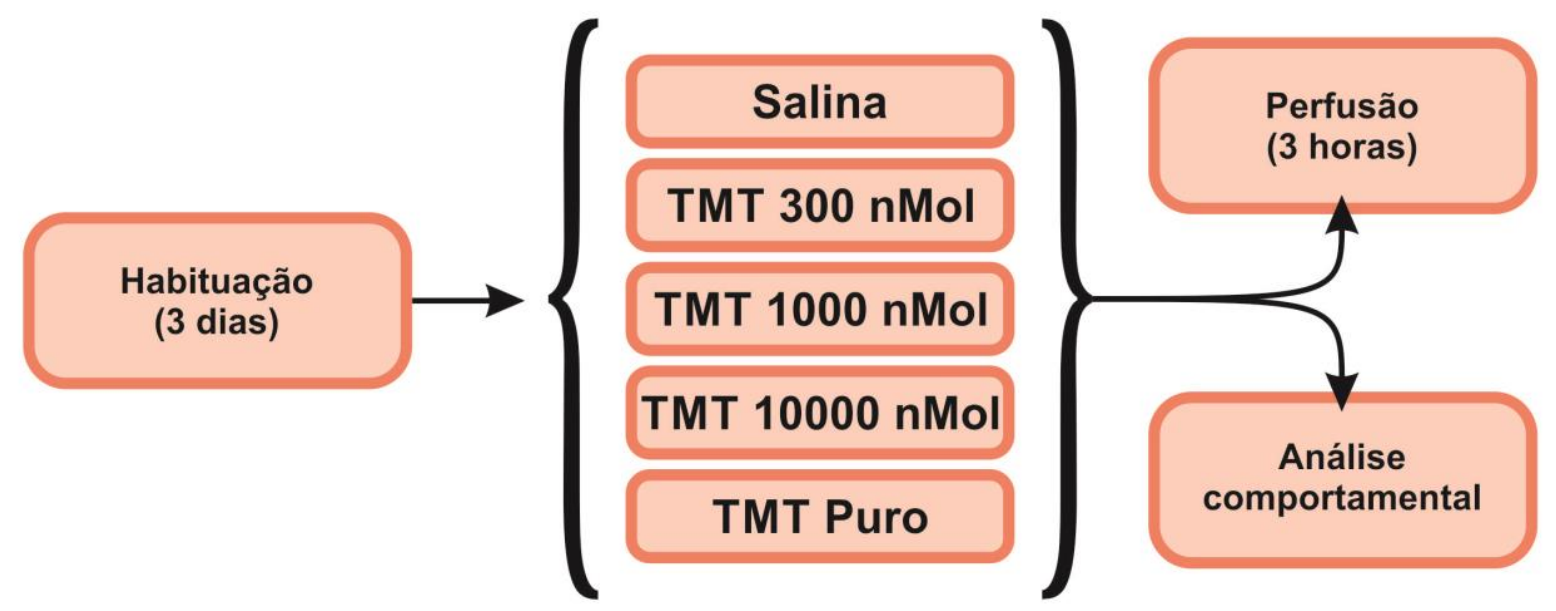

Figura 4. Desenho experimental: esquema resumido dos grupos de animais e protocolos experimentais da curva Dose-Resposta ao TMT.

No dia do experimento, a câmara foi preparada antes da exposição do rato ao odor, ou seja, para cada animal foram colocados $5 \mu$ L (FENDT; ENDRES, 2008) da substância a ser testada sobre um pedaço de papel filtro (dimensão: 4,5 x 4,5), com a câmara totalmente 

e caracterização neuroetológica dos efeitos da exposição ao estímulo olfatório com TMT em ratos Wistar fechada, durante determinado tempo, obedecendo aos dados obtidos pela técnica de cromatografia gasosa (ver item 5.2.2). Na sequência, o animal foi colocado na câmara e seu comportamento filmado durante todo o período, para posterior análise. Após a retirada de cada animal, o sistema de exaustão foi acionado para retirar a substância.

Na tentativa de otimizar a exposição olfatória, a câmara foi reparada com borrachas nas saídas, permitindo uma melhor vedação (Figura 5).
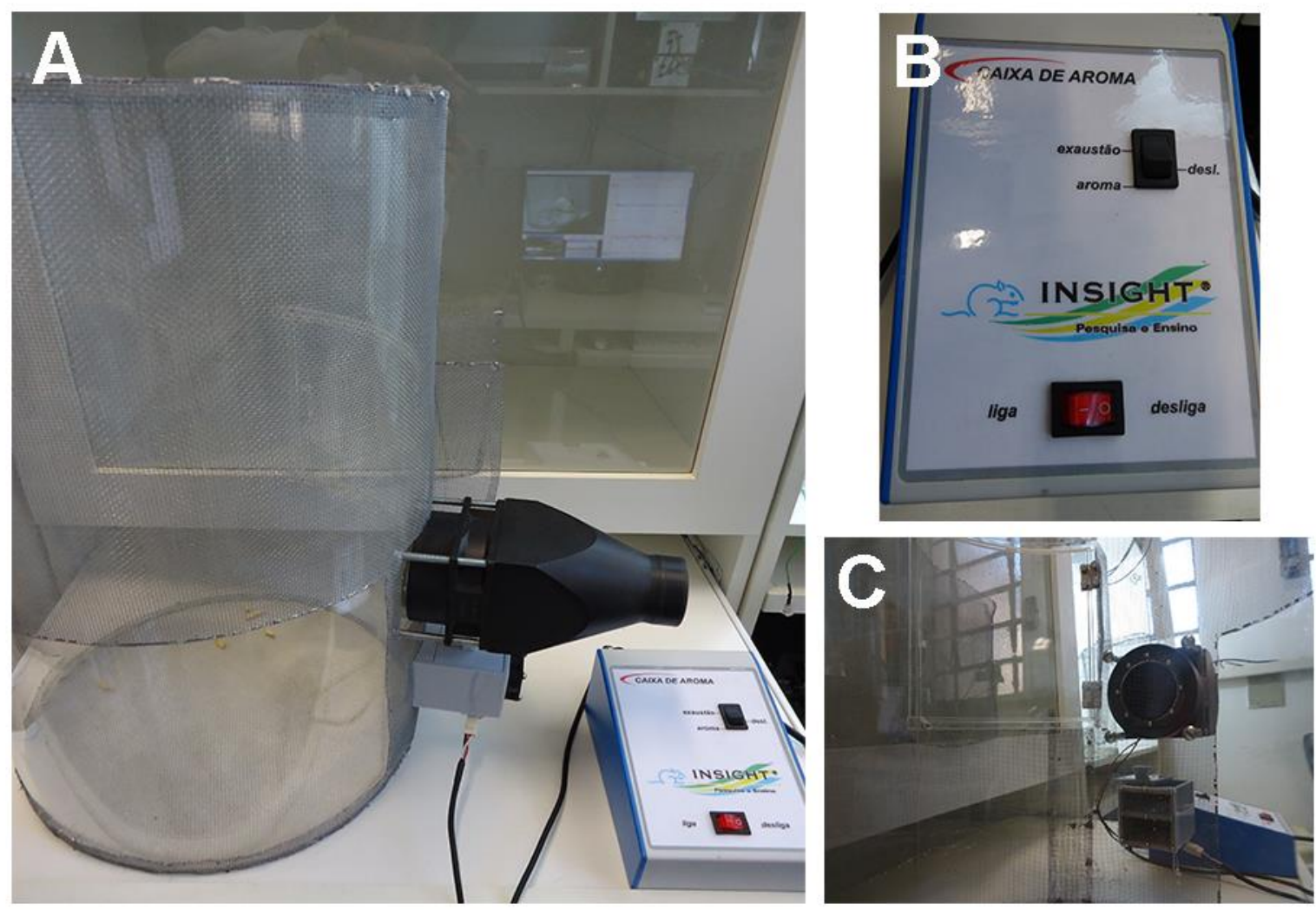

Figura 5. Câmara utilizada durante os protocolos experimentais: curva Dose-Resposta ao TMT e $21^{\circ}$ estímulo elétrico. Em (A) Câmara, (B) Sistema de controle e (C) Sistema de exaustão (idealizada pelo nosso grupo, LNNE).

Após 3 horas da exposição olfatória, os animais foram perfundidos, respeitando a janela recomendada para a imunohistoquímica de c-Fos. E seus cérebros crioprotegidos, congelados e devidamente armazenados em freezer $-20^{\circ} \mathrm{C}$, para futuro processamento.

A análise comportamental foi realizada mediante observação de itens comportamentais clássicos de medo e pela neuroetologia (Ethomatic; GARCIA-CAIRASCO et al., 1992; ver item 5.2.5). 


\subsubsection{Escolha das Concentrações do TMT}

A escolha das concentrações utilizadas na curva Dose-Resposta de TMT baseou em estudos descritos na literatura, como indicado na Tabela 1.

Tabela 1. Respostas comportamentais nas diferentes concentrações.

\begin{tabular}{|c|c|c|}
\hline Dose & Referências & Comportamento (s) \\
\hline $37,8 \mathrm{nMol} \% 400$ & LASKA et al., 2005 & Limiar de detecção olfatória \\
\hline 37,8 nMol & $\begin{array}{c}\text { ENDRES; APFELBACH; FENDT, } \\
2005\end{array}$ & Congelamento \\
\hline $250 \mathrm{nMol}$ & HOLMES; GALEA, 2002 & Congelamento \\
\hline $300 \mathrm{nMol}$ & ROSEN et al., 2008 & $\begin{array}{c}\text { Congelamento semelhante ao } \\
\text { choque nas patas com corrente de } \\
1,5 \mathrm{~mA}\end{array}$ \\
\hline $1,10,100,300$, e $600 \mathrm{nMol}$ & WALLACE; ROSEN, 2000 & $\begin{array}{c}\text { Aumento significativo do } \\
\text { congelamento com as duas doses } \\
\text { mais elevadas }\end{array}$ \\
\hline 77,$4 ; 387,0$ e $774,0 \mathrm{nMol}$ & BLANCHARD et al., 2003 & $\begin{array}{l}\text { Variedade comportamentos, entre } \\
\text { eles o congelamento quando } \\
\text { expostos as duas maiores } \\
\text { concentrações }\end{array}$ \\
\hline TMT Puro & $\begin{array}{c}\text { DIAS SOARES } \text { et al., 2003; } \\
\text { HOLMES; GALEA, 2002; HORII } \\
\text { et al., 2010; NIKAIDO; } \\
\text { NAKASHIMA, 2009; REDMOND } \\
\text { et al., 2002; THOMAS; URBAN; } \\
\text { PETERSON, 2006; WALLACE; } \\
\text { ROSEN, } 2000\end{array}$ & $\begin{array}{c}\text { Diferentes alterações } \\
\text { comportamentais }\end{array}$ \\
\hline
\end{tabular}

Assim, optamos por concentrações que tivessem sido utilizadas em um maior número de estudos, e portanto os grupos experimentais compreenderam:

1. Grupo Salina $(\mathrm{N}=6)$.

2. Grupo TMT $300 \mathrm{nMol}(\mathrm{N}=6$, ou $0,3 \mathrm{mMol})$.

3. Grupo TMT $1000 \mathrm{nMol}(\mathrm{N}=6$, ou $1 \mathrm{mMol})$.

4. Grupo TMT $10000 \mathrm{nMol}(\mathrm{N}=6$, ou $10 \mathrm{mMol})$.

5. Grupo TMT Puro (N=5). 


\subsubsection{Tempo de Exposição ao TMT}

Outro importante parâmetro que poderia interferir na informação espacial e temporal e consequentemente na resposta gerada é o tempo de exposição ao TMT. Dados da literatura indicam tempos que variam entre 5 a 60 minutos como demonstrado na Tabela 2.

Tabela 2. Diferentes tempos de exposição ao TMT.

\begin{tabular}{cc} 
Tempo (minutos) & Referências \\
\hline 5 & MORICEAU et al., 2004; ROSEN et al., 2008 \\
ROSEN et al., 2008 \\
\\
20 & BLANCHARD et al., 2003; DAY; MASINI; \\
& CAMPEAU, 2004; MCGREGOR et al., 2002; \\
& MORROW; ROTH; ELSWORTH, 2000; REDMOND \\
& et al., 2002; THOMAS; URBAN; PETERSON, 2006; \\
30 & WALLACE; ROSEN, 2000 \\
60 & HOLMES; GALEA, 2002; NIKAIDO; \\
& NAKASHIMA, 2009 \\
\hline
\end{tabular}

Entendendo que a ativação dos circuitos neurais de medo com as consequentes respostas antipredadores necessariamente devem ser rápidas, afim de garantir a sobrevivência do animal, escolhemos o menor tempo de exposição de 5 minutos e 30 segundos. Tempo este que foi mantido durante a exposição ao odorante no $21^{\circ}$ estímulo do abrasamento elétrico rápido, ou seja, durante o pareamento com água ou TMT (na concentração definida - ver protocolos 6.2.5 e 6.2.6 do Capítulo II).

Além disso, outro cuidado adicional foi a importação da solução de TMT da mesma origem (PheroTech Inc., Canadá) que os estudos publicados e utilizados como base para a realização dos nossos experimentos (DIAS SOARES et al., 2003; REDMOND et al., 2002; THOMAS; URBAN; PETERSON, 2006). Assim, todos esses critérios objetivaram garantir um estudo com menor número de variações e que pudesse ser reproduzido por outros grupos.

\subsubsection{Perfusão, Crioproteção e Congelamento}

Os animais utilizados no protocolo Dose-Resposta de TMT foram perfundidos respeitando a janela temporal de 3 horas pós-estímulo, para futuro processamento tecidual, para investigação da ocorrência de ativação celular (imunohistoquímica de c-Fos). 
Todos os animais foram profundamente anestesiados com Thiopentax - tiopental sódico $(60 \mathrm{mg} / \mathrm{kg}$; intra peritoneal - i.p., Cristália Produtos Químicos Farmacêuticos LTDA, Itapira, SP, Brasil) e perfundidos transcardiamente através de uma bomba de perfusão Masterflex® (Cole Parmer), com fluxo contínuo de $20 \mathrm{~mL} / \mathrm{min}$, utilizando de $300 \mathrm{~mL}$ de Tampão Fosfato Salina (PBS, 0,1M; pH 7,4), seguido por 300 mL de Paraformaldeído (PFA, 4\% em PBS 0,1M, pH 7,4).

O procedimento consistiu na fixação do animal pelas patas em uma estrutura de acrílico, expondo o tórax. Fez-se então uma incisão a partir do processo xifóide com completa exposição do coração. O pericárdio foi removido e uma cânula foi introduzida no ventrículo esquerdo em direção à aorta ascendente. Uma pequena incisão foi feita no átrio direito para o extravasamento do sangue e das soluções.

Finalizado o procedimento da perfusão, o animal foi decapitado, e o encéfalo foi cuidadosamente removido da caixa craniana preservando o bulbo olfatório e colocado em solução de PFA 4\% por pelo menos 4 horas ou overnight em tubo Falcon de $50 \mathrm{~mL}$.

Todos os encéfalos foram crioprotegidos por imersão em solução de sacarose a $20 \%$ e então a 30\% em PBS. Após submersão na sacarose 30\%, os encéfalos foram congelados utilizando isopentano 99\% (Vetec Química Fina LTDA, Rio de Janeiro, Brasil) resfriado em gelo seco $\left(-65^{\circ} \mathrm{C}\right)$. Posteriormente foram devidamente embalados, identificados e armazenados em freezer $-20^{\circ} \mathrm{C}$.

\subsubsection{Registro e ANÁlise COMPORTAMENTAL}

Os animais foram filmados (câmera VHS, Sony, modelo DCR-DVD308) e a imagem foi enviada através da placa conversora de captura e saída de vídeo para a tela do computador, assim na tela do computador foi possível visualizar o comportamento. O registro de todos os animais foi realizado durante 05 minutos e 30 segundos. $\mathrm{E}$ os animais permaneceram dentro da câmara por no máximo 6 minutos, independente do tempo de registro, garantindo a homogeneidade da amostra.

Garcia-Cairasco e colaboradores utilizam a avaliação neuroetológica desde 1983 para o estudo do comportamento e sua correlação neurofisiológica (Neuroetologia) em modelos experimentais de epilepsia (GARCIA-CAIRASCO; SABBATINI, 1983; GARCIACAIRASCO et al., 1992, 1996; ROSSETTI et al., 2006). Essa análise também vem sendo aplicada em humanos (BERTTI et al., 2010; DAL-CÓL et al., 2008; DAL-CÓL et al., 2006).

A análise consiste na observação e registro segundo a segundo em termos de sequência temporal de todos os itens comportamentais (baseando-se em um dicionário 
comportamental, Tabela Complementar 1) expressos pelo animal, durante o período de observação.

Após o registro, os dados coletados foram codificados e inseridos no programa estatístico ETHOMATIC (GARCIA-CAIRASCO et al., 1992), que forneceu a freqüência de ocorrência de cada item, sua duração média e as interações entre comportamentos, calculadas através da construção de matrizes de transição de primeira ordem, pelo número de vezes que ocorrem as interações. O programa também realizou a verificação estatística de associação entre itens pela análise do $\mathrm{X}^{2}$, sendo as interações consideradas estatisticamente significativas quando $\mathrm{p}<0,05 ; \log \mathrm{X}^{2} \geq 0,25$.

Após a análise efetuada pelo programa, os comportamentos foram representados graficamente no programa Power Point 2010 (Microsoft) sob a forma de fluxogramas, que indicam as sequências comportamentais registradas durante o período de observação. No fluxograma, cada retângulo representa um comportamento. A altura dos retângulos simboliza a frequiência de ocorrência; sua base representa a duração média do comportamento durante a observação e as cores identificam qualitativamente classes relacionadas de comportamentos. Para isso, utilizou-se o padrão de calibração da Figura 6.

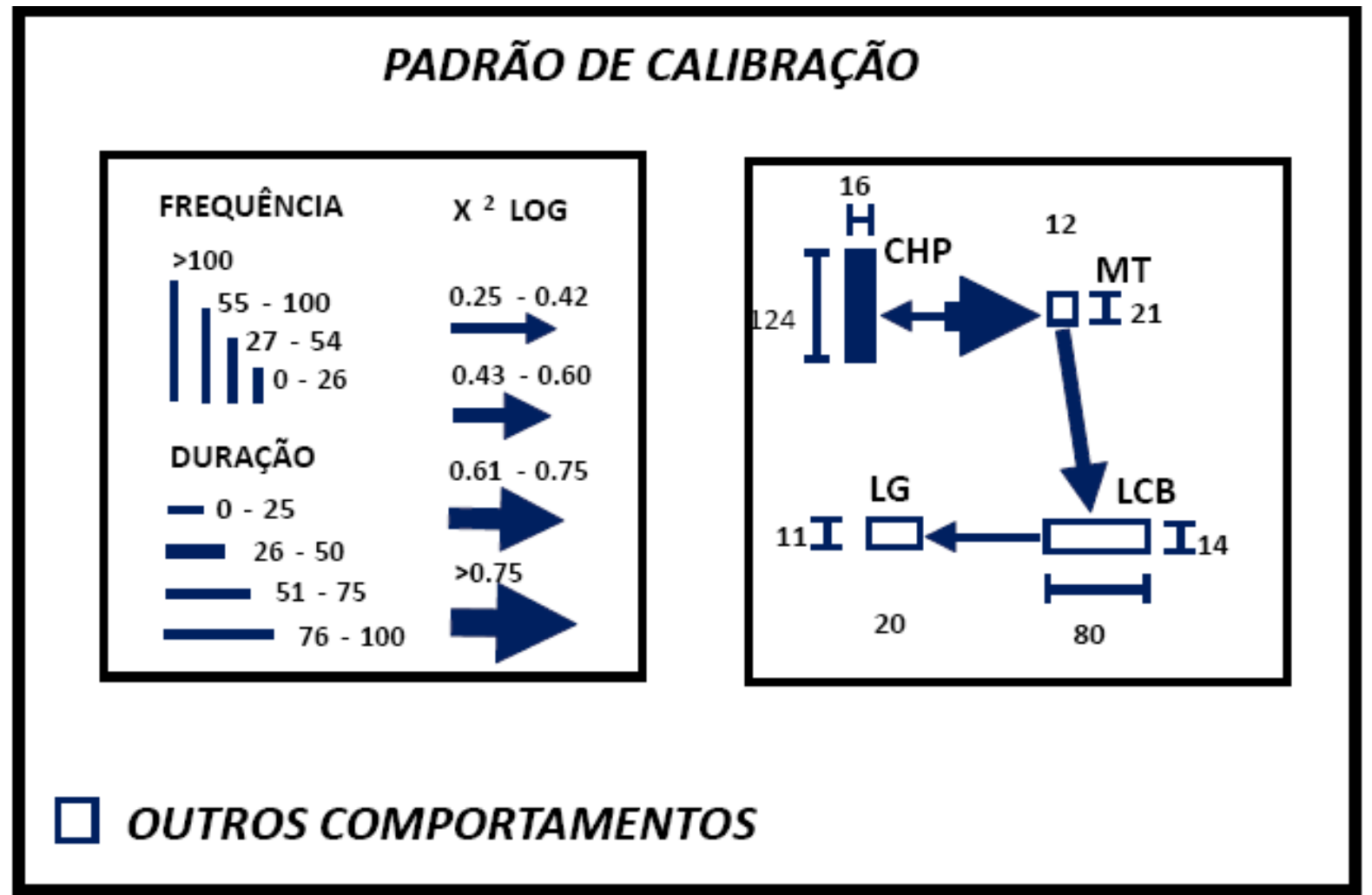

Figura 6. Padrão de calibração para confecção dos fluxogramas (GARCIA-CAIRASCO et al., 1992). Cada retângulo representa um comportamento. A altura dos retângulos simboliza a freqüência de ocorrência, e a base, a duração média do comportamento durante a observação. As setas representam valores estatísticos $\left(\mathrm{X}^{2} \geq 3,841\right.$; $\left.\log \mathrm{X}^{2} \geq 0,25 ; \mathrm{p}<0,05\right)$ que indicam a probabilidade de um segundo comportamento ocorrer após um dado 
e caracterização neuroetológica dos efeitos da exposição ao estímulo olfatório com TMT em ratos Wistar

comportamento. A cor do retângulo tem o objetivo de identificar qualitativamente a classe comportamental. A cor das setas representa o ponto de partida das mesmas ao acompanhar a cor do retângulo que origina a interação entre pares comportamentais.

Além da caracterização neuroetológica foi realizada a análise da frequência e duração dos itens comportamentais clássicos de medo, como: alerta (ALER), bocejar (BC), congelar (CG), defecar (SCR) e sobressalto (SOB) para todos os grupos, durante o período de experimentação.

\subsection{Resultados E Discussão}

\subsubsection{ESCOLHA DO TMT}

É notório e bem descrito que mamíferos de pequeno porte apresentam seu sistema olfatório mais preservado que nós, humanos (BLANCHARD; BLANCHARD; ROSEN, 2008; LASKA et al., 2005). Esse fato se deve segundo Blanchard e colaboradores (2008) a evolução que ao longo dos tempos permitiu adaptações frente aos diferentes estímulos externos e ao concomitante uso adicional de informações de outros sistemas sensoriais (visão e audição). Entretanto o olfato ainda desempenha um importante papel modulatório nas emoções, em especial no medo (BLANCHARD; BLANCHARD; ROSEN, 2008).

Uma vantagem evolutiva importante do olfato é a capacidade para detectar a proximidade ou presença de um predador. Essa detecção precoce e a consequente resposta adequada da presa frente ao predador seja de reconhecimento, evasão e/ou defesa, é uma característica importante para o comportamento de defesa e fundamentais para a sobrevivência das espécies (BLANCHARD; BLANCHARD; ROSEN, 2008).

Dessa forma, odores de predadores são amplamente utilizados em estudos comportamentais e neurobiológicos de medo inato e condicionado (McGREGOR et al., 2002), por se tratarem de odorantes não nocivos e etologicamente relevantes. Entretanto esses estudos utilizam de diferentes metodologias, seja pela exposição ao predador vivo, ou pela exposição ao cheiro do predador procedente de coleiras, panos ou da própria pele do predador, ou então pela utilização de componentes da urina, fezes dos predadores, e finalmente pela própria exposição in natura a urina e fezes.

Para os roedores, os principais predadores são carnívoros, incluindo cães, gatos, lobos e raposas (FENDT et al., 2005). Neste contexto, dois dos odorantes mais utilizados em pesquisas recentes são: o odor proveniente da pele de gato e o da raposa, mais especificamente o TMT. 
O odor felino é um importante indutor de medo inato bem como também de medo condicionado, o que sugere um maior efeito ansiogênico dessa fonte odorífera, quando comparados a outros odorantes (APFELBACH et al., 2005; BLANCHARD; BLANCHARD; ROSEN, 2008).

Entretanto, Rosen (2004) demonstra que o TMT tem importância fundamental para os efeitos aversivos, induzindo comportamentos defensivos em ratos semelhantes aos deflagrados pelo odor de gato. E ainda, o TMT apresenta algumas vantagens por se tratar de um composto sintético, pode ser adquirido comercialmente, além disso é uma substância isolada o que facilita sua quantificação - como realizado em nosso estudo (STAPLES; MCGREGOR, 2006). E principalmente por ativar o sistema olfatório principal diferentemente do odor de gato que ativa o sistema olfatório acessório (TAKAHASHI, 2014).

Outro importante odorante é o Tolueno que foi utilizado como potencial supressor e inibidor de crises no modelo de abrasamento elétrico da amígdala (EBERT; LÖSCHER, 2000). Posteriormente no modelo audiogênico utilizando-se animais da cepa $W A R$, o Tolueno também foi capaz de diminuir a gravidade de crises, demonstrando a interferência do odorante na expressão comportamental das crises (BERTTI et al., 2010, 2011, 2013;).

Porém o Tolueno foi descrito como principal ativador do componente trigeminal e não apenas olfatório, possuindo neurocircuitos diferentes e reflexos protetores específicos (HACQUEMAND; JACQUOT; BRAND, 2010), logo os efeitos observados com o seu possível uso, poderiam ser obtidos pela estimulação do nervo trigeminal e não como consequência de estímulo olfatório (ENDRES; APFELBACH; FENDT, 2005; HACQUEMAND; JACQUOT; BRAND, 2010). Interessante mencionar que a estimulação elétrica do nervo trigeminal tem potente efeito anticonvulsivante (FANSELOW; REID; NICOLELIS, 2000) no modelo químico com pentilenetetrazol (PTZ), e se esse mecanismo pode ser acionado com estímulos olfatórios, não seria portanto um efeito específico.

Além disso, o Tolueno possui outras desvantagens metodológicas para o desenho desse estudo, entre as quais por se tratar de uma substância tóxica (WIN-SHWE; FUJIMAKI, 2010; YÜCEL et al., 2008), seu uso poderia trazer ao rato um eventual dano cerebral (WINSHWE; FUJIMAKI, 2010; YÜCEL et al., 2008), mesmo com uma breve exposição olfatória, mascarando os dados. Além da toxicidade no ambiente para o pesquisador, que poderia sofrer o efeito cumulativo da exposição (WIN-SHWE; FUJIMAKI, 2010; YÜCEL et al., 2008), aliada à dificuldade em dispersar a substância tóxica no ambiente externo. O Tolueno também apresenta efeito cumulativo (de "memória") e é corrosivo em material de acrílico, o que inviabiliza sua utilização na câmara, por poder contaminar os dados dos animais (em especial 
e caracterização neuroetológica dos efeitos da exposição ao estímulo olfatório com TMT em ratos Wistar os experimentos finais). Por fim, a eventual publicação desses dados seria dificultosa por se tratar de um produto controlado e em alguns países banido para experimentos desse gênero.

Por esses inúmeros motivos o TMT mostrou-se como uma alternativa segura, ou seja, sem efeitos tóxicos (MASINI et al., 2010), e principalmente por ter um importante significado biológico, uma vez que elucida sinais comportamentais e autonômicos de medo (DIAS SOARES et al., 2003; FENDT et al., 2005; HACQUEMAND; JACQUOT; BRAND, 2010; HORII et al., 2010; MORROW et al., 2000; NIKAIDO; NAKASHIMA, 2009; REDMOND et al., 2002; ROSEN et al., 2008; TAKAHASHI, 2014; THOMAS; URBAN; PETERSON, 2006). Assim, o TMT representa uma importante ferramenta de estimulação sensorial por possuir circuitos antagônicos e convergentes com a ELT, como supracitado.

\subsubsection{CARACTERIZAÇÃo dOS EFEITOS DA EXPOSIÇÃo AO EsTímulo OLFATÓRIO COM TMT EM RATOS WISTAR}

Esse protocolo tinha como objetivo avaliar a expressão comportamental de medo, da salina versus as diferentes concentrações de TMT (rever protocolo 5.2.3). Para a posterior implementação da concentração considerada adequada de TMT nos protocolos envolvendo abrasamento elétrico rápido da amígdala e estimulação olfatoria com o TMT. 


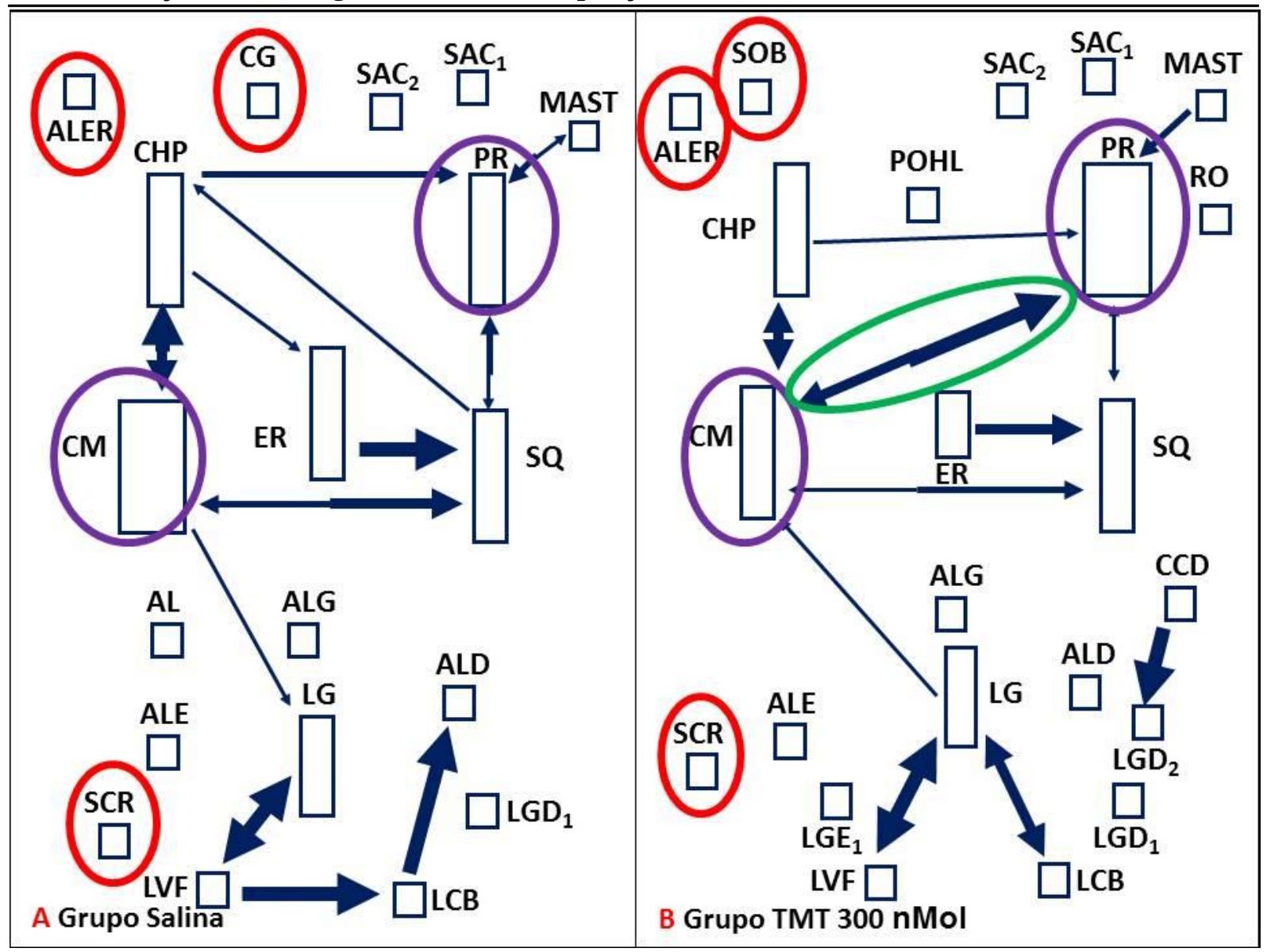

Figura 7. Fluxograma da resposta comportamental de medo induzidas pela Salina versus TMT na concentração de 300 nMol. Notamos a presença de comportamentos como: ALER, CG, SCR e SOB (círculos vermelhos). Alteração da duração dos comportamentos exploratórios de: caminhar (CM) e parar (PR) (círculos roxos). Bem como a interação estatística (seta) presente entre estes dois comportamentos (CM e PR, círculo verde) no Grupo TMT 300 nMol, e nas demais concentrações. Retângulos, setas e cores (Figura 6), siglas (Tabela Complementar 1).

Assim, na Figura 7 estão representadas as diferentes respostas comportamentais observadas pela exposição dos animais à Salina (A) versus TMT (B) na concentração de 300 nMol. Nos círculos na cor vermelha destacamos comportamentos como ALER, CG, SCR e SOB, que sugerem a presença de medo. Além disso, é possível verificar nos círculos na cor roxa que a duração de CM foi maior nos animais do grupo Salina quando comparados com o grupo TMT $300 \mathrm{nMol}$, e que em contrapartida a duração de PR foi maior no grupo TMT 300 nMol quando comparado ao grupo Salina. Esse dado se manteve para as demais concentrações de TMT, como pode ser visto nas Figura 8 -Figura 10. Ou seja, os animais expostos ao TMT na menor concentração, bem como nas demais concentrações permaneceram um maior tempo parados quando comparados ao grupo controle. E é possível observar uma interação entre CM e PR (círculo na cor verde) presente em todas as concentrações de TMT, incluindo a concentração de $300 \mathrm{nMol}$ e ausente no grupo Salina. 


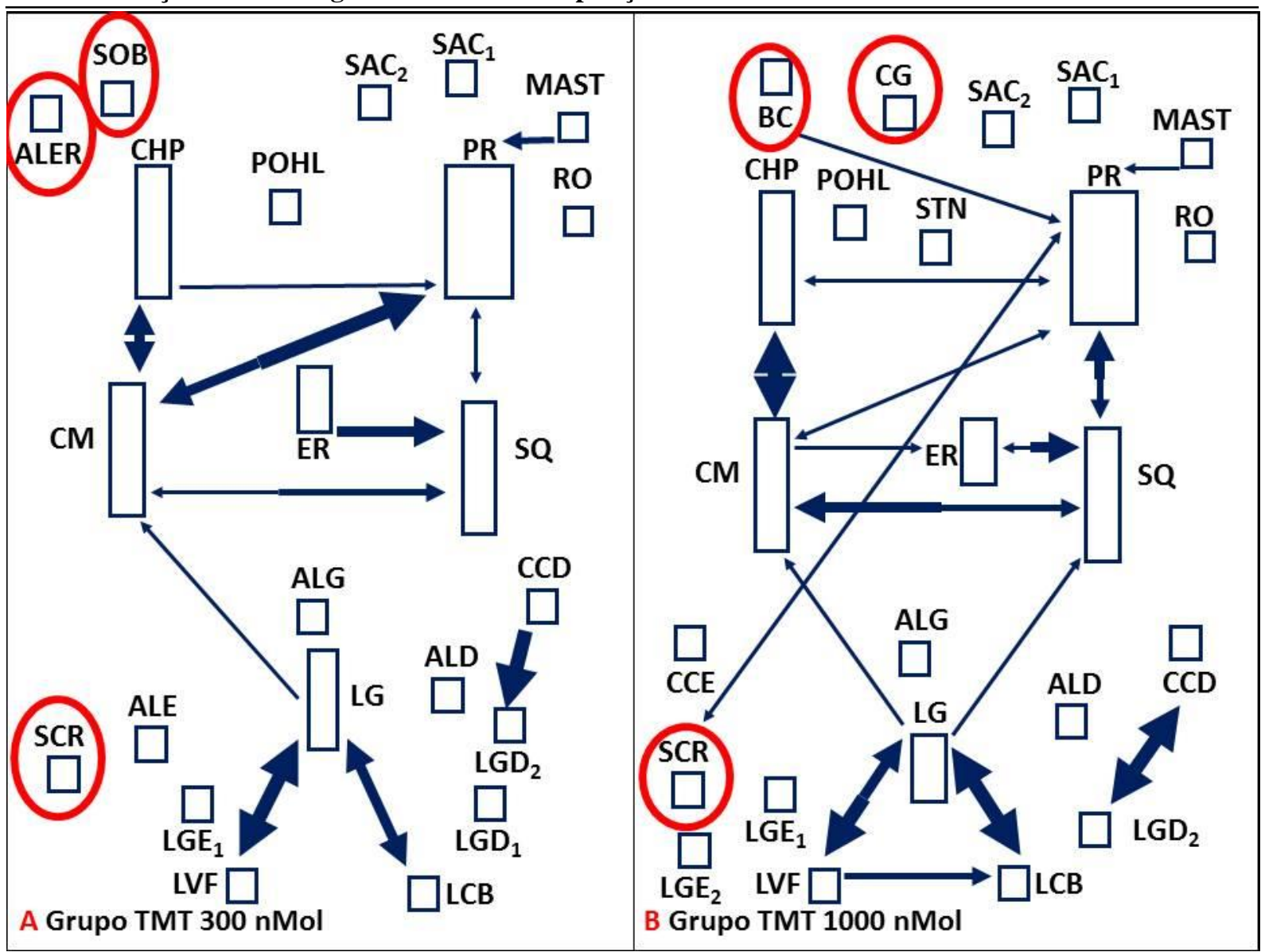

Figura 8. Fluxograma da resposta comportamental de medo induzidas pela TMT na concentração de $300 \mathrm{nMol}$ versus TMT na concentração de 1000 nMol. Notamos a presença de comportamentos como: ALER, BC, CG, SCR e SOB (círculos vermelhos). Retângulos, setas e cores (Figura 6), siglas (Tabela Complementar 1).

Comparando as respostas comportamentais de medo induzidas pelo TMT na concentração de $300 \mathrm{nMol}$ versus TMT na concentração de $1000 \mathrm{nMol}$ (Figura 8), é possível observar comportamentos que sugerem medo, como: ALER, SCR e SOB na concentração de 300 nMol. E na concentração de 1000 nMol: ALER, BC, CG e SCR (todos circulados em vermelho). É possível verificar uma redução no número de comportamentos de autolimpeza expressos no grupo com concentração de 1000 nMol comparado ao grupo com menor concentração, entretanto, no grupo exposto a maior concentração houve a formação de um grupo de interações entre os comportamentos de autolimpeza: lavar a cabeça (LCB), limpeza de garra (LG) e lavar o focinho (LVF) presentes, além de um maior número de comportamentos exploratórios e também um maior número de interações entre pares comportamentais. Devido aos resultados controversos, a concentração de $1000 \mathrm{nMol}$ foi descartada para utilização na vigência de crises. 


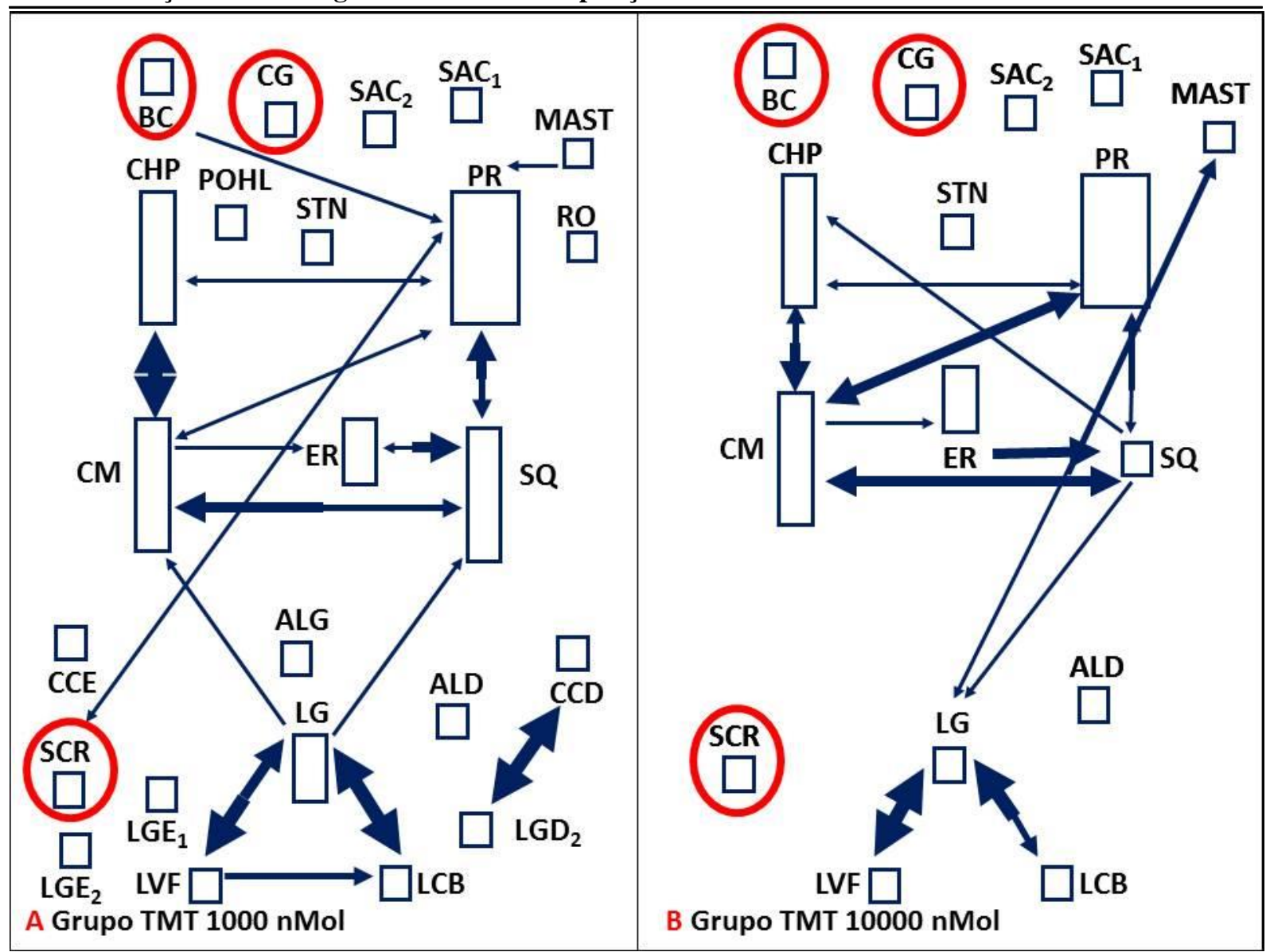

Figura 9. Fluxograma da resposta comportamental de medo induzidas pela TMT na concentração de $1000 \mathrm{nMol}$ versus TMT na concentração de $10000 \mathrm{nMol}$. Notamos a presença de comportamentos como: ALER, BC, CG e SCR (círculos vermelhos). Redução na quantidade de comportamentos expressos no grupo TMT na concentração de $10000 \mathrm{nMol}$ comparado ao grupo TMT na concentração de $1000 \mathrm{nMol}$, como também do menor número de interações estatísticas entre díades (setas). Retângulos, setas e cores (Figura 6), siglas (Tabela Complementar 1).

Na concentração de 1000 nMol versus TMT na concentração de 10000 nMol (Figura 9), é possível observar diferentes respostas comportamentais que sugerem medo como: ALER, BC, CG e SCR (círculos vermelhos). Além da redução no número de comportamentos expressos no grupo TMT na concentração de $10000 \mathrm{nMol}$, (em especial de comportamentos de autolimpeza) comparado ao grupo TMT na concentração de $1000 \mathrm{nMol}$, como também do menor número de interações entre os comportamentos. Finalmente com ausência das interações entre os comportamentos de autolimpeza na concentração de 10000 nMol comparado ao grupo TMT na concentração de 1000 nMol. 


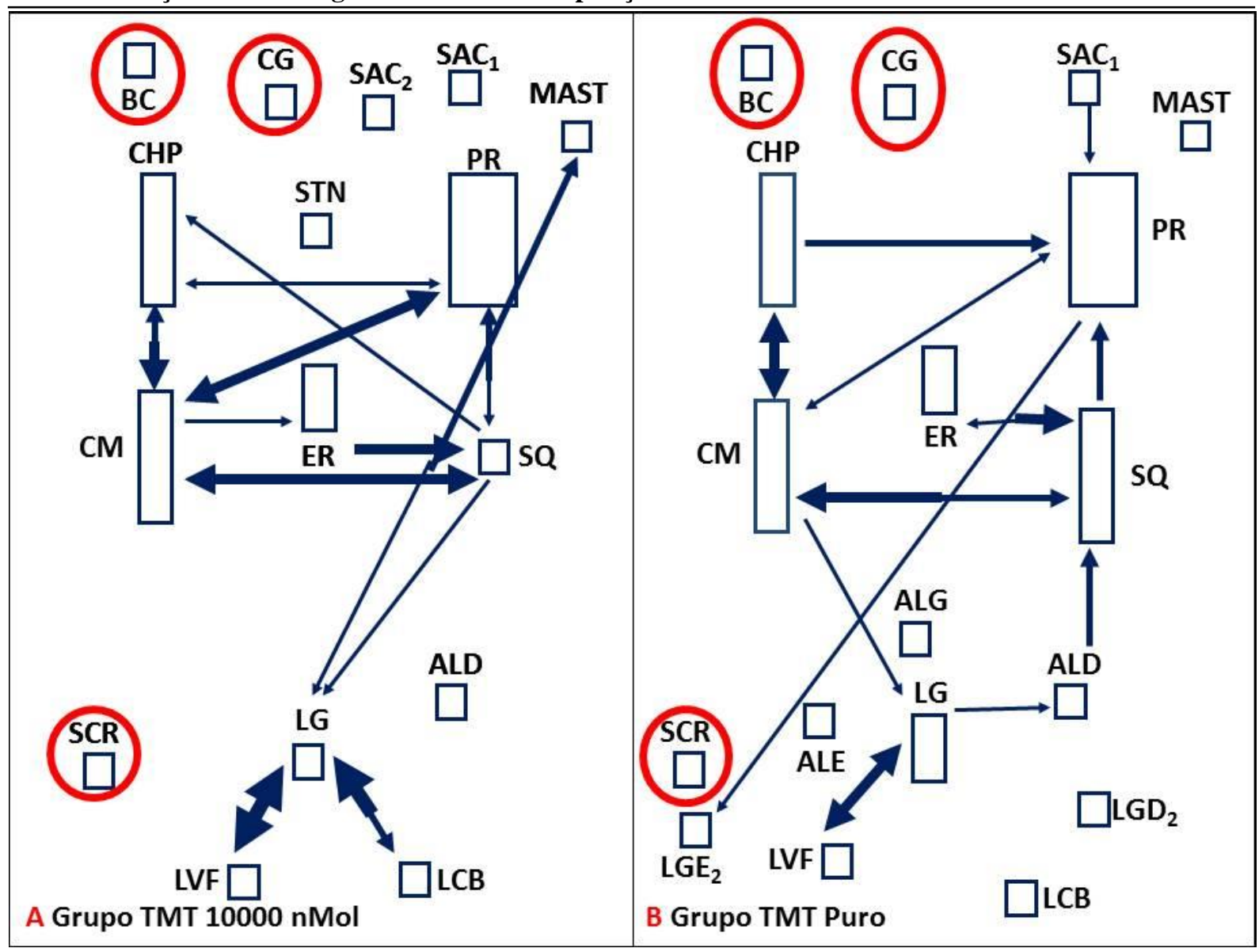

Figura 10. Fluxograma da resposta comportamental de medo induzidas pela TMT na concentração de 10000 nMol versus TMT Puro. Notamos a presença dos mesmos comportamentos em ambos os grupos, como: BC, CG e SCR (círculos vermelhos). Redução no número de interações estatísticas entre pares comportamentais no grupo TMT Puro, apesar dos animais expostos ao TMT na concentração de $10000 \mathrm{nMol}$ apresentarem menor número de comportamentos de autolimpeza como: autolimpeza a direita (ALD) e esquerda (ALE), autolimpeza de genitais (ALG), LCB, LG, LVF, limpar a garra posterior direita $\left(\mathrm{LGD}_{2}\right)$ e esquerda $\left(\mathrm{LGE}_{2}\right)$. Retângulos, setas e cores (Figura 6), siglas (Tabela Complementar 1).

Finalmente na última comparação entre as concentrações de 10000 nMol versus TMT Puro (Figura 10), é possível observar os mesmos comportamentos sugestivos de medo como: CG, SCR e BC (círculos vermelhos). Além disso, o grupo TMT Puro, apresentou uma frequência de interações entre (todos) comportamentos menores que TMT na concentração de $10000 \mathrm{nMol}$. Apesar dos animais expostos ao TMT na concentração de $10000 \mathrm{nMol}$ apresentarem menor número de comportamentos de autolimpeza, o grupo TMT Puro apresentou um menor número de interações entre estes comportamentos.

Assim é possível inferir que o TMT nas diferentes concentrações induziu comportamentos de medo como: CG, ALER, BOC, SCR e SOB. Entretanto o grupo salina também apresentou alguns desses comportamentos. Logo a solução salina usada como controle, pode ter sido uma escolha inadequada, podendo, portanto não ter sido inócua e inodora. Desta forma a solução controle nos estudos subsequentes com abrasamento elétrico 

e caracterização neuroetológica dos efeitos da exposição ao estímulo olfatório com TMT em ratos Wistar rápido foi realizada com água destilada (DIAS SOARES et al., 2003; HORII et al., 2010; NIKAIDO; NAKASHIMA, 2009).

Além da análise neuroetológica, foi realizada a observação somente dos itens comportamentais de medo expressados nos diferentes grupos, representados pela frequência de cada comportamento na Figura 11. 


\section{Congelar}

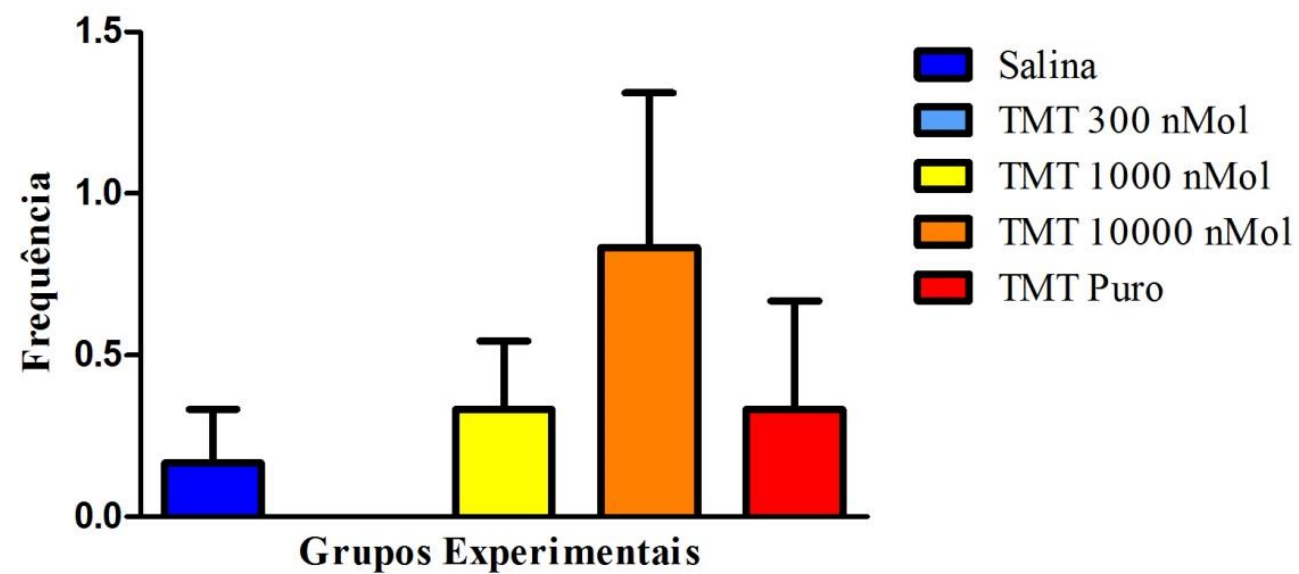

Alerta

Bocejar
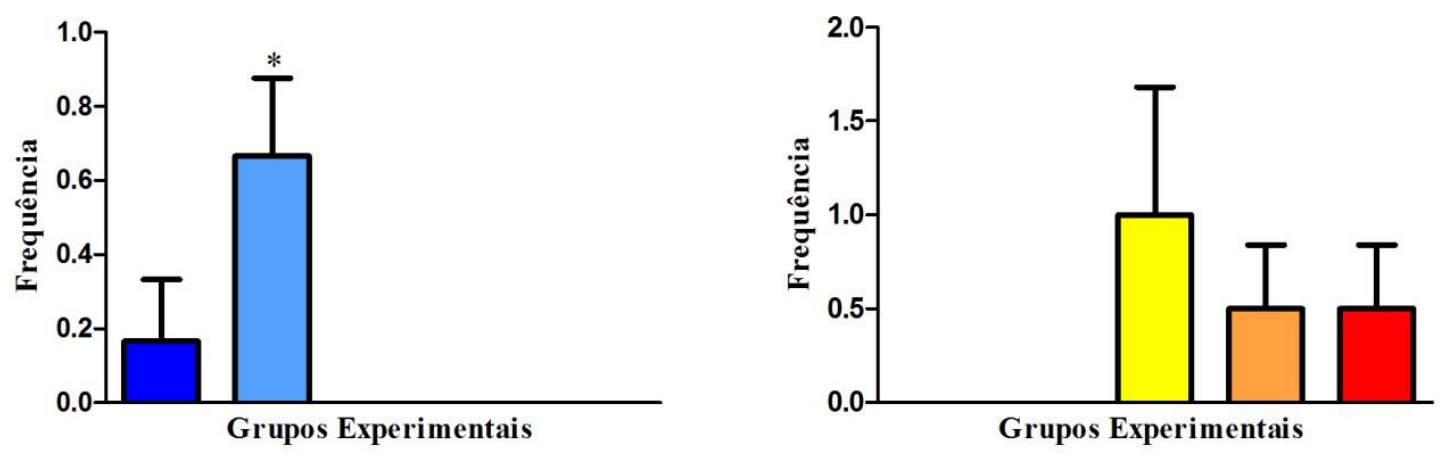

Grupos Experimentais

Defecar

Sobresalto
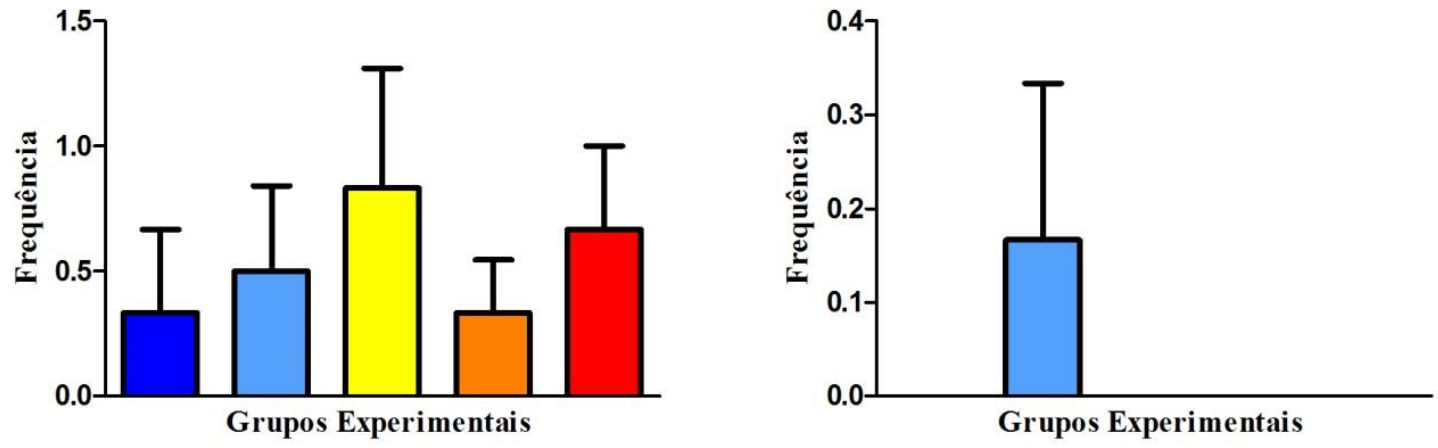

Figura 11. Frequência dos itens comportamentais de medo expressados pelo grupo salina e pelos grupos com diferentes concentrações de TMT ( $300 \mathrm{nMol}, 1000 \mathrm{nMol}, 10000 \mathrm{nMol}$ e Puro). Anova One way, Kruskal-Wallis, $* \mathrm{p}<0,05$.

Nessa figura é possível verificar um resultado bastante heterogêneo, no qual a concentração de $300 \mathrm{nMol}$ apresentou a frequência maior para os comportamentos de ALER (único comportamento com $\mathrm{p}<0,05$, entre essa concentração e as demais concentrações de TMT) e SOB. O BC e a SCR foram observados um maior número de vezes no grupo TMT na concentração de $1000 \mathrm{nMol}$, e finalmente o CG, considerado o comportamento mais 

e caracterização neuroetológica dos efeitos da exposição ao estímulo olfatório com TMT em ratos Wistar importante de medo segundo a literatura (FENDT et al., 2005; HACQUEMAND; JACQUOT; BRAND, 2010), foi observado com maior a frequência no grupo TMT na concentração de $10000 \mathrm{nMol}$.

Essa diversidade de resultados também pode ser observada quando agrupamos os itens presentes em cada grupo, como:
A. Grupo Salina: ALER, CG e SCR.
B. Grupo TMT 300 nMol: ALER, SCR e SOB.
C. Grupo TMT 1000 nMol: BC, CG e SCR.
D. Grupo TMT 10000 nMol e Puro: foram observados os mesmos itens comportamentais de medo, como: BC, CG e SCR.
Além disso, a duração para cada item comportamental - dada em segundos, foi analisado separadamente, e representadas na Figura 12. 


\section{Congelar}

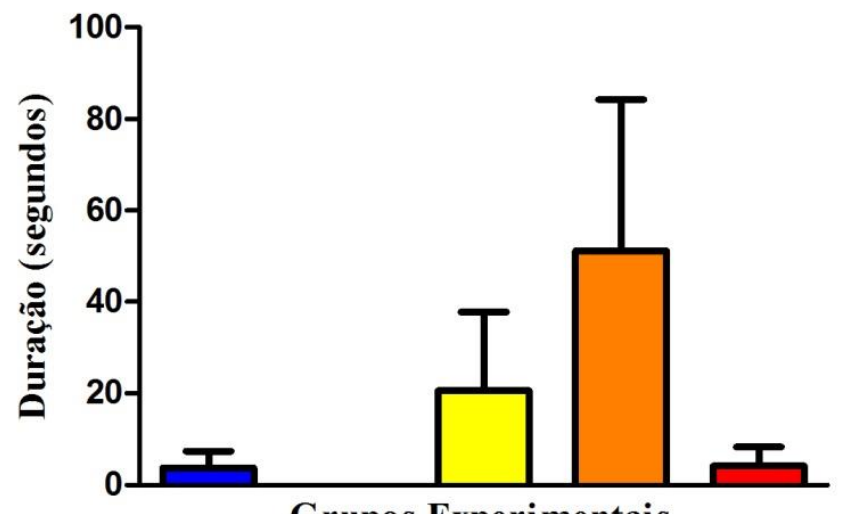

Alerta

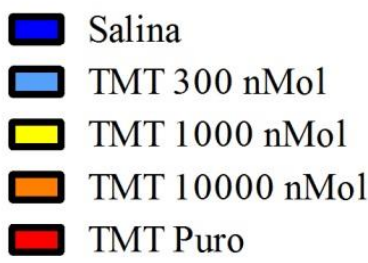

Grupos Experimentais

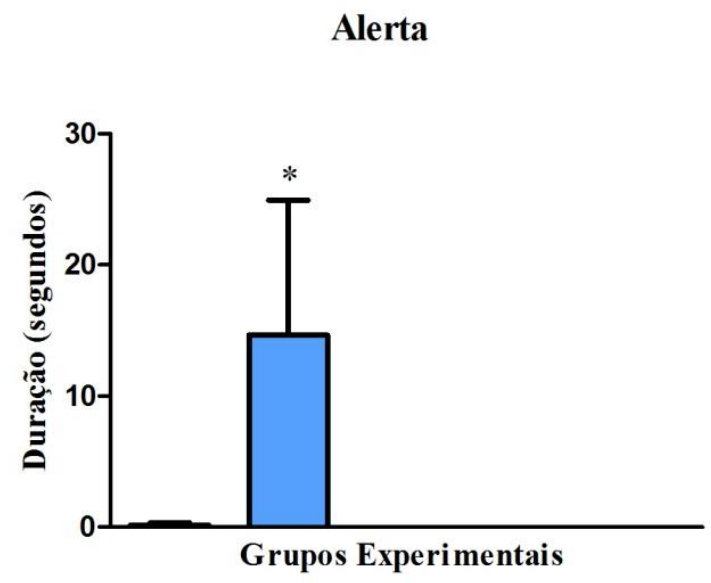

Bocejar

Defecar
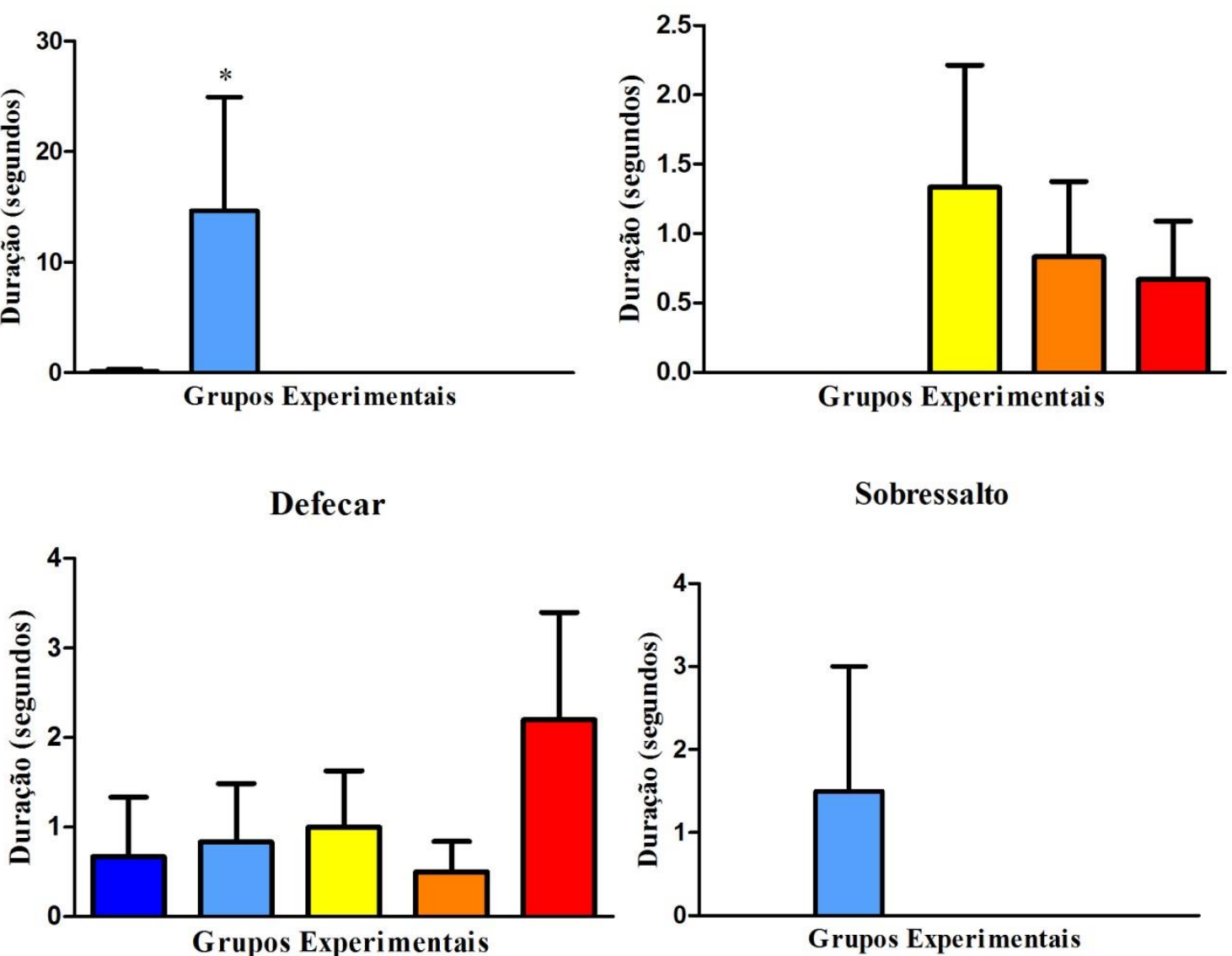

Sobressalto

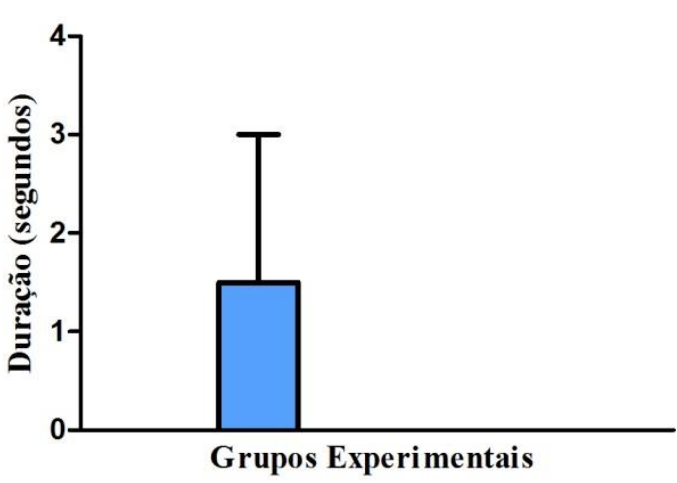

Figura 12. Duração (segundos) dos itens comportamentais de medo expressados pelo grupo salina e pelos grupos com diferentes concentrações de TMT (300 nMol, $1000 \mathrm{nMol}, 10000 \mathrm{nMol}$ e Puro). Anova One way, Kruskal-Wallis, ${ }^{*} \mathrm{p}<0,05$.

Os dados da duração dos itens comportamentais de medo também refletem a heterogeneidade citada para a frequência, quando o ALER foi observado com uma maior duração no grupo TMT na concentração de $300 \mathrm{nMol}$ (único comportamento com p<0,05, 
entre essa concentração e as demais concentrações de TMT). A duração do BC seguiu o mesmo padrão observado na frequência. Os grupos que apresentaram a maior frequência mantiveram também um maior tempo nos respectivos comportamentos, sendo em ordem descrente: grupo TMT 1000 nMol, 10000 nMol e Puro. Para o CG os grupos que permaneceram os maiores tempos, também em ordem decrescente foram: grupo TMT 10000 nMol, 1000 nMol, Puro e ainda o Grupo Salina. Já a SCR foi observada nessa ordem decrescente: Grupo TMT Puro, TMT 1000 nMol, TMT 300 nMol, Grupo Salina e TMT $10000 \mathrm{nMol}$. E finalmente o SOB naturalmente foi observado com maior duração para o Grupo TMT 300 nMol, já que apenas esse grupo apresentou tal comportamento.

Logo, através dos itens comportamentais de medo não é possível inferir qual a concentração que melhor induz comportamentos de medo, dada a complexidade do resultado. Neste sentido, Hegab \& Wei (2014) descrevem que mesmo quando as respostas comportamentais de medo estão ausentes, isto não significa necessariamente em uma falta de reconhecimento do odor do predador pela presa.

Entretanto, apesar das dificuldades originadas pela heterogeneidade dos resultados comportamentais de medo (Figura 11 e Figura 12) para os diferentes grupos, foi possível verificar que com o aumento das concentrações de TMT, os animais apresentaram uma redução da atividade motora e das interações entre os diferentes comportamentos (Figura 7 Figura 10). Essa redução da atividade motora é descrita como uma importante resposta defensiva específica (APFELBACH et al., 2005; BRANDÃO et al., 2004; ENDRES; APFELBACH; FENDT, 2005; FENDT et al., 2005; HACQUEMAND; JACQUOT; BRAND, 2010; ROSEN et al., 2008; THOMAS; URBAN; PETERSON, 2006; WALLACE; ROSEN, 2000).

E ainda os resultados sugerem discretamente uma redução do comportamento de autolimpeza presentes nas duas maiores concentrações, corroborando aos dados da literatura que indicam a supressão desse comportamento durante o medo, por tratar-se de uma resposta não defensiva (BRANDÃO et al., 2004; FENDT et al., 2005; ROSEN et al., 2008).

Assim, o TMT modificou as sequências comportamentais, com redução da atividade motora, e ainda que discreta, do comportamento de autolimpeza, principalmente nas duas maiores concentrações. Apoiando em dois dos achados de medo, dentro de uma ampla gama de respostas do TMT, como indicado na Tabela 3. 
Tabela 3. Respostas comportamentais e endócrinas induzidas pelo TMT.

\begin{tabular}{|c|c|}
\hline Comportamentos & Referências \\
\hline \multirow{7}{*}{ Congelar } & APFELBACH et al., 2005; AYERS et al., 2013; \\
\hline & BLANCHARD et al., 2003; BRANDÃO et al., 2004; \\
\hline & ENDRES; APFELBACH; FENDT, 2005; FENDT et al., \\
\hline & 2005; HACQUEMAND et al., 2013; HOLMES; \\
\hline & GALEA, 2002; HORII et al., 2010; LASKA et al., 2005; \\
\hline & ROSEN et al., 2008; THOMAS; URBAN; PETERSON, \\
\hline & 2006; WALLACE; ROSEN, 2000 \\
\hline \multirow{7}{*}{ Evitar } & APFELBACH et al., 2005; AYERS et al., 2013; \\
\hline & BLANCHARD et al., 2003; ENDRES; APFELBACH; \\
\hline & FENDT, 2005; FENDT et al., 2005; HACQUEMAND et \\
\hline & al., 2013; HOLMES; GALEA, 2002; LASKA et al., \\
\hline & 2005; WALLACE; ROSEN, 2000 \\
\hline & APFELBACH et al., 2005; BRANDÃO et al., 2004; \\
\hline & ENDRES; APFELBACH; FENDT, 2005; FENDT et al., \\
\hline \multirow[t]{3}{*}{ Reduzir a atividade motora } & 2005; HACQUEMAND et al., 2013; ROSEN et al., \\
\hline & 2008; THOMAS; URBAN; PETERSON, 2006; \\
\hline & WALLACE; ROSEN, 2000 \\
\hline \multirow[t]{3}{*}{ Ficar em alerta } & BRANDÃO et al., 2004 \\
\hline & APFELBACH et al., 2005; BRANDÃO et al., 2004; \\
\hline & ENDRES; APFELBACH; FENDT, 2005; \\
\hline \multirow[t]{3}{*}{ Reduzir comportamento alimentar } & HACQUEMAND et al., 2013; NIKAIDO; \\
\hline & NAKASHIMA, 2009; ROSEN et al., 2008; WALLACE; \\
\hline & ROSEN, 2000 \\
\hline Reduzir comportamento de auto limpeza & $\begin{array}{c}\text { BRANDÃO et al., 2004; FENDT et al., 2005; ROSEN et } \\
\text { al., } 2008\end{array}$ \\
\hline $\begin{array}{l}\text { Outros: Reduzir comportamento sexual, bocejar e } \\
\text { defecar }\end{array}$ & BRANDÃO et al., 2004; FENDT et al., 2005 \\
\hline Ativar SNA & $\begin{array}{c}\text { BRANDÃO } \text { et al., 2004; HORII et al., 2010; ROSEN et } \\
\qquad a l ., \text { 2008; TAKAHASHI, } 2014\end{array}$ \\
\hline \multirow{8}{*}{ Ativar eixo hipotálamo-hipófise-adrenal } & APFELBACH et al., 2005; BLANCHARD et al., 2003; \\
\hline & BRANDÃO et al., 2004; ENDRES; APFELBACH; \\
\hline & FENDT, 2005; FENDT et al., 2005; HACQUEMAND; \\
\hline & JACQUOT; BRAND, 2010; HORII et al., 2010; LASKA \\
\hline & et al., 2005; MORROW et al., 2000; DIAS SOARES et \\
\hline & al., 2003; NIKAIDO; NAKASHIMA, 2009; REDMOND \\
\hline & et al., 2002; TAKAHASHI, 2014; THOMAS; URBAN; \\
\hline & PETERSON, 2006 \\
\hline
\end{tabular}


Certamente esse resultado foi somente possível de verificar com a análise qualitativa e quantitativa de todos os itens comportamentais expressos pelo rato, ou seja, pela neuroetologia.

Algumas possíveis explicações para essa resposta tão diversa encontrada nos diferentes estudos que utilizam o TMT como indutor de medo, podem ser as variações nas metodologias aplicadas, como indicado na Tabela 4.

Tabela 4. Metodologias diferentes geram respostas diferentes.

\begin{tabular}{|c|c|}
\hline Variáveis & Referências \\
\hline \multirow{4}{*}{ Contexto da apresentação do odor } & DIAS SOARES et al., 2003; FENDT et al., 2005; \\
\hline & FENDT; ENDRES, 2008; MORROW et al., 2000; \\
\hline & ROSEN et al., 2008; THOMAS; URBAN; \\
\hline & PETERSON, 2006 \\
\hline \multirow{4}{*}{ Característica da câmara } & FENDT; ENDRES, 2008; MORROW; \\
\hline & ELSWORTH; ROTH, 2002; ENDRES; \\
\hline & APFELBACH; FENDT, 2005; WALLACE; \\
\hline & ROSEN, 2001 \\
\hline \multirow{7}{*}{ Componente genético } & DIAS SOARES et al., 2003; ENDRES; \\
\hline & APFELBACH; FENDT, 2005; FENDT et al., \\
\hline & 2005; ROSEN, 2004; ROSEN et al., 2008; \\
\hline & THOMAS; URBAN; PETERSON, 2006; ROSEN; \\
\hline & WEST; DONLEY, 2006; STAPLES; \\
\hline & MCGREGOR, 2006 \\
\hline & AYERS et al., 2013; BLANCHARD et al., 2003; \\
\hline \multirow{3}{*}{ Concentração do TMT } & ENDRES; APFELBACH; FENDT, 2005; FENDT \\
\hline & et al., 2005; LASKA et al., 2005; WALLACE; \\
\hline & ROSEN, 2000 \\
\hline Duração de exposição & THOMAS; URBAN; PETERSON, 2006 \\
\hline Condições ambientais que os ratos são criados e & FENDT; ENDRES, 2008; MORROW et al., 2000; \\
\hline mantidos & WALLACE; ROSEN, 2000 \\
\hline
\end{tabular}

Desses itens dois merecem destaque nessa discussão como uma possível explicação da falta de efeito do TMT na geração de respostas tradicionais de medo (observadas nas Figura 7 - Figura 10). É descrito que diferentes cepas de ratos podem ter respostas variadas quando submetidas à situação de medo, sendo que ratos Wistar são descritos como a cepa que menos responde com comportamentos de medo, quando comparados a Sprague Dawley, por exemplo (ENDRES; APFELBACH; FENDT, 2005; ROSEN; WEST; DONLEY, 2006). Além disto, as características da câmara podem ser um facilitador ou não do número de comportamentos de 
e caracterização neuroetológica dos efeitos da exposição ao estímulo olfatório com TMT em ratos Wistar medo expressos pelo animal, sendo visualizados comportamentos mais expressivos de medo quando o rato é exposto em câmara com ambiente aberto e fechado.

Em suma, o TMT, uma molécula com relevância biológica, foi capaz de desencadear reações de medo, e modificar as sequências comportamentais, com uma redução da atividade motora e do comportamento de autolimpeza.

A estimulação olfatória com TMT puro foi escolhida como uma potencial concentração supressora ou inibidora de crises epilépticas induzidas pelo abrasamento elétrico rápido em ratos Wistar.

\subsubsection{ANÁLISE QUímica do TMT}

Nos estudos com o TMT foram encontradas duas importantes diferenças, como exposto anteriormente: (1) Eficácia do TMT na resposta fisiológica e comportamental de medo, e (2) Dose necessária para induzir tais efeitos.

Entretanto ao usar diferentes concentração de TMT em um ambiente fechado, a saturação interna dessa câmara logicamente pode variar, logo a quantidade que o rato inala também. Apesar de ser uma medida indireta (comparado à concentração plasmática, por exemplo, que detectaria a quantidade inalada pelo rato), a quantificação da saturação odorífera à qual o rato foi exposto nas diferentes concentrações de TMT, tornou-se importante, dadas as análises da Curva Dose-Resposta de TMT, expostas no tópico anterior 5.3.2.

Além disso, com o objetivo de eliminar ao máximo os fatores de variação, decidimos verificar o tempo necessário para saturação e dessaturação da câmara ao TMT e avaliar se a modificação do posicionamento da fibra dentro da câmara poderia alterar a captação de TMT.

Inicialmente foram obtidas informações da composição do TMT pelo seu espectrômetro de massas. Permitindo detectar pelo modo universal (SCAN) os principais íons presentes na amostra: 88, 114 e 129 (Figura 13). Com a obtenção dessa informação, pôde ser realizada a comparação com os espectros de massas armazenados na biblioteca do computador, identificando a substância analisada (Experimento 1). 


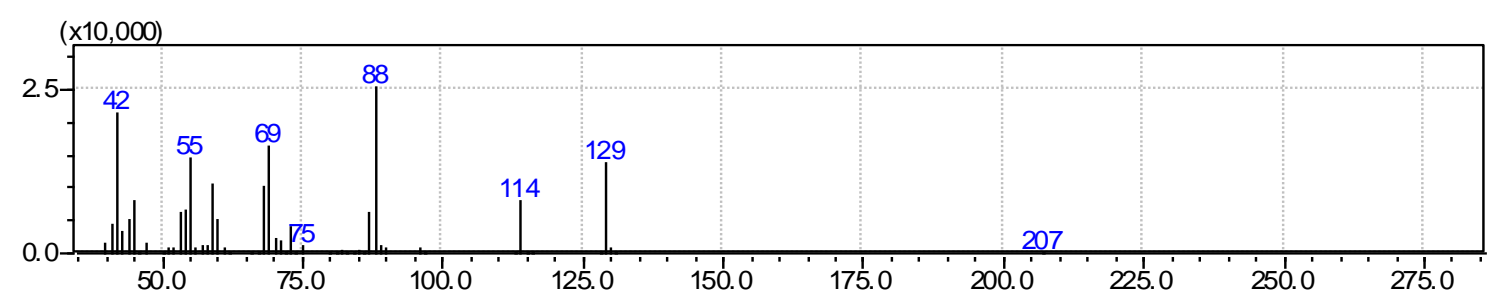

Figura 13. Espectro de massas do TMT (valores dados em $\mathrm{m} / \mathrm{z}$ ). No eixo x representa o tempo de retenção, e em y a concentração dos íons.

Assim, com esse dado foi possível fazer o monitoramento seletivo dos íons chave (SIM), aumentando a seletividade da análise, e obter cromatogramas convencionais usados para confecção da curva analítica do TMT nas diferentes concentrações. Sendo então realizada a integração dos sinais através de métodos eletrônicos, transformando os sinais digitalizados transmitidos pelo detector, em medida relacionada com o teor da substância analisada. Essas medidas foram relacionadas com a concentração da amostra e contemplam: o tempo de retenção, a altura e as áreas de pico (COLLINS et al., 2006).

Dessa forma foi possível construir a curva analítica (Figura 14) que tinha como propósito verificar a concentração interna da câmara nas diferentes doses de TMT (Experimento 4). Entretanto para identificar quantitativamente essa concentração foi necessário realizar equações empregando algoritmos matemáticos, em detrimento das análises quantitativas cromatográficas, após ter verificado que a fibra extraia uma concentração de aproximadamente $10^{4}$ além da concentração da câmara, logo o valor da fibra não era condizente a concentração real da câmara.

Assim os valores (aproximados) obtidos para a concentração interna da câmara nas diferentes doses de TMT são:

A. TMT $300 \mathrm{nMol}(0,3 \mathrm{mMol}): 0,0000066 \mu \mathrm{g} / \mathrm{mL}$ (partes por milhão, ppm)=0,0066 (partes por bilhão, ppb).

B. TMT $1000 \mathrm{nMol}(1 \mathrm{mMol}): 0,00002 \mu \mathrm{g} / \mathrm{mL}(\mathrm{ppm})=0,02 \mathrm{ppb}$.

C. TMT $10000 \mathrm{nMol}(10 \mathrm{mMol}): 0,0002 \mu \mathrm{g} / \mathrm{mL}(\mathrm{ppm})=0,2 \mathrm{ppb}$.

D. TMT Puro: $0,165 \mu \mathrm{g} / \mathrm{mL}(\mathrm{ppm})=165 \mathrm{ppb}$. 


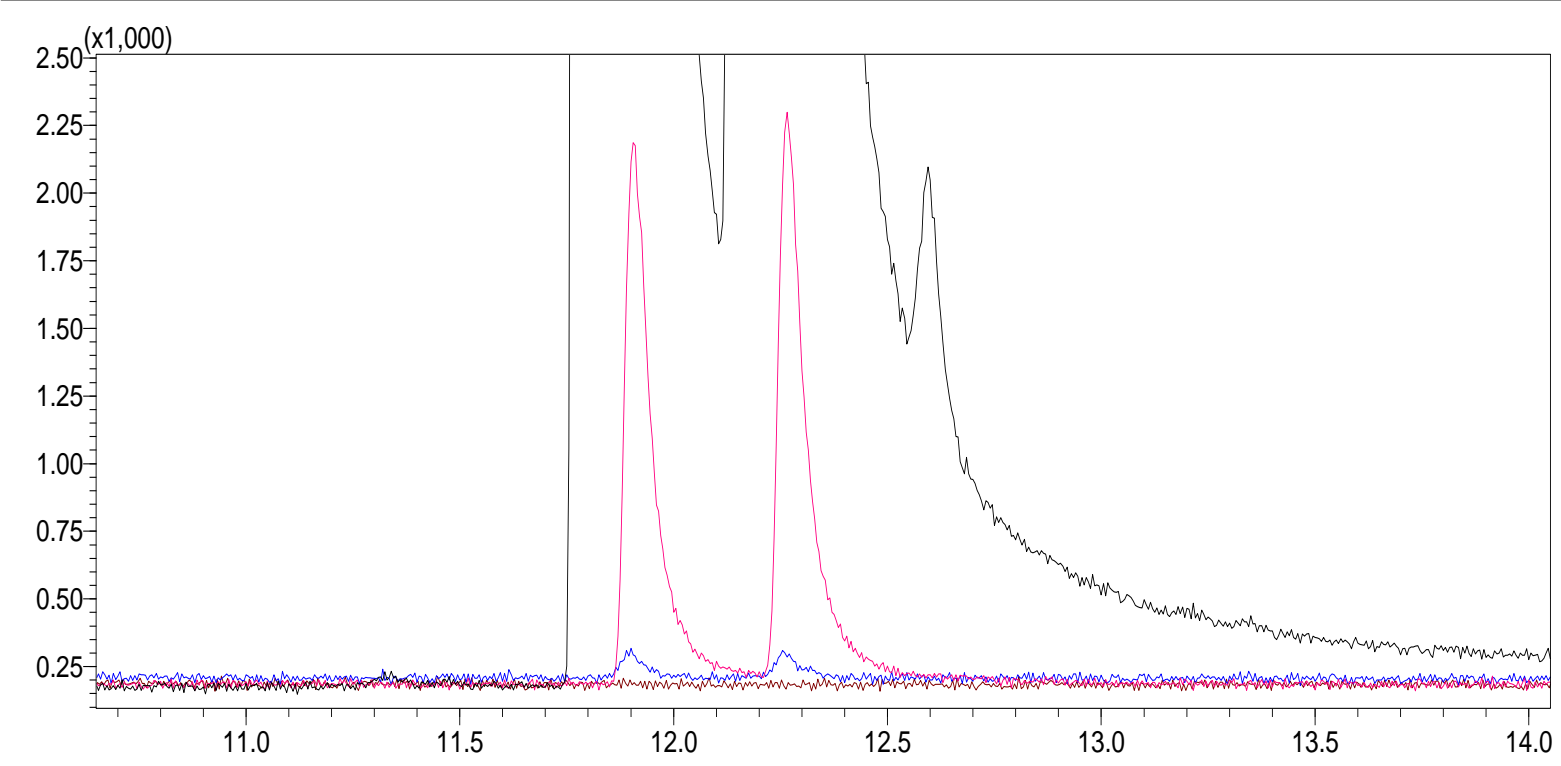

Figura 14. Curva cromatográfica da concentração interna da câmara nas diferentes doses de TMT (TMT 300 nMol - marron; TMT $1000 \mathrm{nMol}$ - azul; TMT $10000 \mathrm{nMol}$ - rosa e TMT Puro - preto): representação qualitativa da concentração interna da câmara. Eixo X indica o tempo de retenção, e Y a concentração total de íons em cada dose. Parâmetros utilizados: volume de $5 \mu \mathrm{L}$ na concentração a ser testada de TMT, com modo de aquisição SIM e injeção Split.

Em suma, a Figura 14 permitiu demostrar a linearidade da diluição do TMT, com a alteração concomitante da concentração interna da câmara. E ainda possibilitou correlacionar os teores aos valores obtidos com os algoritmos equações matemáticas, indicando coerência entre as análises.

Para verificar o tempo necessário para saturação e dessaturação do composto na câmara, utilizamos a concentração de $300 \mathrm{nMol}$ e volume de $500 \mu \mathrm{L}$ da solução como citado no item 5.2.2, e foi proposto alterações crescentes no tempo de exposição da fibra ao TMT. Assim, foi possível verificar que 30 minutos é o tempo necessário para que o ambiente interno da câmara esteja saturado, e o mesmo tempo para a completa dessaturação (Experimento 2).

Durante os experimentos, foi também realizada a modificação no posicionamento da fibra dentro da câmara, e pôde ser verificado que essa mudança não alterava os resultados obtidos na cromatografia, indicando uma saturação homogênea (Experimento 3).

Dessa maneira, os teores obtidos por cromatografia em fase gasosa permitiu correlacionarmos aos valores obtidos por cálculos matemáticos, identificando através desses algoritmos os valores (aproximados) da concentração interna da câmara para as diferentes doses de TMT. Além de identificar que 30 minutos é o tempo necessário para saturação e dessaturação da câmara ao TMT, e indicar uma saturação homogênea do interior dessa câmara. 



\subsection{OBJETIVOS ESPECÍ́ficos}

$\rightarrow$ Verificar o Índice de Gravidade para Crises Límbicas durante o abrasamento elétrico rápido, e em especial no $21^{\circ}$ estímulo quando o TMT e seu controle foram testados.

$\rightarrow$ Avaliar através da neuroetologia a expressão comportamental no $1^{\circ}, 20^{\circ}$ e $21^{\circ}$ estímulos.

$\rightarrow$ Avaliar a expressão EEGráfica do $1^{\circ}, 20^{\circ}$ e $21^{\circ}$ estímulos.

$\rightarrow$ Verificar a presença ou ausência de neurodegeneração no complexo amigdalóide, formação hipocampal e córtex piriforme.

$\rightarrow$ Comparar os resultados obtidos no presente projeto com dados provenientes de protocolo semelhante de estimulação olfatória em animais da cepa WAR que apresentam crises audiogênicas. Projeto de Pós-Doutorado da Dra. Poliana Bertti Dutra (Processo 2012/18637-2). 


\subsection{MATERial E MÉtodos}

Esse protocolo experimental foi aprovado pelo Comitê de Ética em Pesquisa Animal da FMRP - USP (Número do protocolo: 200/2011). Para tanto foram utilizados ratos Wistar, machos, naives, adultos, 280-300 gramas, provenientes do Serviço de Biotério do Campus de Ribeirão Preto da USP.

Os animais foram submetidos a um ciclo claro-escuro de 12/12 horas, sob temperatura controlada de $21^{\circ} \mathrm{C}$, com água e ração ad libitum. Todos foram armazenados em caixas de polietileno com tampa de ferro cromado (40,5 x 33,5 x $21 \mathrm{~cm})$, em grupos de no máximo 4 ratos por caixa no período anterior a cirurgia, e após este procedimento foram armazenados em caixas individuais até o término do experimento.

Para cumprir os objetivos foi realizado o protocolo representado na Figura 15 abaixo:

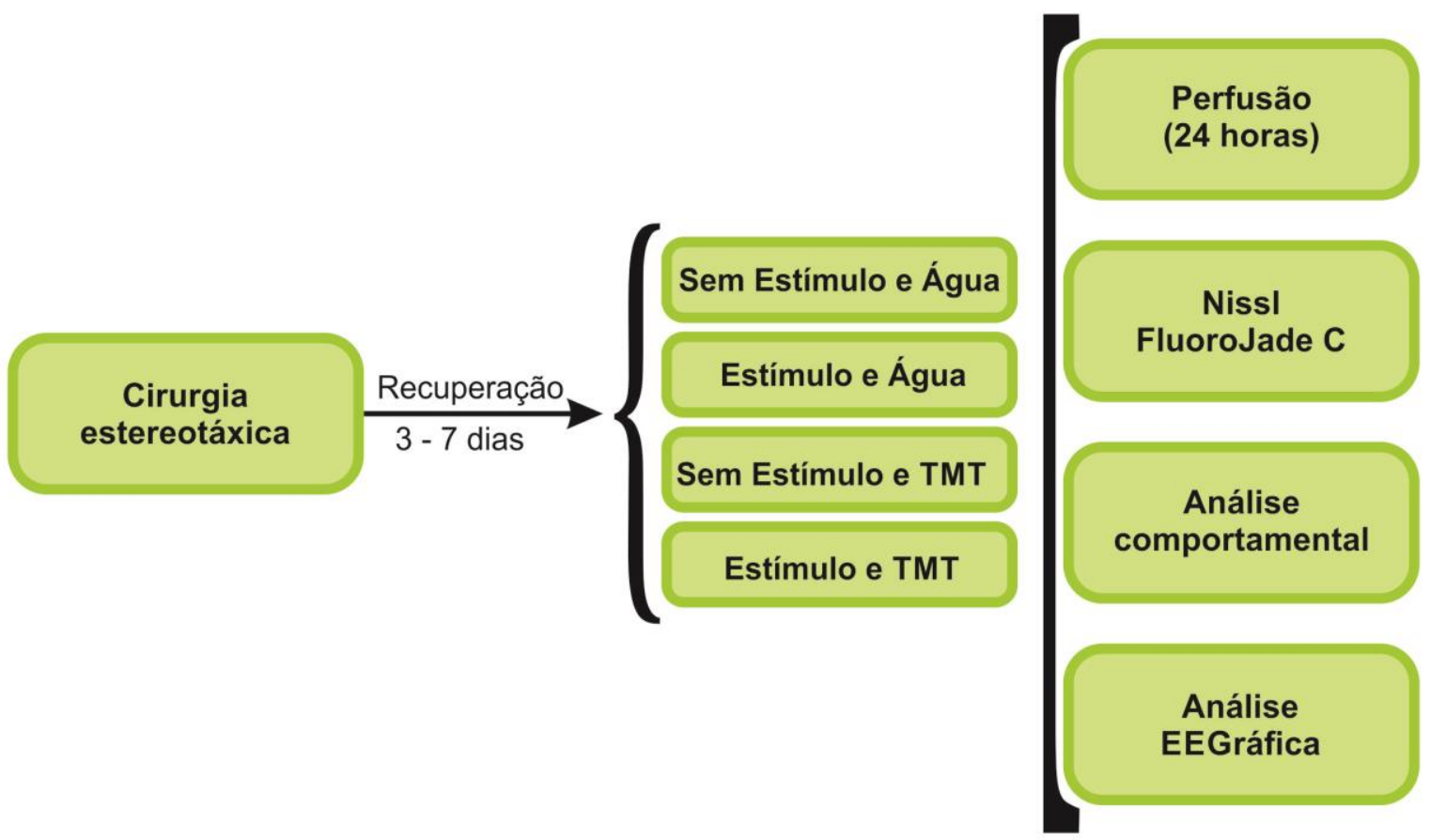

Figura 15. Desenho experimental: esquema resumido dos grupos e protocolos experimentais do modelo de abrasamento elétrico rápido.

\subsubsection{GRUPOS EXPERIMENTAIS}

Essa segunda parte do estudo congrega as ferramentas metodológicas utilizadas para a caracterização da influência do estímulo olfatório nas crises epilépticas de ratos Wistar, submetidos ao abrasamento elétrico rápido da amígdala. Para isso, os animais foram submetidos à cirurgia estereotáxica para implante dos eletrodos de registro em áreas importantes relacionadas com o medo inato e com crises límbicas, tais como: complexo 
Influência da estimulação olfatória com TMT no modelo de abrasamento elétrico rápido da amígdala amigdalóide, hipocampo e córtex piriforme, e eletrodo de estímulo no complexo amigdalóide. Após o período de recuperação e habituação, os animais foram submetidos ao protocolo de abrasamento elétrico rápido, e no dia do $21^{\circ}$ estímulo os animais receberam a estimulação olfatória previamente ao estímulo elétrico, sendo que metade dos animais abrasados foram expostos ao TMT Puro e a outra metade exposta a água destilada, constituindo assim o grupo controle. Vinte e quatro horas (Figura 15) após o estímulo olfatório os animais foram sacrificados para a coleta e o armazenamento dos encéfalos que foram utilizados para as histoquímicas de Fluoro-Jade C (FJC) e Nissl. Durante todo o protocolo de estimulação realizamos o registro de vídeo-eletrencefalograma (vídeo-EEG) que foi utilizado para as análises comportamentais e EEGráficas.

Assim, os animais foram divididos nos seguintes grupos:

- Grupo Sem Estímulo e Água: os animais permaneceram na caixa de estimulação e não receberam estímulos elétricos. Esse protocolo foi cuidadosamente desenhado para mimetizar o que seriam todas as etapas do modelo de abrasamento elétrico rápido, porém sem aplicar de fato o estímulo elétrico. Vinte e quatro horas após a simulação do " $20^{\circ}$ estímulo elétrico", os animais foram expostos à estimulação olfatória por 20 segundos com água destilada e em seguida permaneceram dentro da câmara, sem receber o $21^{\circ}$ estímulo elétrico.

- Grupo Estímulo e Água: Todos foram submetidos ao protocolo de abrasamento elétrico rápido, sendo que após 24 horas do $20^{\circ}$ estímulo elétrico, os animais foram expostos à estimulação olfatória por 20 segundos com água destilada e em seguida foram submetidos ao $21^{\circ}$ estímulo elétrico.

- Grupo Sem estímulo e TMT: Todos os animais permaneceram na câmara de estimulação e não receberam estímulos elétricos. Assim, 24 horas após a simulação do " $20^{\circ}$ estímulo elétrico", os animais foram submetidos à estimulação olfatória por 20 segundos com TMT e em seguida permaneceram dentro da câmara sem receber o $21^{\circ}$ estímulo elétrico.

- Grupo Estímulo e TMT: Todos foram submetidos ao protocolo de abrasamento elétrico rápido, sendo que após 24 horas do $20^{\circ}$ estímulo elétrico, os animais foram expostos à estimulação olfatória por 20 segundos com TMT e em seguida foram submetidos ao $21^{\circ}$ estímulo elétrico.

Observação: todos os animais dessa segunda parte experimental foram submetidos à cirurgia estereotáxica. 


\subsubsection{ANESTESIA}

Os animais foram anestesiados com Thiopentax - tiopental sódico 4\% (30 mg/kg; i.p.; Cristália Produtos Químicos Farmacêuticos LTDA, Itapira, SP, Brasil) com doses de manutenção $(0,1 \mathrm{~mL})$ utilizando-se a combinação dos anestésicos Ketamina $3 \%(0,6 \mathrm{mg} / \mathrm{kg}$; i.p.; Agener União Saúde Animal - Embu-Guaçu, SP, Brasil) e Xilazina 0,02\% (0,4 mg/kg; i.p.; Bayer Saúde Animal - São Paulo, SP, Brasil). Todos receberam na região da pele do dorso do crânio injeção de anestésico local subcutâneo composto por cloridrato de lidocaína $2 \%$ contendo epinefrina na combinação de 1:100.000 (Astra - Naucalpan, México). Ainda receberam durante o procedimento cirúrgico, o pentabiótico veterinário intramuscular com dose única de 0,15 mL (i.p.; FORT DODGE Saúde Animal LTDA - São Paulo, SP, Brasil), para prevenção de infecções. A eficácia da anestesia foi cuidadosamente verificada pela compressão da ponta da cauda do animal e dos coxins gordurosos das patas, além do reflexo córneo.

\subsubsection{Cirurgia Estereotáxica}

Após devidamente anestesiados e não responsivos aos estímulos dolorosos, os animais tiveram a pele do dorso do crânio tricotomizada. Em seguida, foram colocados no aparelho estereotáxico (David Kopf 962 - Tujunga, CA, EUA) e presos por barras auriculares e barra para incisivos. Com o animal devidamente posicionado no equipamento, foi aplicada a anestesia local subcutânea na pele do dorso da cabeça. E posteriormente foi realizada uma incisura com lâmina de bisturi, para expor a calota craniana, onde foi raspado o periósteo para facilitar a visualização das suturas que serviram como guias para o procedimento estereotáxico.

Nesse momento foi implantado o parafuso de aço inoxidável (FST Inc.) soldado a um pequeno fio para aterramento do animal ao sistema. Adicionalmente foram fixados quatro parafusos adicionais no escalpo do animal sem coordenadas estereotáxicas definidas que serviram para a fixação do capacete. E finalmente foi realizada a implantação dos eletrodos bipolares de aço inoxidável revestidos de teflon (A-M System, Inc.; diâmetro= $400 \mu \mathrm{m}$ ), na formação hipocampal (coordenadas estereotáxicas: Ântero-posterior, AP: -6.3 mm; Médiolateral, ML: -4,5 mm; Dorso-ventral, DV: $-4.5 \mathrm{~mm}$ ) e no córtex piriforme (coordenadas estereotáxicas: AP: no bregma; ML: - 5,0 mm; DV: $-8,8 \mathrm{~mm}$ ); e um eletrodo tripolar no complexo amigdalóide utilizando como referência o núcleo basolateral (BLA) para estimulação e registro (coordenadas estereotáxicas: AP: $-2.3 \mathrm{~mm}$; ML: $-4.7 \mathrm{~mm}$; DV: -7.1 
Influência da estimulação olfatória com TMT no modelo de abrasamento elétrico rápido da amígdala $\mathrm{mm})$. Todos os eletrodos foram implantados no hemisfério esquerdo, e as referências utilizadas para este procedimento cirúrgico foram o Bregma, a Fissura inter-hemisférica e a Dura-máter, além do atlas The Rat Brain in Stereotaxic Coordinates de Paxinos \& Watson (1997).

$\mathrm{Na}$ região de contato parafuso/osso e eletrodo/osso foi aplicado cimento dental de zinco (S.S. White - Rio de Janeiro, RJ, Brasil), para garantir a fixação. Os eletrodos e o fio terra foram soldados a fios do conector macho de seis pinos $R J 11$, e esse conector foi fixado ao crânio com acrílico dental, formando assim o capacete (Figura 16).

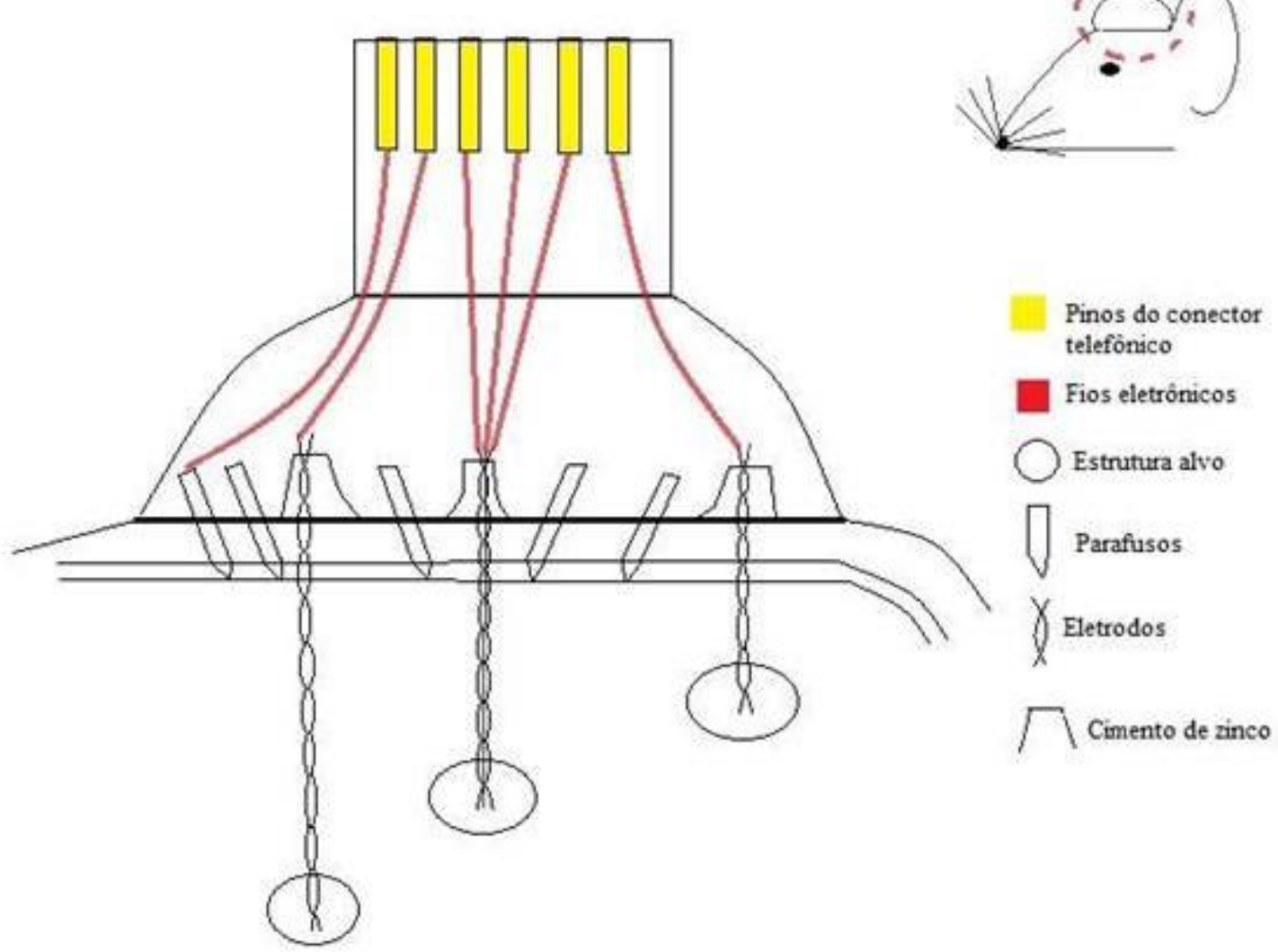

Figura 16. Desenho esquemático do rato implantado com os eletrodos após a cirurgia, no canto superior à direita. E a ampliação desta área, no desenho central (adaptado de TILELLI, 2003).

Após a cirurgia os animais foram acompanhados até a completa recuperação da anestesia e então colocados em caixas individuais. Os animais permaneceram no Biotério do Departamento de Fisiologia da FMRP-USP, por um período de 3-7 dias para recuperação, antes do início dos procedimentos subsequentes. 
Influência da estimulação olfatória com TMT no modelo de abrasamento elétrico rápido da amígdala

\subsubsection{ESTIMULAÇÃO ELÉTRICA}

Para o estímulo e registro elétrico, cada animal era colocado individualmente, em uma câmara de acrílico cilíndrica transparente $(29,5 \mathrm{~cm}$ de diâmetro x $49 \mathrm{~cm}$ de altura) envolvida por uma tela metálica (gaiola de Faraday) para eliminação de artefatos de registro elétrico. $\mathrm{O}$ animal era então conectado ao sistema, através do encaixe do plug RJ11 (6 pinos) ao respectivo encaixe (jac) acoplado a um cabo ligado ao swivel Airflyte Eletronics Co.. Esse cabo, apesar de conectado à cabeça do animal não comprometeu sua mobilidade dentro da gaiola, e também não sofreu qualquer tipo de deformação dos fios.

Os sinais eletrofisiológicos eram enviados para a caixa de distribuição, através de um cabo com amplificadores de alta impedância de entrada e baixa de saída, construídos com transistores de efeito de campo (fets) localizados no jac onde conectava o plug do animal. Os sinais de registro eram conduzidos a um sistema de amplificação e filtragem (CyberAmp 320, Axon Instruments, Foster City, EUA), e a um conversor analógico digital acoplado ao computador (Biopac Systems mod. MP100, Santa Bárbara, EUA). O software utilizado para captura dos sinais eletrofisiológicos foi o Acknowledge (Biopac Systems).

Para o registro o ganho do sistema era ajustado pelo programa Quick300 (Axon Instruments) com ganho total de 2000 vezes, filtro passa baixa em $1000 \mathrm{Hertz}(\mathrm{Hz})$, filtro passa alta em $0,1 \mathrm{~Hz}$ e notch filter para $60 \mathrm{~Hz}$. Para análise dos sinais do eletrencefalograma (EEG) foram utilizados: o Acknowledge (Biopac Systems) e o Matlab (versão 2009, The Math Works, Inc).

Os estímulos elétricos realizados no complexo amigdalóide (vide grupos estimulados, item 5.1) foram realizados por meio do estimulador Grass 5 e as unidades de isolamento SIU 5 (West warwick, EUA) que nos permitiram fazer a montagem dos pulsos bifásicos, ligados à switching box que controla o tempo (segundos) da descarga aplicada no animal. Além do osciloscópio (Hewlett-Packard 130C HP, Palo Alto, EUA) que nos permitiu monitorar e regular a corrente do pulso elétrico transmitido ao animal (Figura 17).

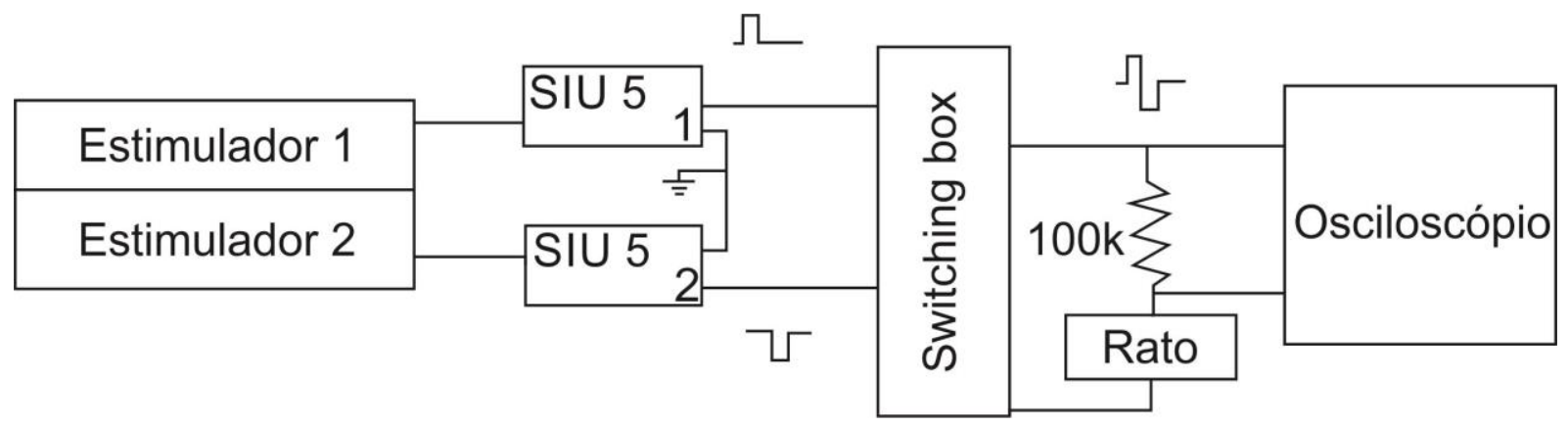

Figura 17. Esquema ilustrativo do sistema de estimulação elétrica. 
Influência da estimulação olfatória com TMT no modelo de abrasamento elétrico rápido da amígdala

Um importante critério que diferencia o protocolo de abrasamento elétrico convencional do rápido é quanto ao estímulo ser sub ou supralimiar, respectivamente. Segundo Lothman et al., (1985) para superar o eventual efeito da adaptação, que acumula mediante intervalos curtos entre estímulos, a intensidade da corrente indutora de crise deve ser supralimiar, com duração mínima de 10 segundos. Assim, baseados no estudo desenvolvido por Foresti e colaboradores (2008), os parâmetros utilizados nesse estudo para estimulação elétrica foram: estímulo elétrico bipolar com trens de ondas quadradas bifásicas, corrente constante de $500 \mu \mathrm{A}$, com frequência de $60 \mathrm{~Hz}$, pulsos de $1 \mathrm{~ms}$ e 10 segundos de estimulação.

Para a realização das técnicas experimentais propostas foram utilizados 2 sistemas de registro e estímulo, que permitiram a realização de 2 animais a cada 4 dias. Abaixo ilustrada uma das câmaras de experimentação (Figura 18).
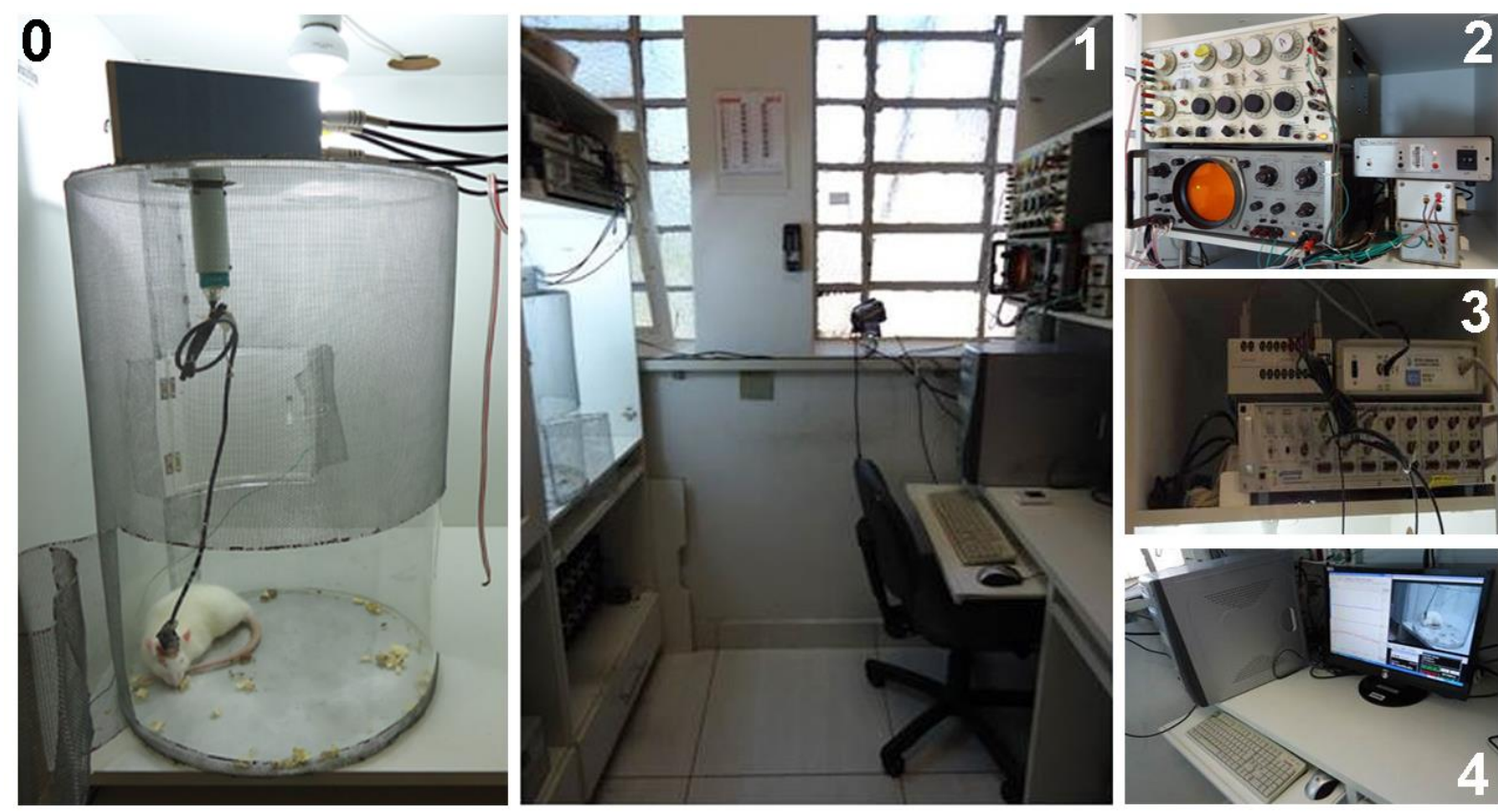

Figura 18. Diagrama esquemático do sistema de registro de EEG (18.0, 18.1, 18.3 e 18.4) e estímulo (18.0, 18.1, 18.2 e 18.4).

\subsubsection{INDUÇÃo DE CRISES EPILÉPTICAS}

Durante os últimos três dias consecutivos do período de recuperação, os animais passaram pelo protocolo de habituação. Após esse período, ou seja, no primeiro dia de experimento após o período de recuperação da cirurgia, foi realizado o cálculo do limiar da pós-descarga necessário para provocar crise - em todos os grupos.

Para o estabelecimento do limiar foram aplicados estímulos com duração de 2 segundos, intervalos de 5 minutos e com correntes crescentes de $100 \mu \mathrm{A}$ a cada novo 
Influência da estimulação olfatória com TMT no modelo de abrasamento elétrico rápido da amígdala estímulo, até que o animal apresentasse alteração EEGráfica, de acordo com Ebert e Löscher (1995).

O abrasamento elétrico rápido foi iniciado no dia seguinte após a determinação do limiar. Como descrito previamente, esse protocolo foi realizado nos grupos Estímulo e Água, e Estímulo e TMT enquanto os animais dos outros grupos Sem Estímulo e Água, e Sem Estímulo e TMT foram apenas conectados ao aparato de registro e estímulo e não sofreram qualquer estimulação elétrica, sendo apenas coletado o vídeo-EEG para fins de análise comportamental e EEGgráfica controles. É importante ressaltar que para os animais dos grupos Sem Estímulo todos os passos foram cuidadosamente seguidos de modo que a única diferença em relação aos animais dos grupos Com Estímulo era a ausência de corrente elétrica.

O abrasamento elétrico rápido seguiu o modelo proposto por Foresti e colaboradores (2008), consistindo na aplicação de 20 estímulos elétricos, durante 2 dias, sendo portanto 10 estímulos por dia, com intervalo de 30 minutos entre os estímulos que tinham a duração de 10 segundos cada. No $3^{\circ}$ dia, 24 horas após o $20^{\circ}$ estímulo, os animais receberam o último estímulo elétrico, após o estímulo olfatório.

\subsubsection{ESTIMULAÇÃo OLFATÓRIA}

Previamente ao $21^{\circ}$ estímulo elétrico, os animais foram expostos ao TMT Puro ou a Água durante 20 segundos. Esse protocolo de estimulação olfatória foi semelhante ao descrito no item 5.2.3. Assim, na câmara foram colocados $5 \mu 1$ de líquido (TMT ou água) sob papel filtro (dimensão: 4,5 x 4,5) e essa foi mantida completamente fechada por 30 minutos (rever 5.3.3). Na sequência, o animal foi colocado na câmara e o vídeo-EEG gravado durante todo o período de observação (5 minutos e 30 segundos), para posterior análise. Após ter retirado o animal, a exaustão foi acionada por 30 minutos, para retirada da substância/odor de dentro da câmara.

A câmara utilizada nesse experimento foi a mesma (rever Figura 5) do protocolo descrito no item 5.2.3.

\subsubsection{Perfusão, CrioproteÇão e Congelamento}

Os animais foram perfundidos respeitando a janela temporal de 24 horas após o último estímulo, para o processamento tecidual para FJC. O procedimento não diferiu do protocolo descrito no item 5.2.4, assim como a crioproteção e o congelamento. 
Influência da estimulação olfatória com TMT no modelo de abrasamento elétrico rápido da amígdala

Para as análises histoquímicas, os tecidos cerebrais foram cortados a $40 \mu \mathrm{m}$ no plano coronal em criostato (Microm HM-5005-E) com a temperatura variando entre $-18^{\circ} \mathrm{C}$ e $-22^{\circ} \mathrm{C}$. Os cortes contendo as lesões de ponta de eletrodos foram colocados em lâminas gelatinizadas (gelatina 0,5\% e sulfato de cromo-alumínio 0,05\%) para localização dos eletrodos e os demais cortes foram mantidos em placa de cultura com 24 escavações, imersos em solução anticongelante (50\% de PBS $50 \mathrm{mM}, 30 \%$ etilenogligol e $20 \%$ glicerina).

Entretanto, foi realizado previamente um estudo para permitir que, as áreas de interesse fossem cortadas na íntegra, e armazenadas em placas para cultura de células. Logo, todos os animais dispunham de tecidos com áreas semelhantes, permitindo assim, a posterior realização de diferentes técnicas, com comparação segura dos tecidos, além de possibilitar a análise quantitativa através cálculos estereológicos.

Além disso, houve também o cuidado com os tecidos que não fossem utilizados nesse estudo, fossem mantidos congelados, embalados, identificados e armazenados em freezer $20^{\circ} \mathrm{C}$, para futuro processamento.

As placas com os poços e parte do tecido contido nessas placas foram utilizados na histoquímica de FJC e armazenados em freezer $-20^{\circ} \mathrm{C}$.

As lâminas contendo os cortes foram armazenadas em caixas apropriadas e também armazenados em freezer $-20^{\circ} \mathrm{C}$.

\subsubsection{HistoquímicA DE NisSL}

Essa técnica cora corpúsculos de Nissl, que são grupos de cisternas e ribossomos agregados, constituindo o retículo endoplasmático rugoso, que está presente no corpo celular dos neurônios, e que possuem afinidade com corantes básicos. Sua coloração é dependente do corante utilizado.

A histoquímica de Nissl permite verificar não apenas a qualidade do tecido, mas também a localização dos eletrodos, usando como referência as pranchas do Atlas de Paxinos \& Watson (1997). Para a realização da técnica, os tecidos já fixados às lâminas foram hidratados com banhos decrescentes de álcool, passando por banho em água (10 minutos) e colocados em corante (acetato de Cresil Violeta 0,25\%) por aproximadamente 1 minuto, após lavados em água corrente (10 minutos) e em seguida desidratados em concentrações crescentes de etanol, passando pelo processo de diafanização com banhos de xilol e cobertos por lamínulas usando Entellan (Merck Indústria Química Rio de Janeiro, Brasil) como meio de montagem. Os cortes histológicos foram analisados e as imagens adquiridas através do 
Influência da estimulação olfatória com TMT no modelo de abrasamento elétrico rápido da amígdala

Estereoscópio (Olympus SZX12, Melville, USA) acoplado a uma câmera digital (Olympus DP11) ligado a um computador (PC Pentium II $500 \mathrm{MHz}$ ).

\subsubsection{HistoquímiCA DE FJC}

Todo o protocolo experimental foi baseado em publicações do nosso laboratório (CASTRO et al., 2011; FORESTI et al., 2008; FURTADO et al., 2002, 2011; ROMCYPEREIRA; GARCIA-CAIRASCO, 2003) no qual foi constatado que o FJC pode ser usado com segurança em protocolos experimentais que mimetizam neurodegeneração na epilepsia (SCHMUED; ALBERTSON; SLIKKER, 1997).

As secções armazenadas em free floating nos poços de cultura foram montadas em lâminas gelatinizadas e colocadas para secar em temperatura ambiente com antecedência de 24 horas. De acordo com o protocolo de Schmued e colaboradores (1997) as lâminas foram submetidas a banhos sucessivos, começando com o etanol absoluto por 3 minutos, etanol 70\% por 1 minuto, água destilada por 1 minuto, permanganato de potássio $(0,06 \%)$ por 15 minutos em agitação branda, 3 lavagens em água destilada por 1 minuto. Então as lâminas foram submersas em solução FJC (preparado e utilizado no mesmo dia) por 30 minutos em agitação branda, após 3 lavagens em água destilada por 1 minuto, secagem das lâminas, e posteriormente as lâminas foram montagem utilizando Fluoromont.

- $\quad$ FJC (solução estoque 0,01\%): $10 \mathrm{mg}$ de FJ em $100 \mathrm{~mL}$ de água destilada, estável por até 2 meses se conservado em geladeira.

- $\quad$ FJC (solução de uso 0,01\%): diluído em ácido acético 0,1\%.

- Permanganato de potássio 0,06\%: pode ser utilizado por uma semana se guardado em recipiente de vidro bem fechado.

As lâminas foram analisadas utilizando o miscroscópio confocal Leica TCS-NT (SP2 e SP5) e software Leica LCS (ambos, Leica Microsystems-Heidelberg, Germany) com luz de excitação e usando um sistema de filtro que permite a visualização da fluoresceína ou FITC resultando em emissão de cor verde.

\subsubsection{Registro e AnÁlise COMPORTAMEntal}

Os animais foram filmados (câmera VHS, Sony, modelo DCR-DVD308) e tiveram sua imagem enviada através da placa conversora de captura e saída de vídeo para a tela do computador, conforme descrição prévia (vide item 6.2.4). 
Influência da estimulação olfatória com TMT no modelo de abrasamento elétrico rápido da amígdala

$\mathrm{Na}$ tela do computador foi possível visualizar além do comportamento expresso por cada animal, o traçado de EEG. Todos os registros foram realizados por 05 minutos antes e 05 minutos após cada estímulo, durante todo protocolo de abrasamento elétrico rápido (vide itens 6.2.4 e 6.2.5). Já no $21^{\circ}$ estímulo os animais foram imediatamente colocados na câmara para a estimulação olfatória e a subsequente estimulação elétrica (ver grupos experimentais em 6.2.1), portanto sem o registro comportamental do período pré, uma vez que a caixa já estava saturada com o odorante. Foi realizado também o registro do período de estimulação, compreendendo 10 segundos.

A avaliação comportamental baseou-se no trabalho de Pinel \& Rovner (1978; Tabela 5); que adiciona ao Índice de Gravidade de Crises Límbicas sugerido por Racine (1972), alguns eventos que descrevem comportamentos tipicamente evocados pela ativação de estruturas do sistema límbico (até a classe 5), outros associados a repetição de classes 5 (classe 6) e aqueles evocados por recrutamento de estruturas do tronco cerebral (classes 7 e $8)$.

Tabela 5. Índice de Gravidade para Crises Límbicas.

\begin{tabular}{cc}
\hline Classe 1 & Automatismos faciais \\
Classe 2 & Mioclonia de cabeça \\
Classe 3 & Mioclonia de patas anteriores \\
Classe 4 & Elevação \\
Classe 5 & Elevação e queda \\
Classe 6 & Mais de uma classe 5 \\
Classe 7 & Corridas e pulos \\
Classe 8 & Convulsão tônico-clônica generalizada \\
RACINE (1972) modificada por PINEL \& ROVNER (1978)
\end{tabular}

Além disso, a análise comportamental foi realizada também através da abordagem neuroetológica, que é baseada em uma análise detalhada de todos os itens comportamentais, como citado anteriormente (o que constitui um glossário ou dicionário; Tabela Complementar 1) apresentados pelo animal durante o período de observação. Cada comportamento recebe um código que é inserido no programa estatístico ETHOMATIC. O programa permite tanto a análise de uma única crise, quanto à da soma de crises de um mesmo indivíduo ou grupo, fornecendo a frequência de ocorrência de cada item, sua duração média e as interações entre comportamentos, calculadas através da construção de matrizes de transição de primeira ordem, pelo número de vezes que ocorrem as interações. O programa também realiza a 
Influência da estimulação olfatória com TMT no modelo de abrasamento elétrico rápido da amígdala verificação estatística de associação entre ítens pela análise do $\mathrm{X}^{2}$, sendo as interações consideradas estatisticamente significativas quando $\mathrm{p}<0,05 ; \log \mathrm{X}^{2} \geq 0,25$.

Após a análise os dados obtidos foram representados graficamente no programa Power Point 2010 (Microsoft) sob a forma de fluxogramas, que indicam as sequências comportamentais registradas durante o período de observação. Para isto, utilizou-se o padrão de calibração da Figura 19, acrescentando a essa análise comportamentos observados durante crises límbicas (GARCIA-CAIRASCO et al., 1996).

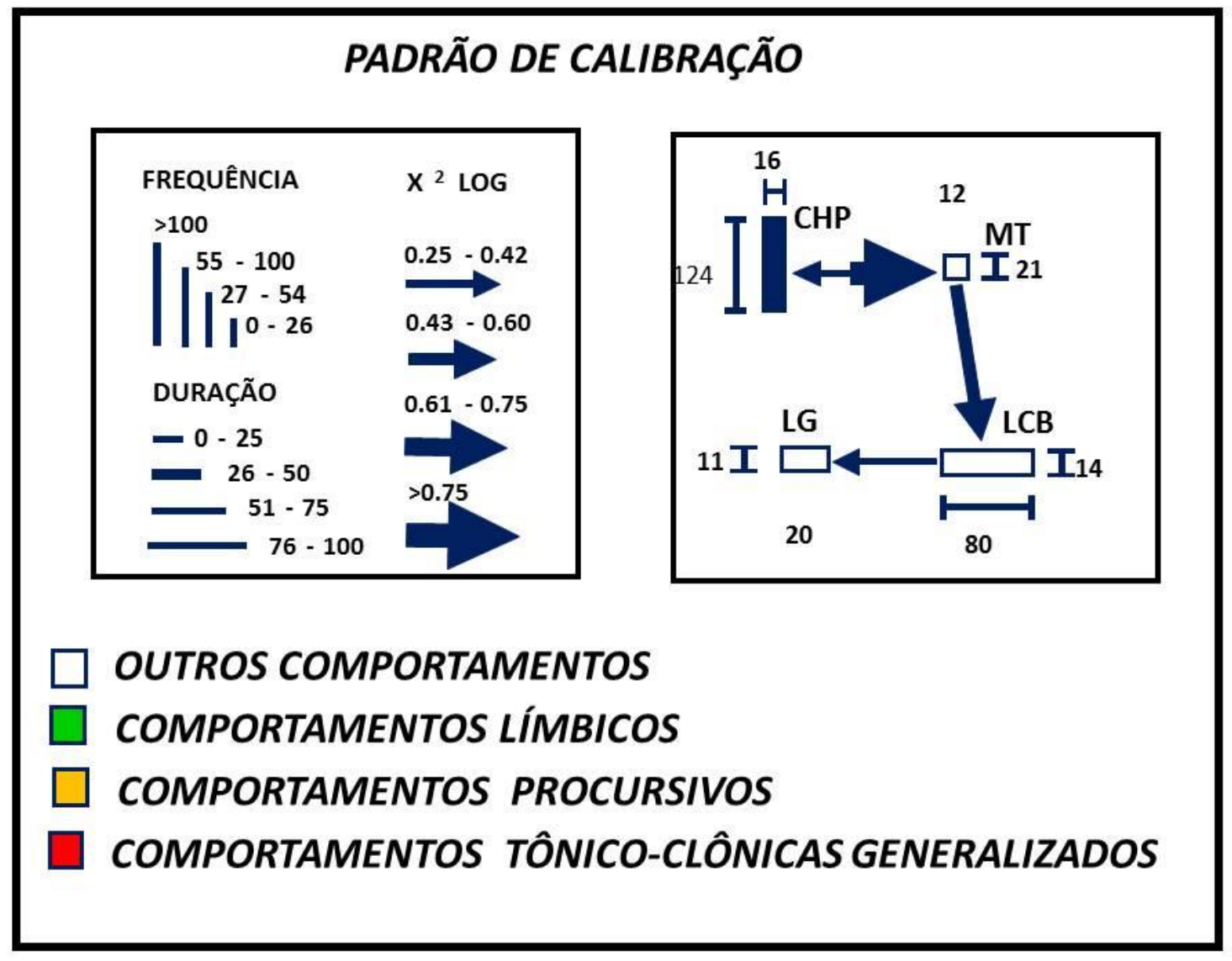

Figura 19. Padrão de calibração para confecção dos fluxogramas (GARCIA-CAIRASCO et al., 1992). Cada retângulo representa um comportamento. A altura dos retângulos simboliza a frequência de ocorrência, e a base, a duração média do comportamento durante a observação. As setas representam valores estatísticos $(\mathrm{X} 2 \geq 3,841$; $\log \mathrm{X} 2 \geq 0,25 ; \mathrm{p}<0,05)$ que indicam a probabilidade de um segundo comportamento ocorrer após um dado comportamento. As cores utilizadas nos retângulos têm o objetivo de identificar qualitativamente classes relacionadas de comportamentos. A cor das setas representa o ponto de partida das mesmas ao acompanhar a cor do retângulo que origina a interação entre pares comportamentais.

No fluxograma, cada retângulo representa um comportamento. A altura dos retângulos simboliza a frequência de ocorrência; a base representa a duração média do comportamento durante a observação e as cores identificam qualitativamente classes relacionadas de comportamentos. As setas indicam a presença de interação estatística entre dois itens (díade) e 
Influência da estimulação olfatória com TMT no modelo de abrasamento elétrico rápido da amígdala

a largura das setas representa valores estatísticos que indicam a probabilidade de um segundo comportamento ocorrer após outro. A cor das setas acompanha a cor do retângulo de partida.

\subsubsection{ESTIMULAÇÃO OLFATÓRIA EM ANIMAIS WAR}

Os experimentos de estimulação olfatória em animais da cepa WAR, foram desenvolvidos em colaboração ao projeto da Pós-Doutoranda Dra. Poliana Bertti Dutra (Processo FAPESP 2012/18637-2). Esse estudo tinha como objetivo caracterizar através da neuroetologia, as alterações comportamentais induzidas pela estimulação olfatória com o TMT e avaliar a influência desse odorante no desenvolvimento de crises audiogênicas agudas na cepa WAR.

Vinte e oito WAR, machos, adultos passaram por 3 dias de habituação. Na sequência, foram divididos em dois grupos: um grupo para avaliar as alterações comportamentais induzidas apenas pela estimulação olfatória, Grupo Sem Som $(\mathrm{N}=12)$, e outro grupo Com Som (N=16), para avaliar a influência da estimulação olfatória no desenvolvimento de crises audiogênicas agudas.

Os animais do grupo Sem Som foram expostos à solução salina (SAL/s, N=6), ou ao TMT Puro (TMT/s, N=6), enquanto os animais do grupo Com Som foram submetidos por 20 segundos a salina ( $\mathrm{SAL} / \mathrm{som}, \mathrm{N}=8$ ) ou ao TMT Puro (TMT/som, $\mathrm{N}=8$ ), com subsequente estimulação acústica por 1 minuto ou até a presença da convulsão tônica clônica (CVT).

A análise das sequências comportamentais (Ethomatic, Garcia-Cairasco et al., 1992 ver itens 6.2.10) foi realizada nas seguintes janelas temporais: durante os 20 segundos de exposição olfatória antes do estímulo, seguido pela estimulação sonora com duração máxima de 1 minuto, e após o estímulo os animais foram filmados por mais 1 minuto. Para esse protocolo o som gravado e reproduzido mimetiza um toque de campainha, com frequência de $60 \mathrm{~Hz}$, cuja intensidade final é de $120 \mathrm{~dB}$.

A avaliação comportamental especificamente para os grupos Com Som incluiu ainda, a atribuição do Índice de Gravidade para crises Mesencefálicas (ISc), descrito por GarciaCairasco e colaboradores (1992), e modificado por Rossetti e colaboradores (2006 - Tabela 6), além do cálculo das latências para a $1^{\circ}$ Corrida e CVT. Para fins estatísticos, foi utilizado o Teste Mann Whitney, considerando p<0,05. 
Influência da estimulação olfatória com TMT no modelo de abrasamento elétrico rápido da amígdala

Tabela 6. Índice de Gravidade para Crises Mesencefálicas.

$\begin{array}{cc}\text { Classe } 0 & \text { Nenhuma corrida } \\ \text { Classe } 1 & \text { Uma corrida e giro } \\ \text { Classe } 2 & \text { Uma corrida e giro seguido por pulos e quedas tônicas } \\ \text { Classe } 3 & \text { Duas corridas e giros seguidos por pulos e quedas tônicas } \\ \text { Classe } 4 & \text { Todas as anteriores com CVT com arqueamento do dorso } \\ \text { Classe } 5 & \text { Anteriores seguidas por convulsões clônicas parciais e generalizadas } \\ \text { Classe } 6 & \text { Anteriores seguidas por ventroflexão de cabeça } \\ \text { Classe } 7 & \text { Anteriores seguidas por hiperextensão das patas anteriores } \\ \text { Classe } 8 & \text { Anteriores seguidas por hiperextensão das patas posteriores } \\ \text { GARCIA-CAIRASCO } \text { et. al. } \text { (1992) modificado por ROSSETTI } \text { et al., (2006). }\end{array}$

\subsection{Resultados E Discussão}

\subsubsection{CONFIRMAÇÃo HistológiCa}

A confirmação histológica constitui parte importante para integrar os animais aos seus respectivos grupos amostrais. Porém antes mesmo da cirurgia, a escolha das áreas implantadas foi feita de forma criteriosa, obedecendo aos objetivos propostos no estudo. Contamos nessa etapa com a colaboração da Pós-Doutoranda a Dra. Simone S. Marroni que nos auxiliou na confirmação do posicionamento correto dos eletrodos de registro e estímulo.

Foram realizadas 60 cirurgias estereotáxicas, para implantação no hemisfério esquerdo dos eletrodos de registro na formação hipocampal e córtex piriforme, além da implantação do eletrodo de estimulação e registro no complexo amigdalóide. Após o período de recuperação os animais foram submetidos ao protocolo de abrasamento elétrico rápido, em seguida as técnicas como crioproteção, congelamento e secções dos cérebros. Então parte dos cortes histológicos que continham os eletrodos foi submetida à técnica de coloração de Nissl para a confirmação histológica (descrição destes protocolos, rever Materiais e Métodos, 6.2).

O posicionamento correto de todos os eletrodos nas áreas do córtex piriforme, BLA e hilus do giro denteado foi identificado em 19 animais (31,66\%). Considerando os animais com eletrodos implantados no complexo amigdalóide (nos diferentes núcleos), formação hipocampal e no córtex piriforme, esse número sobe para 40 animais $(66,66 \%)$, que por fim constituíram o número final de animais que foram processados e analisados do ponto de vista comportamental e EEGráfico. Logo, 20 (33,33\%) dos 60 animais não tiveram o 
Influência da estimulação olfatória com TMT no modelo de abrasamento elétrico rápido da amígdala

posicionamento correto dos eletrodos, e não foram incluídos neste estudo. Mas, todos os dados coletados estão armazenados e poderão ser utilizados no futuro.

Abaixo está descrito o número de animais por grupo considerando a posição dos eletrodos no córtex piriforme e nos complexos amígdalóide e a formação hipocampal, seguido pelo número de animais, entre parênteses, com eletrodo implantado no córtex piriforme, BLA e hilus do giro denteado:

A. Grupo Sem Estímulo e Água: 8 (4) animais;

B. Grupo Estímulo e Água: 8 (4) animais;

C. Grupo Sem Estímulo e TMT: 12 (7) animais;

D. Grupo Estímulo e TMT: 12 (4) animais.

A Figura 20 ilustra o posicionamento dos eletrodos, nos grupos: Sem Estímulo e Água, Estímulo e Água, Sem Estímulo e TMT, e Estímulo e TMT, nas seguintes áreas: córtex piriforme (1), complexo amigdalóide (2) e formação hipocampal (3), dos 60 animais que foram implantados com eletrodos na cirurgia extereotáxica. 


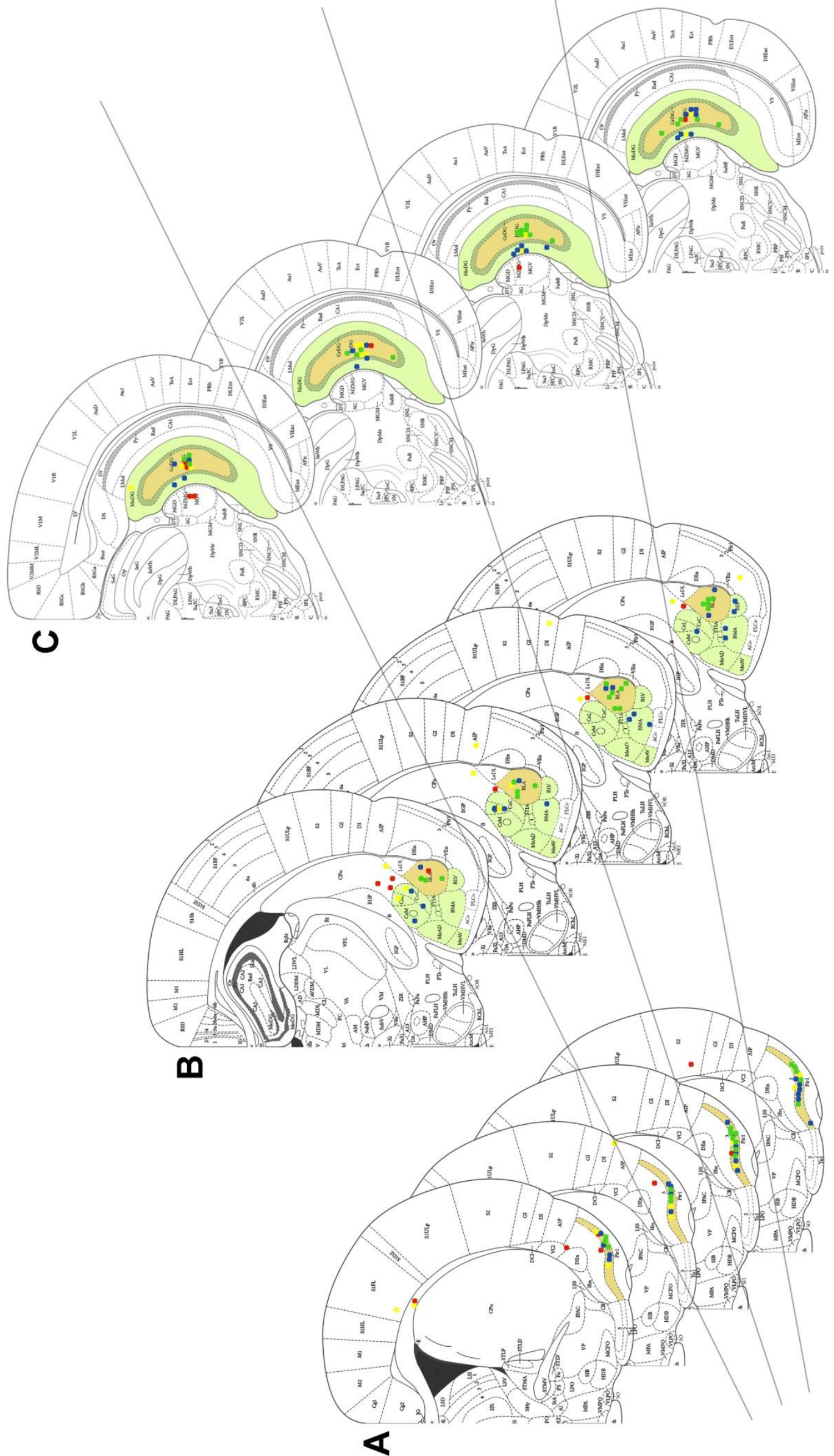


Influência da estimulação olfatória com TMT no modelo de abrasamento elétrico rápido da amígdala

Figura 20. Dados gerais do posicionamento dos eletrodos, nos grupos: Sem Estímulo e Água, Estímulo e Água, Sem Estímulo e TMT, e Estímulo e TMT, com desenho esquemático nas seguintes áreas: córtex piriforme (A), complexo amigdalóide (B) e formação hipocampal (C), todos no hemisfério esquerdo dos 60 animais que foram implantados com eletrodos na cirurgia extereotáxica. Sendo representado em círculos fechados com diferentes cores: vermelho o animal com acerto em apenas umas das áreas cerebrais acima descrita; amarelo o animal com acerto em duas áreas cerebrais (piriforme, complexo amigdalóide e/ou formação hipocampal); em azul o animal com eletrodo posicionado no piriforme, complexo amigdalóide e/ou formação hipocampal; e finalmente em verde o animal com o posicionamento no córtex piriforme, BLA e hilus do giro denteado. *amarelo representa um eletrodo do grupo Estímulo e Água posicionado na área correspondente da prancha inferior, mas que devido a organização da Figura foi representado na prancha do grupo Sem Estímulo e Água.

A título de exemplo, na Figura 21 estão cortes de diferentes animais ilustrando a correta implantação dos eletrodos nas áreas de interesse, utilizando a histoquímica de Nissl (ver item 6.2.8).

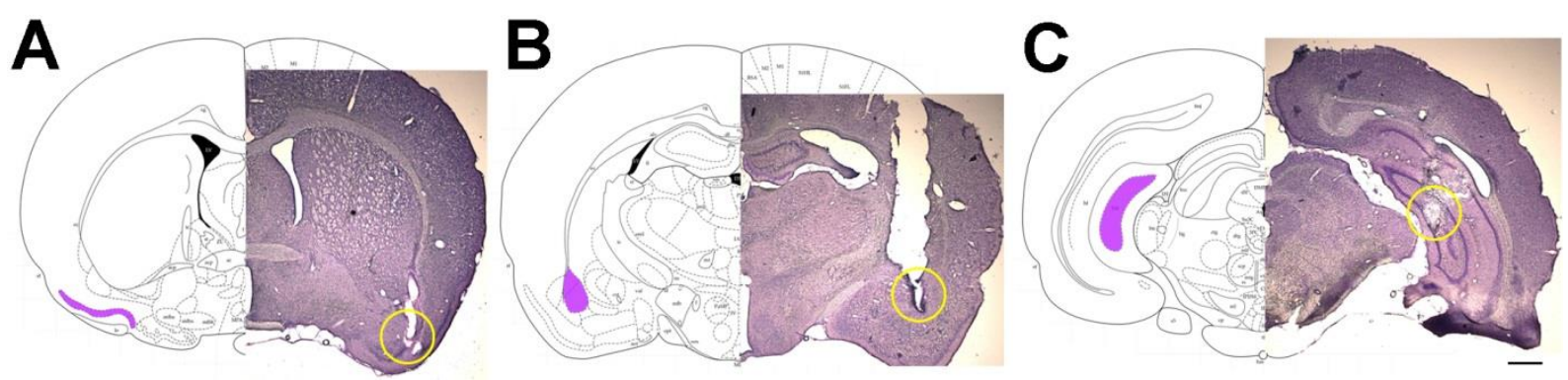

Figura 21. Tecido corados pela técnica de Nissl com posicionamento de eletrodos: (A) córtex piriforme, (B) BLA, (C) hilus do giro denteado no hipocampo, todos no hemisfério esquerdo (lado direito). Esquema do atlas de Paxinos \& Watson (2005) com indicação do posicionamento na área desejada (lado esquerdo). Barra de calibração de $1000 \mu \mathrm{m}$.

Inicialmente um dos nossos objetivos era também verificar a presença ou ausência de ativação celular no complexo amigdalóide, formação hipocampal e córtex piriforme, através da imunohistoquímica de c-Fos. Entretanto com a histoquímica de Nissl foi possível verificar que em $63,15 \%$ dos animais houve comprometimento da integridade e a da qualidade do tecido. Assim as características histológicas evidenciaram um tecido com qualidade inferior, muito provavelmente devido a problemas nas técnicas de perfusão e/ou congelamento, incluindo os animais perfundidos com a janela de perfusão de 90 minutos, para a imunohistoquímica de c-Fos. Somente $36,84 \%$ estavam com uma qualidade moderada. Desses, 78,55\% dos animais foram aproveitados para a análise de FJC, e os 21,45\% da diferença, referem-se aos animais perfundidos para a imunohistoquímica de c-Fos, mas que, devido ao reduzido número de animais por grupo, optamos pelo não processamento.

\subsection{2 ÍNDICE de GRAVIDADE PARA CRISES EPILÉPTICAS}

Racine e colaboradores (1972) descreveram os comportamentos de crise límbica, através de uma escala progressiva de alterações comportamentais que iniciava em 1 com automatismos faciais e prosseguia até o índice 5, com elevação e queda. Em 1978, Pinel \& 
Influência da estimulação olfatória com TMT no modelo de abrasamento elétrico rápido da amígdala Rovner incluíram nesta escala comportamental os índices 6-8, representando comportamentos que aconteciam tardiamente em uma crise límbica, como corridas, pulos e CVT (para maiores detalhes sobre as classes, veja Tabela 5).

O abrasamento é um modelo crônico como citado anteriormente no qual, estímulos repetidos com intensidades constantes, culminam no aumento da excitabilidade cerebral (BERTRAM, 2007; EBERT; LÖSCHER, 1995; FISHER, 1989; FORESTI et al., 2008; GODDARD, 1983; LÖSCHER; BRANDT, 2010; LOTHMAN ., 1985; LÖSCHER; EBERT, 1996; SAYIN et al., 2003). Tal modelo resulta em alterações epileptogênicas e consequentemente epileptiformes proporcionando o aumento gradual da gravidade comportamental, bem como da duração da pós descarga, além da redução do limiar para crises (BERTRAM, 2007; GODDARD, 1983; LÖSCHER; BRANDT, 2010; LÖSCHER; EBERT, 1996; SAYIN et al., 2003).

O Índice de Gravidade para Crises Límbicas representa uma ferramenta inicial simples para avaliar e/ou comparar arbitrariamente a severidade das crises, e é mundialmente usado. Através desse índice é possível sugerir de forma geral, as áreas ativadas durante a propagação da atividade de crise, como nos seguintes índices: (1 e 2) ativação dos núcleos amigdalóides, córtex piriforme, sulco rinal, ínsula (CHASSAGNON et al., 2005 apud FORESTI, 2008) e algumas regiões corticais somatosensoriais e sensitivas (FORSTER; PENFIELD, 1949 apud FORESTI, 2008); (3-5) córtices entorrinal, piriforme, perirrinal, além do hipocampo e amígdala, juntamente com o claustro, ínsula e conexões com o sistema motor permitem a generalização da crise; (6-8) envolve o recrutamento adicional de estruturas mesencefálicas (CHASSAGNON et al., 2005 apud FORESTI, 2008).

Dessa forma, a intensificação da severidade comportamental é explicada pelo recrutamento de áreas neurais inicialmente não envolvidas (GODDARD, 1967, 1983; SAYIN et al., 2003). Essa progressão da atividade epileptiforme foi proposta por alguns estudos como uma divisão em 3 estágios, envolvendo: (Estágio 1) Índices de Gravidade 1 e 2, com características da pós-descarga e comportamental referentes ao foco primário; (Estágio 2) representa o Índice de Gravidade 3, considerado como um estágio intermediário, com uma crise ainda focal mas com progressão em relação ao estágio anterior; e (Estágio 3) abrange os índices de gravidade 4 e 5 com a ativação de substratos que permitem a generalização da crise (LÖSCHER; EBERT, 1996).

É sabido que a localização específica do eletrodo de estímulo interfere diretamente no recrutamento de circuitos, dadas as diferenças nas projeções cerebrais (LÖSCHER; EBERT, 1996). Assim as áreas cerebrais variam a sua resposta ao estímulo, de acordo com a 
Influência da estimulação olfatória com TMT no modelo de abrasamento elétrico rápido da amígdala sensibilidade (FISHER, 1989; GODDARD, 1983; LÖSCHER; BRANDT, 2010; LÖSCHER; EBERT, 1996; LÖSCHER et al., 1995; LOTHMAN et al., 1985; McNAMARA et al., 1980) que pode estar relacionada as conexões da área estimulada com o sistema motor, e/ou às propriedades reativas dos neurônios da região (LÖSCHER; EBERT, 1996).

Vários estudos têm indicado que estruturas do sistema límbico apresentam um limiar reduzido para a geração da atividade epileptiforme (LÖSCHER; EBERT, 1996). E com base no protocolo clássico de abrasamento, os estímulos tetânicos são aplicados na amígdala, mais especificamente no núcleo BLA, considerada a região padrão (FISHER, 1989; GODDARD, 1983; LÖSCHER; BRANDT, 2010; LÖSCHER; EBERT, 1996; LÖSCHER et al., 1995; LOTHMAN et al., 1985; McNAMARA et al., 1980), por exigir menor número de estímulos para abrasar o sistema e por facilitar a generalização da crise, portanto, com alta sensibilidade e responsividade (GODDARD, 1983; LÖSCHER; EBERT, 1996; McNAMARA et al., 1980).

Outro ponto que merece destaque é que as alterações epileptiformes são permanentes (FORESTI, 2008; GODDARD, 1967; LÖSCHER; EBERT, 1996; NOEBELS et al., 2012), o que gera uma redução do limiar para crise, criando condições favoráveis para a crise subsequente. Entretanto é incerto se as CRE ocorrem após repetidas estimulações no modelo de abrasamento, logo esse achado não é universal. Estudos indicam que para encontrar CRE após abrasamento elétrico diário da amígdala, Pinel \& Rovner (1978) fizeram mais de 350 estimulações e mais recentemente Sayin e colaboradores (2003) confirmaram esse achado com cerca de 100 estímulos, em apenas $40 \%$ dos animais.

Mas uma limitação bastante importante para tal detecção refere-se à monitorização contínua, de preferência 24 horas/dia durante meses. Além disso, é necessário que o animal após ter apresentado a generalização da crise (LÖSCHER; EBERT, 1996; PINEL; ROVNER, 1978), continue recebendo estimulações até o aparecimento das CRE (FORESTI, 2008; GODDARD, 1983).

Como resultado do presente estudo, temos que 18 do total de 21 animais estimulados eletricamente foram abrasados. O critério para determinar essa consideração foi a presença de pelo menos 2 comportamentos característicos da classe 4 ou 1 comportamento da classe 5 (Tabela 5 - FORESTI, 2008; FORESTI et al., 2008). Houve 2 animais (considerados abrasados) que apresentaram já no $1^{\circ}$ estímulo classe 4 e 1 animal classe 7 , destoando do comportamento típico do abrasamento. Do número total de animais estimulados, 3 animais do grupo Estímulo e Água, não foram adequadamente abrasados, pois apresentaram índice máximo de classe 2, caracterizado pela presença de mioclonia de cabeça (MIOc). 
Dos animais não abrasados, 1 apresentava o eletrodo fora do complexo amígdalóide, e os outros 2 na região de interesse, com os demais eletrodos localizados no piriforme e no giro denteado. Uma especulação para a não progressão comportamental deve-se a resistência dos circuitos de crise nesses animais (BERTRAM, 2007), tendo em vista que o protocolo, bem como os parâmetros utilizados para estimulação elétrica foram semelhantes para todos os animais deste estudo.

A Figura 22 ilustra a evolução do abrasamento elétrico rápido $\left(1^{\circ}-20^{\circ}\right)$ para animais $(\mathrm{N}=20)$ de ambos os grupos Estímulo e Água, e Estímulo e TMT. Nessa figura pode-se observar que não há uma progressão em diagonal ascendente para tais dados. Existe um aumento dos índices de gravidade, onde encontramos uma diferença estatística significativa ao longo dos estímulos (Tabela 7), com uma pequena alternância de médias com índices maiores, seguidos de menores (Figura 22), o que pode ser explicado por modulações de neurotransmissores a cada estímulo aplicado, alterando a resposta comportamental.

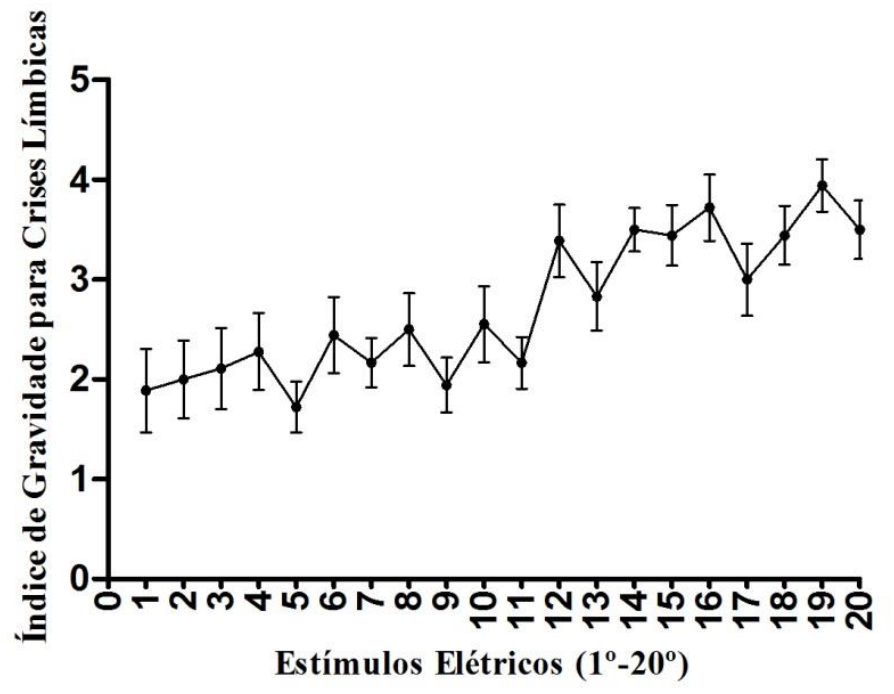

Figura 22. Classificação comportamental de crises observadas durante a evolução do abrasamento elétrico rápido, estímulo a estímulo, dos animais de ambos os grupos Estimulados $(\mathrm{N}=20)$. No eixo Y estão às médias do Índice de Gravidade para Crises Límbicas segundo Racine (1972) alcançado em cada estímulo indicado pelo eixo X. Anova One Way, Friedman test, Dunn's post test, *p<0,05; **p<0,01 e p<0,001. 
Influência da estimulação olfatória com TMT no modelo de abrasamento elétrico rápido da amígdala

Tabela 7. Valor-p durante a evolução do abrasamento elétrico rápido da Figura 22.

\begin{tabular}{|c|c|c|c|c|c|}
\hline $1^{\circ}$ versus $12^{\circ}$ & $*$ & $2^{\circ}$ versus $16^{\circ}$ & $* *$ & $5^{\circ}$ versus $16^{\circ}$ & $* *$ \\
\hline $1^{\circ}$ versus $14^{\circ}$ & $* *$ & $2^{\circ}$ versus $18^{\circ}$ & $*$ & $5^{\circ}$ versus $18^{\circ}$ & $*$ \\
\hline $1^{\circ}$ versus $15^{\circ}$ & $*$ & $2^{\circ}$ versus $19^{\circ}$ & $* * *$ & $5^{\circ}$ versus $19^{\circ}$ & $* * *$ \\
\hline $1^{\circ}$ versus $18^{\circ}$ & $* *$ & $2^{\circ}$ versus $20^{\circ}$ & $*$ & $5^{\circ}$ versus $20^{\circ}$ & $*$ \\
\hline $1^{\circ}$ versus $19^{\circ}$ & $*$ & $3^{\circ}$ versus $16^{\circ}$ & $* *$ & $7^{\circ}$ versus $19^{\circ}$ & $*$ \\
\hline $1^{\circ}$ versus $20^{\circ}$ & $* * *$ & $3^{\circ}$ versus $19^{\circ}$ & $* *$ & $9^{\circ}$ versus $16^{\circ}$ & * \\
\hline $2^{\circ}$ versus $12^{\circ}$ & $*$ & $4^{\circ}$ versus $19^{\circ}$ & $*$ & $9^{\circ}$ versus $19^{\circ}$ & $* *$ \\
\hline $2^{\circ}$ versus $14^{\circ}$ & $* *$ & $5^{\circ}$ versus $14^{\circ}$ & $*$ & $11^{\circ}$ versus $19^{\circ}$ & * \\
\hline $2^{\circ}$ versus $15^{\circ}$ & $*$ & $5^{\circ}$ versus $15^{\circ}$ & $*$ & & \\
\hline
\end{tabular}

Anova One Way, Fridman Test, Dunn's Post Test: *p<0,05; **p<0,01 e ***p<0,001.

Quando esses dados foram analisados separadamente (Figura 23) foi possível confirmar que, em geral, a média alcançada pelo Índice de Gravidade para Crises Límbicas durante a progressão do abrasamento foi semelhante para ambos os grupos ( $\left(1^{\circ}-20^{\circ}\right.$ estímulos). Entretanto, quando os animais foram submetidos a água ou ao TMT, houve uma redução importante para ambos os grupos, em especial para o grupo Estímulo e TMT.

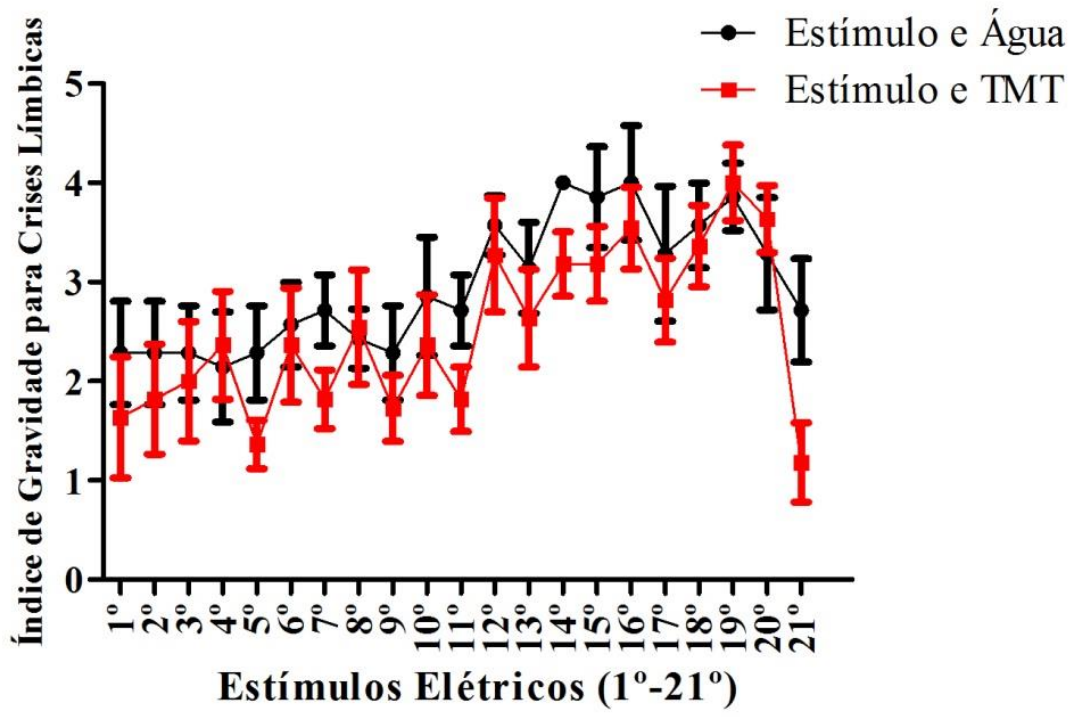

Figura 23. Classificação comportamental de crises observadas durante a evolução do abrasamento elétrico rápido, estímulo a estímulo, dos animais do grupo Estímulo e Água (linha e círculos pretos preenchidos, $\mathrm{N}=8$ ), e do grupo Estímulo e TMT (linha e quadrados vermelhos preenchidos, $\mathrm{N}=12$ ). No eixo Y estão às médias do Índice de Gravidade para Crises Límbicas segundo Racine (1972) alcançado em cada estímulo, indicado pelo eixo X. Two-way ANOVA, com diferença entre os grupos de $\mathrm{p}<0,01$, diferença entre os estímulos de $\mathrm{p}<0,001$. 
Influência da estimulação olfatória com TMT no modelo de abrasamento elétrico rápido da amígdala

Assim, para comparar as médias dos Índices de Gravidade para Crises Límbicas obtidas pelos grupos Estímulo e Água, versus Estímulo e TMT, especificamente no $21^{\circ}$ estímulo, foi realizado o teste $t$ Student não pareado (Figura 24). Dessa forma, foi possível comprovar que a redução do índice foi significativa, e visualmente importante. Logo, o TMT funcionou como um estímulo no mínimo modificador das crises. Corroborando o estudo que indica que estímulos sensoriais podem retardar ou suprimir uma atividade de crise (VALENTINE; FREMIT; TESKEY, 2005). Tal evidência segundo Valentine e colaboradores (2005) data de Artaeus a Capadócia (81-138 depois de Cristo, d.C.) e Galeno (129-199 d.C.).

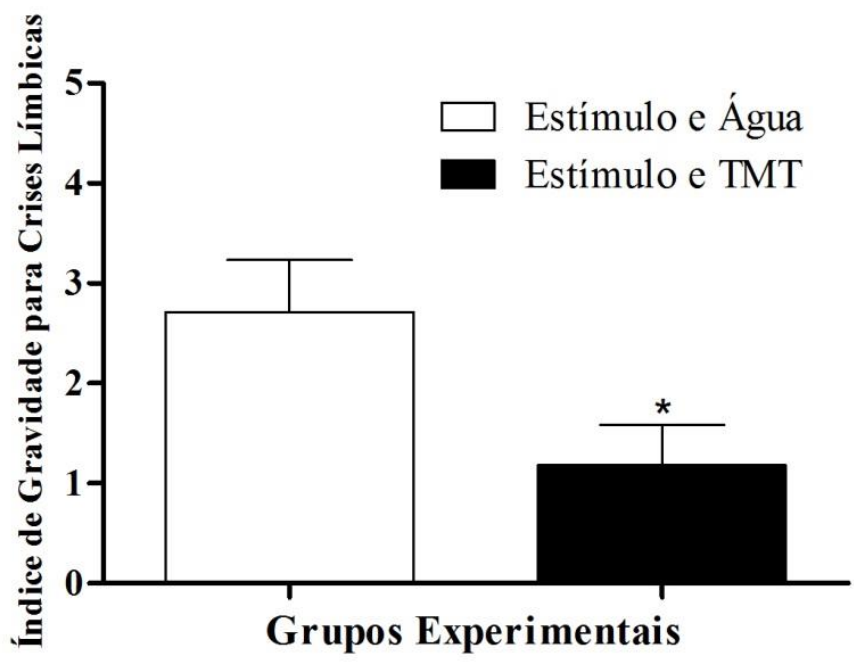

Figura 24. Comparação das médias obtidas pelo Índice de Gravidade para Crises Límbicas observadas no $21^{\circ}$ estímulo elétrico, com a intervenção prévia da água no grupo Estímulo e Água (A, N=8), versus TMT no grupo Estímulo e TMT $(\mathrm{B}, \mathrm{N}=12)$. No eixo Y estão às médias do Índice de Gravidade para Crises Límbicas segundo Racine (1972) alcançado em cada grupo indicado pelo eixo X. Teste $t$ Student não pareado, *p<0,05.

Como já descrito, o protocolo de abrasamento elétrico rápido utilizado para ambos os grupos foi semelhante, o que diferiu foi a exposição prévia ao $21^{\circ}$ estímulo, com água ou TMT. Entretanto, a escolha aleatória dos animais por grupo foi realizada antes mesmo do cálculo do limiar, na tentativa de evitar algum possível viés para a análise dos dados, aumentando assim a confiabilidade dos mesmos.

Além disso, um dado que possibilitou verificar a eficácia do paradigma de estimulação rápida e que permitiu comparar a semelhança dos índices obtidos no abrasamento para os dois grupos foi a quantificação do número de estímulos necessários para alcançar o Índice de Gravidade para Crises Límbicas igual a 4 (NOEBELS et al., 2012). No presente estudo esse dado foi obtido no $9^{\circ}$ estímulo, através da média ponderada para ambos os grupos. Assim, é possível sugerir que os animais foram abrasados igualmente, independentemente do grupo. $\mathrm{E}$ indicam que independentemente da metodologia aplicada no abrasamento, se rápida ou não, o 
Influência da estimulação olfatória com TMT no modelo de abrasamento elétrico rápido da amígdala número de estímulos necessários para evocar um índice 4, são em média 10 estímulos (LOTHMAN et al., 1985).

Dessa forma, o TMT foi capaz de reduzir significativamente o Índice de Gravidade para Crises Límbicas, comparado ao controle, demonstrando efeito supressor para crises límbicas. Critério esse que além de ser validado é frequentemente utilizado na avaliação de intervenções terapêuticas (LÖSCHER; BRANDT, 2010; NOEBELS et al., 2012).

\subsubsection{CARACTERIZAÇÃo NeUroetológica}

Na segunda parte do século 19, antes do advento da eletrofisiologia e outras técnicas, ou seja, do avanço das neurociências, as investigações em epilepsia limitavam-se a autópsia do tecido post mortem ou a análise semiológica dos comportamentos realizados pelos pacientes. O que naquela época já possibilitava ainda de forma muito restrita elaborar hipóteses sobre o funcionamento cerebral e as implicações das possíveis alterações fisiopatológicas (CHAUVEL; MCGONIGAL, 2014).

Se reconhecermos que a epilepsia se comporta como um sistema complexo, dada a extensão da descrição para essa desordem, no qual a crise é o resultado final da interação de vários mecanismos celulares, moleculares e metabólicos, conseguimos compreender que existem inúmeras possibilidades de interação entre tantas variáveis que determinarão uma alteração no funcionamento cerebral e implicarão em diferentes consequências ao paciente com epilepsia, (TEJADA et al., 2013), conferindo a cada indivíduo um perfil de sinais/sintomas muito particular. Assim, a neuroetologia mostra-se como uma importante ferramenta quantitativa e qualitativa confiável para caracterizar a complexa semiologia das crises.

Essa representação foi descrita por Garcia-Cairasco \& Sabbatini (1983) e GarciaCairasco e colaboradores (1992) que propõe uma análise detalhada da sequência comportamental observada durante uma crise. Em estudos experimentais, essa análise detalhada da semiologia é aplicada e validada em modelos de epilepsia (GARCIACAIRASCO; SABBATINI, 1983; GARCIA-CAIRASCO et al., 1992, 1996; ROSSETTI et al., 2006) e de comportamento compulsivo (MARRONI et al., 2007). Na clínica a análise neuroetológica mostrou-se como uma importante ferramenta complementar para o diagnóstico da epilepsia (BERTTI et al., 2010; CLETO DAL-CÓL et al., 2006; 2008), e é particularmente importante na avaliação de pacientes com indicação cirúrgica, contribuindo para a identificação e quantificação de sinais lateralizatórios ou localizatórios da zona epileptogênica (ZE; BERTTI et al., 2010, 2014; DAL-CÓL et al., 2006; TEJADA et al., 2013). 
Influência da estimulação olfatória com TMT no modelo de abrasamento elétrico rápido da amígdala

A neuroetologia é uma combinação da neurofisiologia que compreende o estudo do funcionamento do sistema nervoso, com a etologia, que é o estudo do comportamento, ou seja, é o estudo das bases neurofisiológicas do comportamento. Um grande destaque desta ferramenta semiológica é a observação e registro de todos os itens comportamentais expressos durante o período de observação (BERTTI et al., 2010, 2014; TEJADA et al., 2013), enquanto que em outros métodos, a análise pode se restringir a um único comportamento ou a um grupo de comportamentos, o que em suma reduz a possibilidade de encontrar novos achados comportamentais tão importantes quanto os achados "clássicos" (BERTTI et al., 2014).

Assim, sabendo que a expressão comportamental das crises epilépticas é o conjunto de sinais/sintomas possíveis de serem observados, que refletem a atividade alterada de redes cerebrais (BERTRAM, 2007; BERTTI et al., 2014; DAL-CÓL et al., 2006; TEJADA et al., 2013), é possível pelo estudo neuroetológico inferir quais áreas foram ativadas com a crise, de acordo com os comportamentos expressados pelo indivíduo/animal (BERTTI et al., 2014; ROMCY-PEREIRA, 2001; TEJADA et al., 2013). Logo com base nas sequências comportamentais pode-se sugerir a conectividade de regiões distintas do cérebro, dada a progressão da crise (BERTTI et al., 2014; TEJADA et al., 2013), em especial das crises parciais generalizadas secundariamente, modelo utilizado nesse estudo.

Nessa lógica, a atividade epileptiforme assim como qualquer atividade cerebral fisiológica propaga por vias anatômicas específicas. Entretanto apesar dos modelos utilizarem de diferentes estímulos indutores, as alterações comportamentais são em sua maioria bastante semelhantes, sugerindo o envolvimento de certas regiões como denominadores comuns para o desenvolvimento das crises. No entanto, quando uma crise induzida pelo abrasamento tornase secundariamente generalizada, a importância relativa de cada estrutura bem como das vias de propagação são "mascaradas", dificultando a identificação da propagação da atividade epileptiforme para as diferentes regiões (LÖSCHER; EBERT, 1996).

A abordagem neuroetológica é baseada em uma análise detalhada de todos os itens comportamentais - como citado anteriormente - apresentada pelo animal durante o período de observação. E apesar dos registros iniciais serem individuais (quesito animal e estímulo), os fluxogramas foram construídos com base na soma das crises de cada grupo, para um determinado estímulo e período de observação. O glossário de todo o conjunto de comportamentos apresentados pelos diferentes grupos é representado na Tabela Complementar 1 . 
Influência da estimulação olfatória com TMT no modelo de abrasamento elétrico rápido da amígdala

A análise termina com a interpretação dos dados representados no fluxograma, ou seja, faz-se uma descrição dos fluxogramas com base na literatura, indicando todos os comportamentos e suas interações apresentados durante o período (BERTTI et al., 2014; TEJADA et al., 2013).

Para esse estudo, os fluxogramas foram divididos em 3 células correspondendo aos períodos: Pré Estímulo - com tempo de análise de 5 minutos para o $1^{\circ}$ e $20^{\circ}$ estímulos elétricos, correspondendo ao período precedente ao estímulo elétrico; Estímulo - com a duração de 10 segundos, correspondendo ao período de estimulação elétrica e Pós Estímulo com tempo de análise de 5 minutos, correspondendo ao período subsequente ao estímulo elétrico. Para o $21^{\circ}$ estímulo foi feita a análise neuroetológica de apenas 20 segundos no período Pré Estímulo, correspondendo ao período de estimulação olfatória, os períodos de Estímulo e Pós foram semelhantes aos demais.

Assim na Figura 25 temos os fluxogramas do grupo Sem Estímulo e Água (A) e do grupo Sem Estímulo e TMT (B), ambos referentes ao $21^{\circ}$ estímulo, divididos em 3 células correspondendo ao período de estimulação olfatória (1), período de simulação do estímulo (2, rever item 6.2.1) e o período pós estímulo (3). 
Influência da estimulação olfatória com TMT no modelo de abrasamento elétrico rápido da amígdala

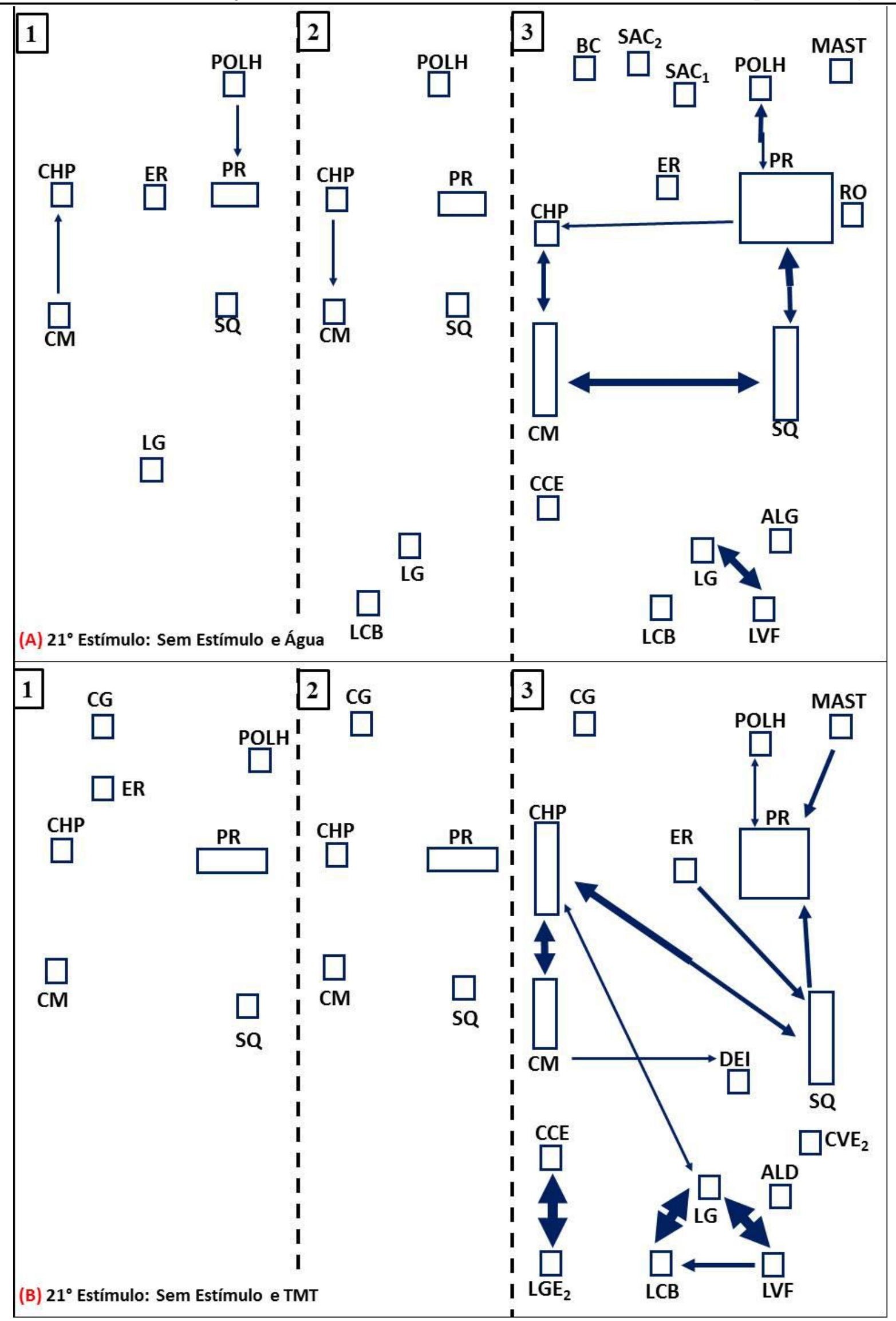

Figura 25. Fluxogramas ilustrando o efeito comportamental da Água (A) e do TMT (B), com as sequências comportamentais da simulação do $21^{\circ}$ estímulo elétrico dos grupos Sem Estímulo e Água (A), e Sem Estímulo e TMT (B), ambos com 5 animais por grupo. Sendo apresentado na primeira célula de cada estímulo, o período pré 
Influência da estimulação olfatória com TMT no modelo de abrasamento elétrico rápido da amígdala

de estimulação olfatória (1) de 20 segundos; na célula intermediária (2) o período de simulação do "estímulo" elétrico por 10 segundos; e finalmente na última célula (3) o período pós estímulação, com duração de 05 minutos. Retângulos, setas e cores (Figura 19), siglas (Tabela Complementar 1).

É possível verificar nas células 1 e 2 da Figura 25, que o TMT (B) causou efeito de CG e que os animais permaneceram um maior tempo parados (PR) comparados a Água (A). Tanto CG quanto PR são dois dos efeitos comportamentais do TMT descritos na literatura (ver Tabela 3). Entretanto na última célula (3), ambos os grupos apresentaram a mesma quantidade de comportamentos, mas os animais submetidos ao TMT apresentaram menor duração de PR e maior frequiência de cheirar exploratório (CHP), além de terem maior número de interações entre os itens comportamentais. Estes dados sugerem que o TMT não foi inócuo aos animais, ou seja, pode ter incentivado uma natural exploração em busca de pistas que indicassem a localização do predador representando um efeito agudo dessa substância.

A Figura 26 ilustra o efeito comportamental observado no $1^{\circ}$ (A) e $20^{\circ}$ (B) estímulos elétricos, para ambos os grupos estimulados (Estímulo e Água, e Estímulo e TMT, N=10) nos períodos: (1) pré estimulação elétrica de 5 minutos; (2) estimulação de 10 segundos e (3) pósestimulação, com duração de 05 minutos. 


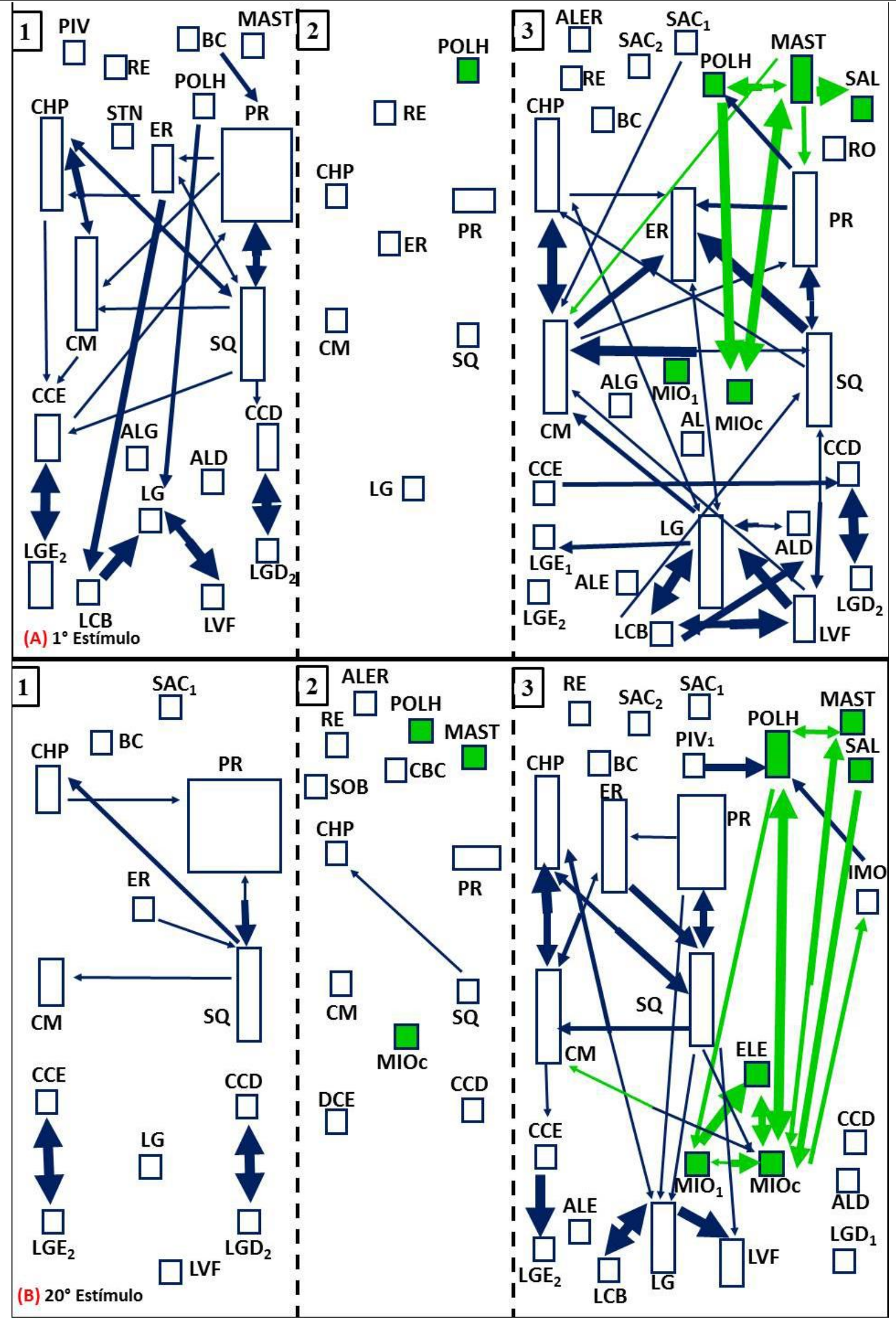

Figura 26. Fluxogramas da somatória das sequências comportamentais registradas no $1^{\circ}$ (A) e $20^{\circ}$ estímulos elétricos (B) de 10 animais de ambos os grupos estimulados (Estímulo e Água, e Estímulo e TMT). Sendo (1) 
Influência da estimulação olfatória com TMT no modelo de abrasamento elétrico rápido da amígdala

período pré estimulação elétrica de 5 minutos; (2) período de estimulação elétrica de 10 segundos e (3) período pós-estimulação elétrica, com duração de 05 minutos. Retângulos, setas e cores (Figura 19), siglas (Tabela Complementar 1).

$\mathrm{Na}$ primeira célula da Figura 26A1 é possível verificar uma heterogeneidade comportamental, especialmente para os itens exploratórios e de autolimpeza. Essa variedade de comportamentos é esperada e considerada natural, pois apesar da habituação, os animais foram expostos a um ambiente relativamente novo. $\mathrm{E}$ dentro dessa temática, os comportamentos considerados exploratórios incluem: CHP, CM, esquadrinhar (movimentos de cabeça, SQ), ereto (ER) e PR. Também ocorreu uma grande quantidade de comportamentos de autolimpeza como: ALD, ALG, LCB, LVF, LGD2 e LGE2, com fortes interações entre alguns desses comportamentos, o que caracteriza um perfil repetitivo da sequência desses itens.

Na segunda célula (Figura 26A2) verifica-se a presença de alguns comportamentos sem interação entre os pares, com a presença do comportamento de piscar os olhos (POHL), descrito como classe 1 do Índice de Gravidade para Crises Límbicas. Já na última célula (Figura 26A3) é visível o aumento do número de comportamentos e das interações diádicas, com o predomínio de comportamentos nomeados como Outros, que incluem comportamentos exploratórios e de autolimpeza, além da presença de comportamentos límbicos como POHL, mastigação (MAST), salivação (SAL), $\mathrm{MIO}_{\mathrm{c}}$ e mioclonia de patas anteriores $\left(\mathrm{MIO}_{1}\right)$. Foram registrados também alguns comportamentos de medo como ALER e BC que possivelmente surgiram decorrentes do estímulo (GODDARD, 1983).

No período Pré do $20^{\circ}$ estímulo (Figura 26B1), em comparação ao mesmo período do $1^{\circ}$ Estímulo (Figura 26A1), houve uma redução do número de itens comportamentais apresentados pelos animais, com a presença de alguns comportamentos exploratórios e de autolimpeza, além do $\mathrm{BC}$, sacudir a cabeça (SAC1), coçar à direita $(\mathrm{CCD})$ e à esquerda (CCE). Tais comportamentos em geral apresentaram frequência e duração menor que no mesmo período do $1^{\circ}$ Estímulo, mas com o aumento do tempo que os animais encontravam-se PR. Além disso, ocorreu uma redução das interações comportamentais no período pré do $20^{\circ}$ estímulo.

A Figura 26B2 correspondente ao $20^{\circ}$ período de estímulo elétrico observa-se novamente a presença de alguns comportamentos exploratórios (CHP, CM, PR e SQ) e outros comportamentos novos em relação ao mesmo período do $1^{\circ}$ estímulo (Figura 26A2), como: ALER, cabeceio (CBC, movimentação dorsoventral), SOB, dobramento corporal à esquerda (DCE) e CCD, além dos comportamentos límbicos de MAST, POHL e MIOc e da presença de interação entre os comportamentos de SQ e CHP. 
No período posterior ao $20^{\circ}$ estímulo (Figura 26B3), verifica-se uma diminuição no número de comportamentos de autolimpeza comparado ao $1^{\circ}$ estímulo (Figura 26A3), com a permanência dos comportamentos límbicos presentes em Figura 26B2, tais como: MAST, POHL e MIOc, e o acréscimo de SAL, MIO1, elevação (ELE) e ainda a presença da imobilidade pós ictal (IMO). 
Capítulo II:

Influência da estimulação olfatória com TMT no modelo de abrasamento elétrico rápido da amígdala

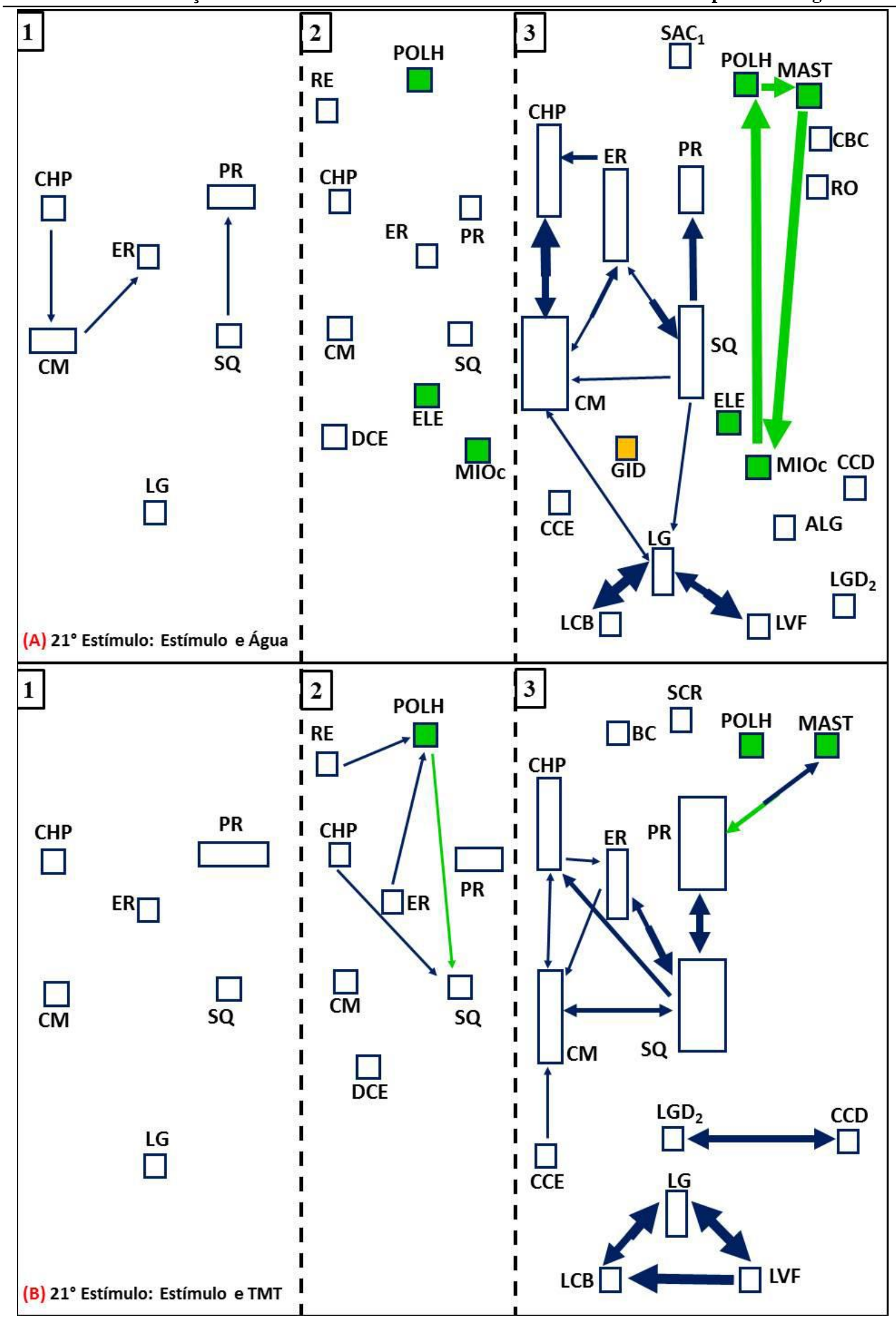

Figura 27. Fluxogramas das sequências comportamentais do $21^{\circ}$ estímulo do grupo Estímulo e Água (A, N=5), e Estímulo e TMT (B, N=5). Os números representam os períodos: (1) pré estimulação elétrica de 20 segundos; 
(2) estimulação de 10 segundos e (3) pós-estimulação, com duração de 05 minutos. Retângulos, setas e cores (Figura 19), siglas (Tabela Complementar 1).

Finalmente, no período Pré do $21^{\circ}$ estímulo (Figura 27A1 e B1) observamos a presença de apenas cinco comportamentos exploratórios e um comportamento de autolimpeza, sendo que os animais expostos ao TMT permaneceram um maior tempo PR. Pode-se também observar apenas três interações comportamentais no grupo Estímulo e Água (Figura 27A1) versus nenhuma interação comportamental no grupo Estímulo e TMT (Figura 27B1).

Durante a realização do $21^{\circ}$ estímulo, o grupo Estímulo e Água (Figura 27A2), apresentou os mesmos comportamentos que em Figura 26B2, com exceção de ALER, CBC, CCD e SOB. Além da presença dos comportamentos límbicos de POHL, MIOc e ELE, e do comportamento exploratório de ER. Para o grupo Estímulo e TMT (Figura 27B2) observamos durante a estimulação a presença dos mesmos comportamentos que o grupo Estímulo e Água (Figura 27A2), mas com ausência de ELE e MIOc, e também a presença de quatro interações entre os itens expressos nesse período (Figura 27B2), comparado ao seu controle (Figura 27A2).

No período posterior ao $21^{\circ}$ estímulo (Figura 27A3 e B3; N=5 animais para cada grupo) observamos uma redução do número de comportamentos em comparação com o mesmo período do $20^{\circ}$ estímulo (Figura 26B3, N=10). Esse dado pode ser explicado pelo menor número de animais incluídos na análise do $21^{\circ}$ estímulo. Para o grupo Estímulo e Água (Figura 27A3) observarmos comportamentos límbicos como MAST, POHL, MIOc e ELE, assim como do item procursivo de giro à direita (GID).

Para a mesma célula do grupo Estímulo e TMT (Figura 27B3) foi possível observar uma redução expressiva do número de comportamentos límbicos tanto em relação ao $20^{\circ}$ estímulo (Figura 26B3) quanto para o $21^{\circ}$ estímulo do grupo controle - Estímulo e Água (Figura 27A3). Mas com a manutenção dos comportamentos límbicos de MAST e POHL. Além do aumento das interações comportamentais, principalmente entre as expressões exploratórias e de autolimpeza - com a formação de clusters desses comportamentos - em comparação ao mesmo período do seu controle (Figura 27A3).

Em suma, podemos observar predominantemente a presença de comportamentos exploratórios e de autolimpeza nos períodos Pré(s) de todos os estímulos e grupos (Figura 26A1 e B1, Figura 27A1 e B1). Com relação ao período de Estímulo (Figura 26A2 e B2, Figura 27A2 e B2), observamos além da presença de comportamentos exploratórios, comportamentos descritos como Outros. Bem como de comportamentos límbicos presentes já 
Influência da estimulação olfatória com TMT no modelo de abrasamento elétrico rápido da amígdala no $1^{\circ}$ estímulo (POHL, Figura 26A2) que ao longo do abrasamento possibilitou o natural agravamento de tais comportamentos, observados no $20^{\circ}$ estímulo (MAST, POHL e MIOc, Figura 26B2). No $21^{\circ}$ estímulo, o grupo controle (Figura 27A2) apresentou POHL, MIOc e ELE, e o experimental (Figura 27B2) somente POHL.

No período Pós Estímulo, é possível notar uma maior severidade dos comportamentos de crise no $20^{\circ}$ estímulo (Figura 26B3) comparado ao $1^{\circ}$ (Figura 26A3). Para o $21^{\circ}$ estímulo, o grupo Estímulo e Água (Figura 26A3) apresentou 1 comportamento procursivo e 4 límbicos (referente ao Índice de Gravidade para Crises Límbicas igual a 4), enquanto o grupo Estímulo e TMT (Figura 27B3) demonstrou a expressão de apenas 2 comportamentos límbicos (referente ao Índice de Gravidade para Crises Límbicas igual a 1). Outro aspecto importante durante o período posterior ao $21^{\circ}$ estímulo é a presença de um maior número de interações entre pares comportamentais no grupo Estímulo e TMT (Figura 27B3) comparado ao controle (Figura 27A3).

Uma importante preocupação que surgiu após as análises neuroetológicas foi a de verificar se os resultados obtidos com este tipo de análise eram de fato condizentes com os resultados obtidos no Índice de Gravidade para Crises Límbicas (ver discussão 6.3.2), já que a escolha dos animais para a análise neuroetológica foi aleatória. Para isto, aplicamos o teste estatístico (Friedman Test, p <0,05, N=5) apenas nos dados dos animais selecionados para a análise neuroetológica. Os índices desses animais estão representados nas Tabela 8 e Tabela 9. Na Figura 28 estão os Índices de Gravidade para Crises Límbicas desses animais (Grupo Estímulo e TMT - A, e Estímulo e Água - C) versus todos os animais do grupo (Grupo Estímulo e TMT - B, e Estímulo e Água - D).

Tabela 8. Avaliação dos índices de gravidade de crises segundo Racine (1972), do grupo Estímulo e TMT analisados pela neuroetologia.

\begin{tabular}{cccc}
\hline Animais & $\mathbf{1}^{\mathbf{0}}$ Estímulo & $\mathbf{2 0}^{\mathbf{0}}$ Estímulo & $\mathbf{2 1}^{\mathbf{0}}$ Estímulo \\
$\mathbf{0 1}$ & 1 & 5 & 0 \\
$\mathbf{0 2}$ & 2 & 2 & 1 \\
$\mathbf{0 3}$ & 1 & 4 & 0 \\
$\mathbf{0 5}$ & 2 & 4 & 1 \\
$\mathbf{1 1}$ & 3 & 4 & 0 \\
\hline
\end{tabular}


Tabela 9. Avaliação dos índices de severidade de crises segundo Racine (1972), do grupo Estímulo e Água analisados pela neuroetologia.

\begin{tabular}{cccc}
\hline Animais & $\mathbf{1}^{\mathbf{0}}$ Estímulo & $\mathbf{2 0}^{\mathbf{0}}$ Estímulo & $\mathbf{2 1}^{\mathbf{0}}$ Estímulo \\
01 & 2 & 2 & 1 \\
02 & 1 & 2 & 2 \\
03 & 1 & 2 & 1 \\
04 & 1 & 2 & 4 \\
12 & 3 & 3 & 4 \\
\hline
\end{tabular}

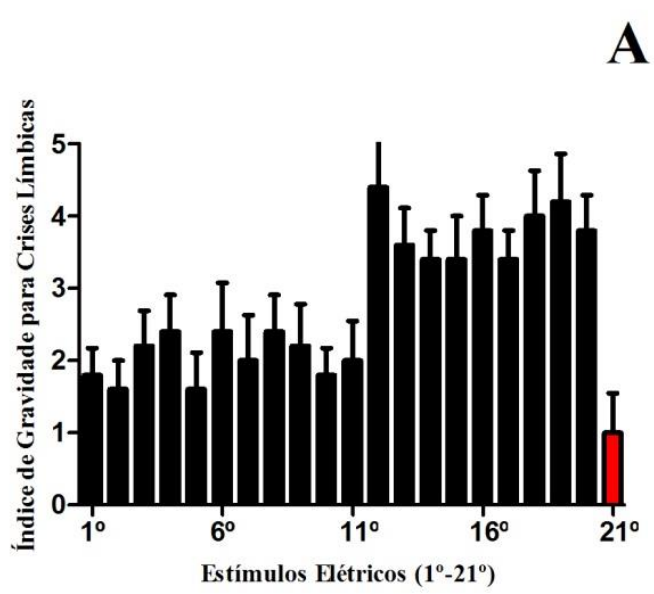

C

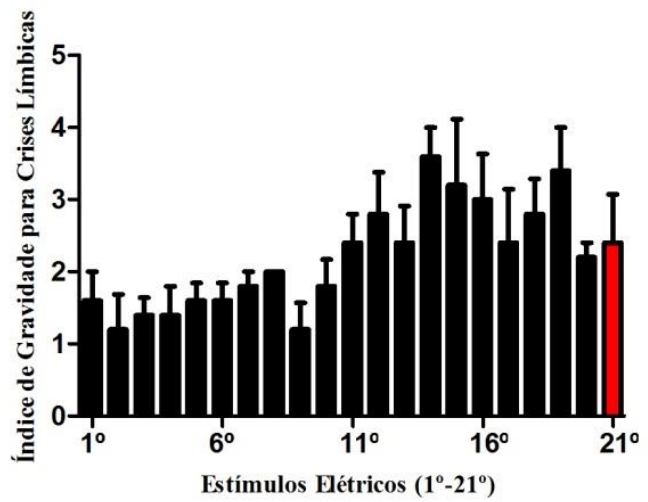

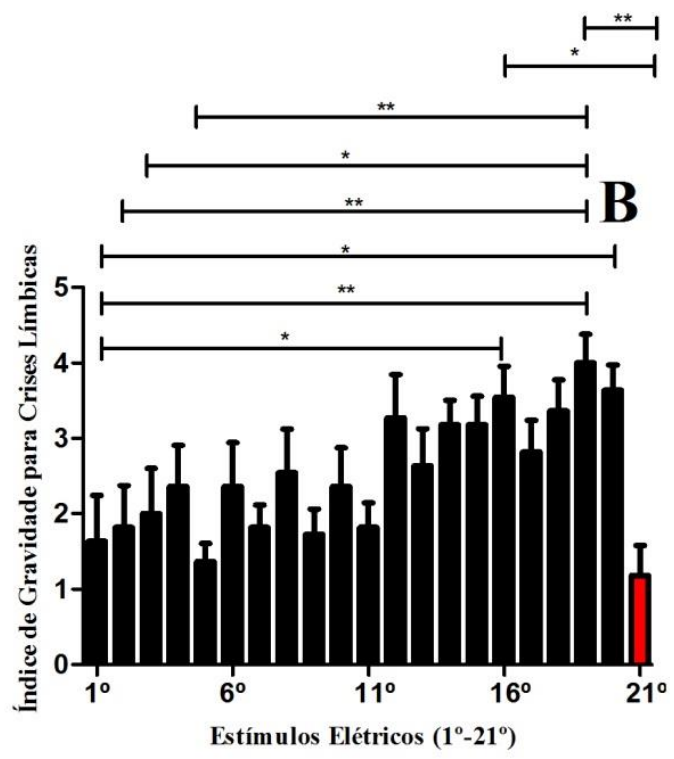

D

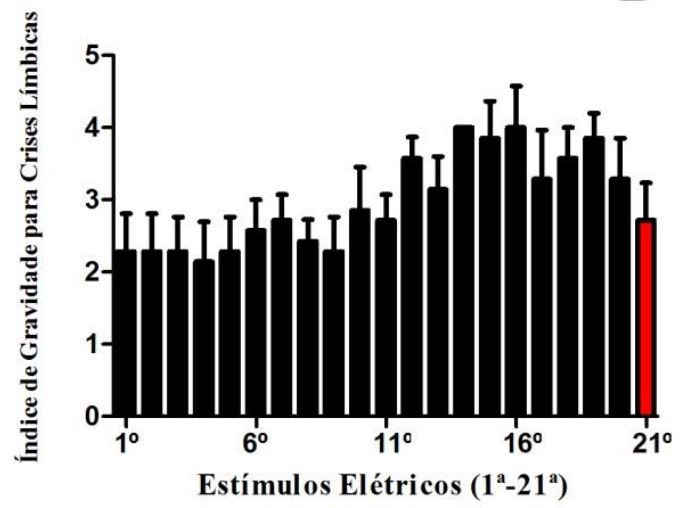

Figura 28. Média dos Índices de Gravidade para Crises Límbicas observadas durante a evolução do abrasamento elétrico rápido, estímulo a estímulo, dos animais do grupo Estímulo e TMT selecionados aleatoriamente para a análise neuroetológica ( $\mathrm{A}, \mathrm{N}=5)$ versus grupo Estímulo e TMT $(\mathrm{B}, \mathrm{N}=12)$. Em $\mathrm{C}$ e $\mathrm{D}$ estão representadas as médias dos Índices de Gravidade para Crises Límbicas dos animais do grupo Estímulo e Água analisados pela neuroetologia $(C, N=5)$ versus grupo Estímulo e Água $(\mathrm{D}, \mathrm{N}=8)$. No eixo $\mathrm{Y}$ estão as médias do Índice de Gravidade para Crises Límbicas alcançadas em cada estímulo indicado pelo eixo X. Teste Friedman, com $* \mathrm{p}<0,05$ e $* * \mathrm{p}<0,01$. 
Influência da estimulação olfatória com TMT no modelo de abrasamento elétrico rápido da amígdala

Nas Tabela 8 e Tabela 9 podemos verificar que houve o abrasamento dos animais, e que o TMT reduziu o Índice de Gravidade para Crises Límbicas nos animais selecionados para a análise neuroetológica, representada na Figura 28A.

Os resultados obtidos para os animais do grupo Estímulo e Água indicam que, apesar desse grupo apresentar uma redução não significativa dos Índices de Gravidade para Crises Límbicas (Figura 28D) quando comparamos o $21^{\circ}$ estímulo com o $20^{\circ}$ estímulo, os animais selecionados para a análise neuroetológica (Figura 28C), apresentaram um aumento do índice para o último estímulo também não significativo (Figura 24).

Uma importante observação é que nem sempre a presença dos sinais elétricos característicos de crise foram acompanhados ao longo do abrasamento por alteração comportamental, principalmente quando a descarga EEGráfica estava presente somente no hipocampo. Outro aspecto é que comportamentos de wet dog shake (WDS; sacudidas de cachorro molhado) frequentemente suprimiam os comportamentos de crise nos animais ao longo do abrasamento, contrariando dados do envolvimento do WDS como marcador de progressão de crises límbicas no modelo de abrasamento elétrico rápido (RODRIGUES et al., 2005). Neste artigo foi feita uma abrangente discussão mostrando também que dependendo do modelo experimental, o WDS pode predizer o bloqueio de crises. Outra classe de comportamentos que também suprimiam as crises era o grooming (autolimpeza exarcebada). Esses comportamentos podem ter efeitos anticonvulsivantes, o que será confirmado em um estudo do nosso laboratório realizado pela Pós-Doutoranda Dra. Simone S. Marroni. Todas essas observações certamente necessitam de uma análise específica e direcionada, para então validar ou não tais hipóteses.

\subsubsection{ANÁLISE EEGráFICA}

O EEG é uma ferramenta de registro da atividade elétrica cerebral, que foi inicialmente descrita em 1875 por Canton, obtendo registros da superfície de macacos (apud FORESTI, 2008; MORAES, 1998), e que mais tarde em 1929, Hans Berger iria fazer o primeiro registro dos sinais elétricos provenientes do escalpo humano (apud FORESTI, 2008; MORAES, 1998; SAKAMOTO et al., 2002; TILELLI, 2003). No final do século XX, o neurologista americano William Gordon Lennox foi pioneiro no uso do EEG, como instrumento de investigação clínica no diagnóstico de epilepsia (apud MEDEIROS; MORAES, 2014; SAKAMOTO et al., 2002).

Com o desenvolvimento tecnológico o EEG alcançou um importante avanço, permitindo a utilização de registro através de multicanais em um sistema digitalizado, além do 
Influência da estimulação olfatória com TMT no modelo de abrasamento elétrico rápido da amígdala acoplamento simultâneo em tela do vídeo-EEG, bem como da monitorização por wireless (FERNANDES, 2014).

Como mencionado anteriormente, os elementos que devem ser considerados para diagnóstico dessa importante alteração neurológica incluem a presença de pelo menos uma crise, que resulta da atividade excessiva e síncrona anormal de substratos neurais (supracitado, item 1.1; FISHER et al., 2005).

Tradicionalmente a hiperexcitabilidade é descrita como o resultado do desequilíbrio de neurotransmissores inibitórios e excitatórios, que regulam a atividade neuronal e ao final resultam na crise. Logo ocorre uma falha das redes neurais em gerar mecanismos de feedback concebidos para impedir a excitação anormal (MEDEIROS; MORAES, 2014). Assim esse fenômeno pode ser o resultado tanto da fisiologia intrínseca do neurônio quanto das interações entre os substratos neurais (SAKAMOTO et al., 2002), por falha dos mecanismos inibitórios, e/ou aumento da atividade excitatória (NOBELS et al., 2012A, C; SAYIN et al., 2003).

Outro importante marcador da epilepsia é a sincronia anormal de grandes populações neuronais (MEDEIROS; MORAES, 2014), que é definida como o aparecimento de atividades oscilatórias de diferentes áreas cerebrais correlacionadas temporalmente (MORAES, 1998; NOEBELS et al., 2012).

Entretanto a excitabilidade e o sincronismo são conceitos comuns dos neurônios e redes neurais e estão presentes em processos fisiológicos normais como por exemplo, o sono, bem como em patologias do sistema nervoso (MEDEIROS; MORAES, 2014; NOEBELS et al., 2012; SAKAMOTO et al., 2002). Entretanto no âmbito da epilepsia, a hipersincronia por vezes é referida como consequência direta da hiperexcitabilidade (MEDEIROS; MORAES, 2014; SAKAMOTO et al., 2002). Embora estudos apontem para o desacoplamento desses dois termos, o limite prático é tênue, visto que para registro EEGráfico é necessário a sincronização dependente da excitabilidade de substratos neurais, do contrário se o disparo oscilatório for assíncrono, sua soma tende a anular-se, ocultando a ativação de substratos neurais (MEDEIROS; MORAES, 2014).

Ao processo dinâmico de alteração do equilíbrio fisiológico controlado em direção a um estado de desequilíbrio dá-se o nome de ictogênese, que pode propagar para outras populações neuronais dadas a conectividade sináptica (MEDEIROS; MORAES, 2014).

À diferença de potencial entre dois pontos recebe o nome de campo elétrico, que pode ser detectado através de eletrodos, sejam superficiais, profundos ou corticais (eletrocorticografia). Logo, os eletrodos captam a atividade elétrica cerebral de crise conhecido como paroxismos epileptiformes, que são ondas com morfologia diferente, formato 
Influência da estimulação olfatória com TMT no modelo de abrasamento elétrico rápido da amígdala tendendo a pontiagudo, habitualmente com maior amplitude, composição variável comparado à atividade basal, e aparecimento abrupto. Entretanto, a simples detecção de uma onda com tais características não permite por si diagnosticar uma crise epiléptica (FERNANDES, 2014). É necessário para tanto, uma análise mais ampla, correlacionando aspectos clínicos incluindo a análise sintomática, com outros exames, além de monitorização EEGráfica confiável.

Assim, a presença de eventos paroxísticos isolados e assintomáticos podem ser descritos como descargas interictais (FERNANDES, 2014), ou seja, que ocorrem entre crises, sendo referidas como marcadores de alterações funcionais em regiões diferentes do foco primário, que começam a gerar spikes (LÖSCHER; EBERT, 1996). Enquanto que os paroxismos (descargas) ictais são utilizados como parâmetros de caracterização de crise, e frequentemente associados a alterações comportamentais.

Adicionalmente, as descargas ictais e pós ictais apresentam ritmicidade, alterações em diferentes faixas de frequiência, com mudanças de: amplitude, morfologia e área de projeção no decorrer da crise. Outro fator indicativo de pós crise é a presença de um período de intensa redução da voltagem, indicando um silenciamento elétrico temporário, por vezes (FERNANDES, 2014), concomitante a presença de imobilidade pós-ictal.

Dessa maneira, as atividades elétricas cerebrais podem ser correlacionadas (de acordo com suas características) aos diferentes estados fisiológicos e comportamentais, e são úteis também para a análise das áreas ativadas e da progressão temporal dessa ativação. Logo, verifica-se a importância da aplicação desse método nas pesquisas clínicas e experimentais em epilepsia (ROMCY-PEREIRA et al., 2008; TILELLI, 2003).

Dessa maneira, as atividades elétricas cerebrais podem ser utilizadas (de acordo com suas características) para correlacionar aos diferentes estados fisiológicos e comportamentais, bem como para análise das áreas ativadas. Logo, verifica-se a importância da aplicação desse método nas pesquisas clínicas e experimentais envolvendo a epilepsia (ROMCY-PEREIRA et al., 2008; TILELLI, 2003).

Apesar dos avanços na neuroimagem, uma grande vantagem do EEG com relação às demais técnicas é sua resolução temporal (MORAES, 1998), em milissegundos (NOEBELS et al., 2012), permitindo a análise dinâmica (caracterização da circuitaria neural) da desordem. Assim essa técnica é fundamental, e portanto utilizada como exame de rotina no diagnóstico da epilepsia (FERNANDES, 2014; ROMCY-PEREIRA, 2001; SAKAMOTO et al., 2002; TILELLI, 2003).

A extração e manipulação dos dados obtidos com o EEG dependem do objetivo do estudo, e podem envolver uma análise qualitativa e/ou quantitativa, empregando diferentes 
Influência da estimulação olfatória com TMT no modelo de abrasamento elétrico rápido da amígdala métodos analíticos, dentre eles a análise de domínio de frequiência com a transformada de Fourier (FFT).

Para esse estudo foi realizada a análise primária da atividade epileptiforme entre os grupos Estímulo e Água versus Estímulo e TMT, utilizando para isso a duração da pósdescarga primária. Esse parâmetro é frequentemente associado à avaliação do efeito de intervenção anticonvulsivante (NOEBELS et al., 2012), e para o presente estudo foi utilizado também para verificar o efeito da aquisição do abrasamento (LÖSCHER; BRANDT, 2010; LÖSCHER; EBERT, 1996). Essas mensurações foram feitas utilizando inicialmente o Programa Matlab e posteriormente o software Acknowledge.

O critério utilizado para verificação da pós-descarga primária foi a ocorrência imediatamente posterior ao estímulo, com uma frequência de pelo menos de $1 \mathrm{~Hz}$, bem como amplitude mínima 2 vezes superior a linha basal (FORESTI, 2008), tomando sempre como referência a atividade basal (período pré estímulo). Ainda, tomamos o cuidado em diferenciar eventuais artefatos provenientes de eventos fisiológicos (movimento, por exemplo) e interferências diversas (sonora, elétrica e outros) que pudessem gerar um resultado falso positivo no registro EEGráfico.

Os resultados dessa análise indicaram que a aquisição do abrasamento foi efetiva, dado o aumento da duração pós descarga primária do $1^{\circ}$ para o $20^{\circ}$ estímulo (Two-way ANOVA, $\mathrm{p}<0,05)$. Tal progressão foi semelhante para ambos os grupos (Figura 29), indicando homogeneidade no abrasamento. E finalmente, apesar do grupo Estímulo e TMT $(\mathrm{N}=12)$ apresentar uma menor duração da pós-descarga primária no $21^{\circ}$ estímulo que o grupo Estímulo e Água ( $\mathrm{N}=8)$, como indicado na Figura 30, esses valores não foram estatisticamente significativos ( $\mathrm{p}>0,05$, Teste $t$ Student não pareado). 

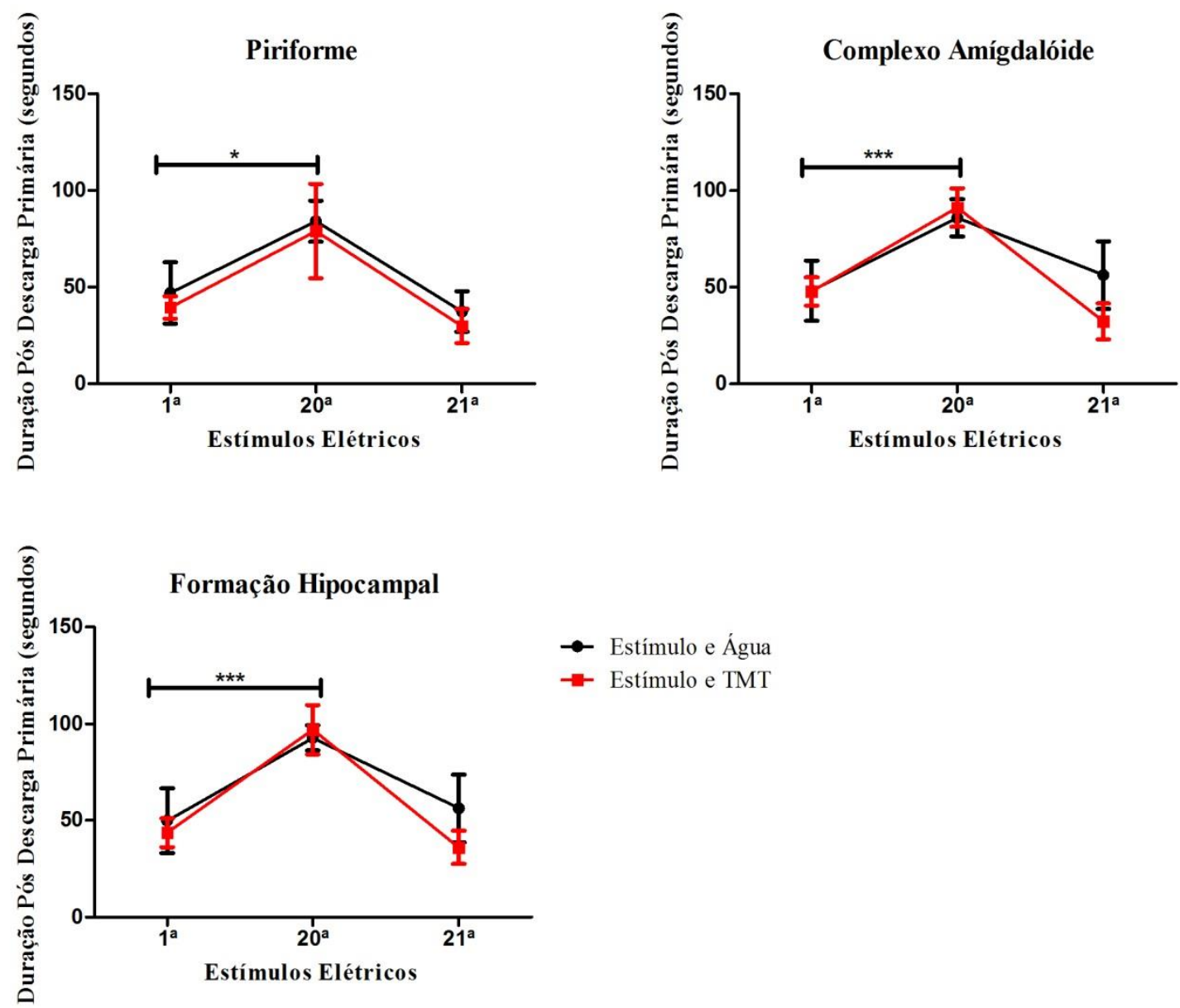

Estímulo e Água

Estímulo e TMT

Figura 29. Duração da pós descarga primária no $1^{\circ}, 20^{\circ}$ e $21^{\circ}$ estímulos, das áreas: Piriforme, Complexo Amígdalóide e Formação Hipocampal, para o Grupo Estímulo e Água (N=8, linha preta) versus Estímulo e TMT $(\mathrm{N}=12$, linha vermelha). Two-way ANOVA, *p<0,05; ***p<0,001. 

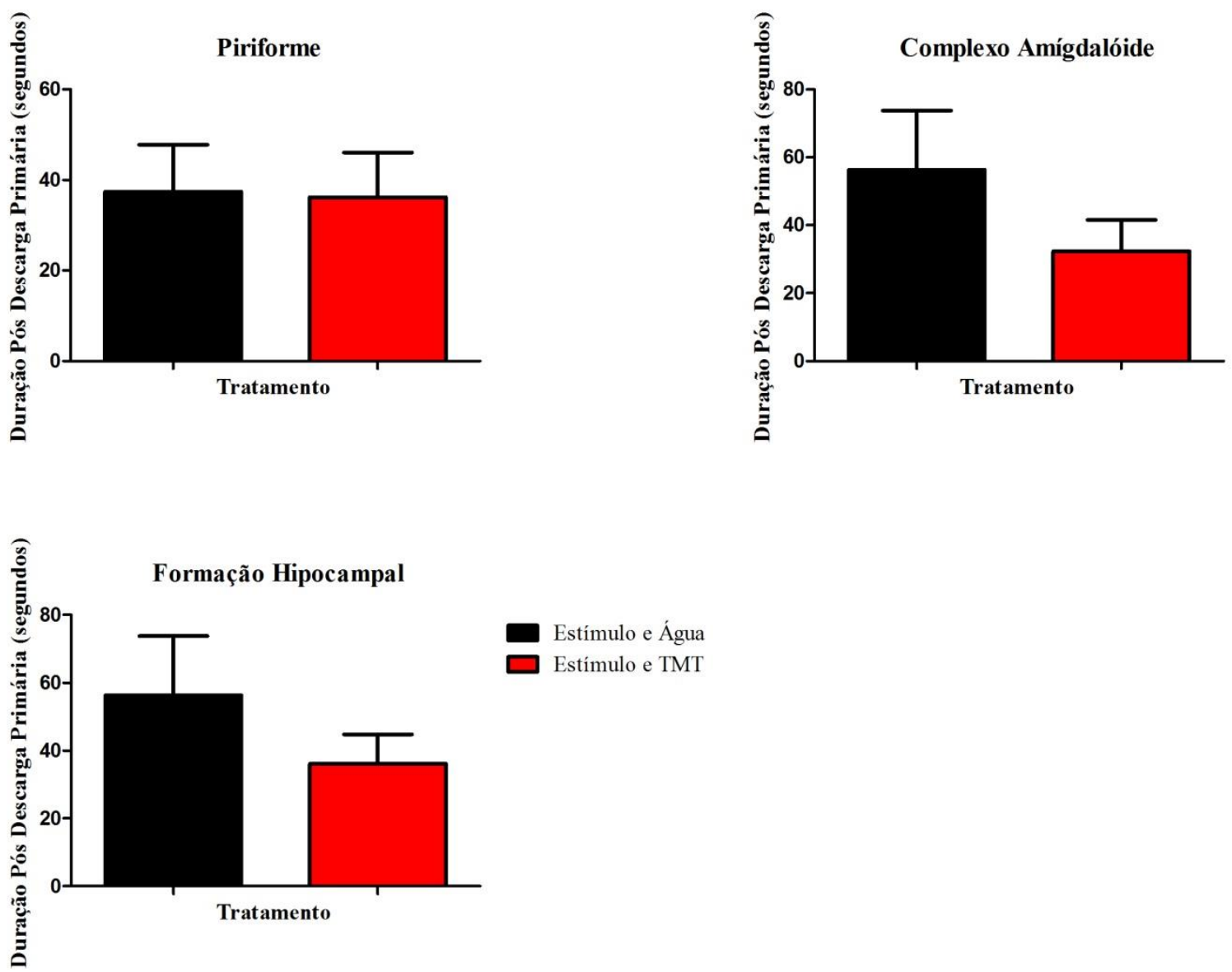

Figura 30. Duração da pós descarga primária no $21^{\circ}$ estímulo, das áreas: Piriforme, Complexo Amígdalóide e Formação Hipocampal, para o Grupo Estímulo e Água ( $\mathrm{N}=8$, coluna preta) versus Estímulo e $\mathrm{TMT}(\mathrm{N}=12$, coluna vermelha). Teste $t$ Student não pareado, $\mathrm{p}>0,05$.

Assim a hipótese inicial de que o TMT poderia agir como um estímulo supressor de crises epilépticas por ativar áreas semelhantes da crise límbica, do ponto de vista EEGráfico foi rejeitada, apesar do maior valor apresentado pelo grupo controle comparado ao experimental - nas Figuras 31 e Figura 32 estão representados o registro EEGráfico do $1^{\circ}(\mathrm{A})$, $20^{\circ}$ (B) e $21^{\circ}$ (C) estímulos de um animal de cada grupo, Estímulo e Água (Figura 31) e Estímulo e TMT (Figura 32).

Logo o TMT foi capaz de impedir a expressão comportamental, mas a crise eletrográfica ocorreu, ou seja, o estímulo elétrico aplicado posteriormente ao olfatório não foi capaz de atingir o limiar para expressão clínica (ver itens 6.3.2 e 6.3.3). Esse resultado é condizente com o fato de que os animais incluídos para tal análise haviam sido abrasados previamente ao $21^{\circ}$ estímulo, isto é as alterações epileptogênicas, que aumentaram a susceptibilidade ao desenvolvimento das crises já haviam sido estabelecidas, e pode ter sido este o motivo pelo qual a atividade epileptiforme não mostrou redução significativa. Mas, 
Influência da estimulação olfatória com TMT no modelo de abrasamento elétrico rápido da amígdala estudos farmacológicos para seleção de drogas anticonvulsivantes frequentemente empregam animais abrasados, por mimetizarem o quadro de epilepsia parcial complexa secundariamente generalizada (LÖSCHER; BRANDT, 2010; NOEBELS et al., 2012). Segundo Noebels e colaboradores (2012), a escolha do período adequado para a intervenção modificadora do abrasamento é bastante controverso.

Entretanto, os resultados da análise EEGráfica corrobora os dados de Ghorbani e colaboradores (2007) que indicam que o efeito inibitório da estimulação profunda (com baixa frequência) no córtex piriforme é inversamente proporcional à generalização da crise.

Outra explicação para esse resultado é a presença de alguns valores considerados extremos (outliers), que podem ter mascarado a média, prejudicando a estatística de significância.

Outra possível razão pode estar relacionada com as variações na localização histológica dos eletrodos, em especial de estímulo, observados pela técnica de Nissl (ver item 6.3.1).

Assim é importante uma análise refinada dos dados, utilizando outros parâmetros como FFT, Análise de Coerência e Energia.

Apesar disso, estudos descrevem que a redução do Índice de Gravidade para Crises Límbicas e/ou da duração da pós descarga primária, são critérios válidos e frequentemente utilizados para a avaliação de intervenção terapêutica (LÖSCHER; BRANDT, 2010; NOEBELS et al., 2012). 

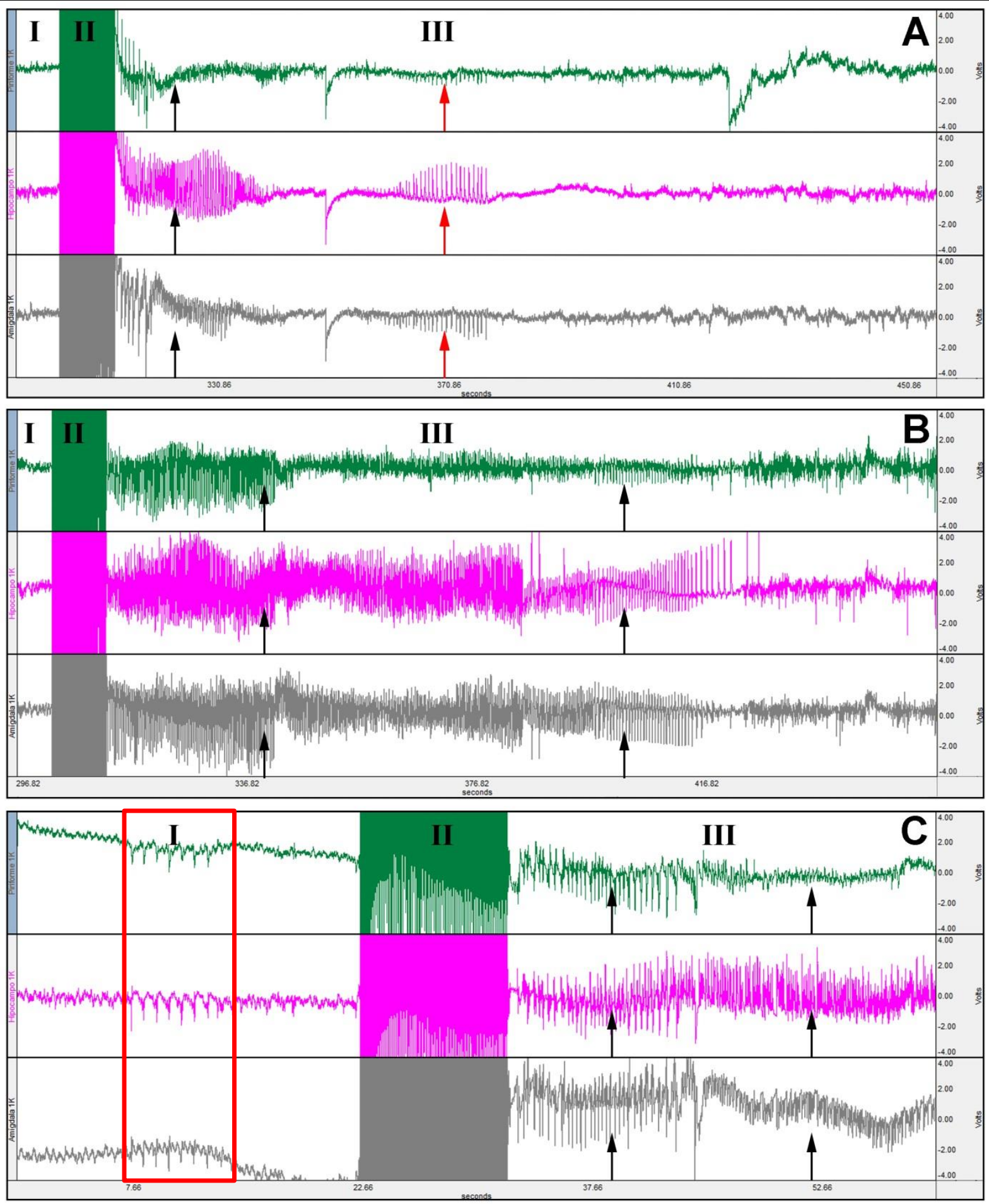

Figura 31. Registro EEGráfico do $1^{\circ}(\mathrm{A}), 20^{\circ}(\mathrm{B})$ e $21^{\circ}(\mathrm{C})$ estímulos de um animal escolhido aleatoriamente do grupo Estímulo e Água, com escala de aumento de 40 segundos/divisão em A e B, e 15 segundos/divisão em C. Períodos pré estímulo (atividade basal), estímulo e pós estímulo estão representados pelos algarismos romanos I, II e III, respectivamente. A barra horizontal indica o tempo (segundos) e a barra vertical à esquerda estão indicados os três canais de registro: em verde o córtex piriforme, rosa a formação hipocampal e em cinza o complexo amigdalóide. E na barra do lado direito o ganho de cada canal, correspondendo os intervalos 2 volts (V), ao valor de $1 \mathrm{mV}$, dado o ganho do sistema igual a 2000 vezes. Nessa figura está também representada a presença de pós-descarga primárias indicada pelas setas pretas e a pós-descarga secundária indicada pelas setas vermelhas, indicando um aumento da duração da pós descarga primária, entre $1^{\circ}$ e $20^{\circ}$ estímulos. E no $21^{\circ}$ estímulo a manutenção da pós descarga primária. No $21^{\circ}$ estímulo elétrico (C) é possível verificar também a presença de descarga interictal no período pré estímulo (I, caixa vermelha). 
Influência da estimulação olfatória com TMT no modelo de abrasamento elétrico rápido da amígdala
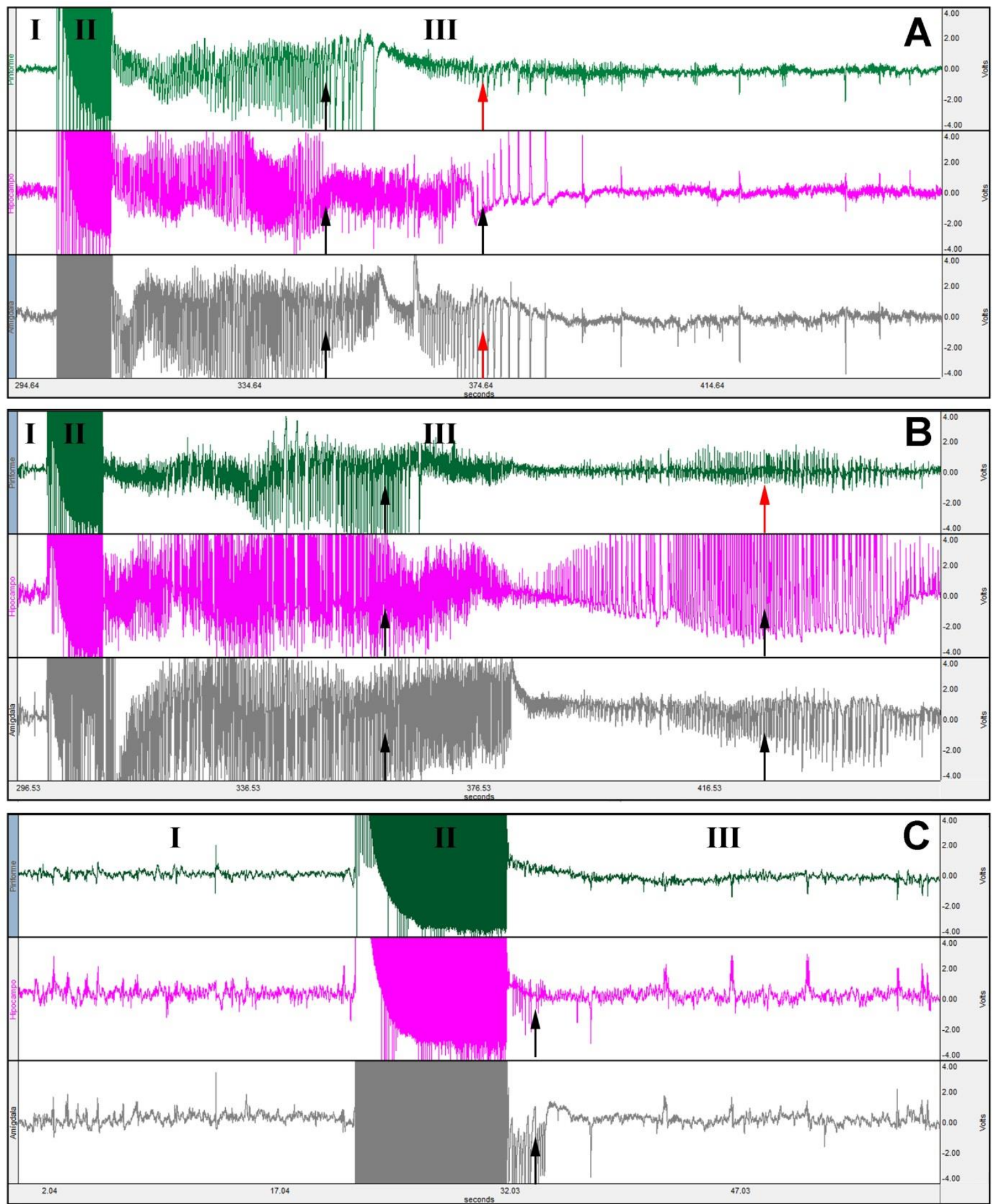

Figura 32. Registro EEGráfico do $1^{\circ}(\mathrm{A}), 20^{\circ}$ (B) e $21^{\circ}$ (C) estímulos de um animal escolhido aleatoriamente do grupo Estímulo e TMT, com escala de aumento de 40 segundos/divisão em A e B, e 15 segundos/divisão em C. Períodos pré estímulo (atividade basal), estímulo e pós estímulo estão representados pelos algarismos romanos I, II e III, respectivamente. A barra horizontal indica o tempo (segundos) e a barra vertical à esquerda estão indicados os três canais de registro: em verde o córtex piriforme, rosa a formação hipocampal e em cinza o complexo amigdalóide. E na barra do lado direito o ganho de cada canal, correspondendo os intervalos 2 volts (V), ao valor de $1 \mathrm{mV}$, dado o ganho do sistema igual a 2000 vezes. Nessa figura está também representada a presença de pós-descarga primárias indicada pelas setas pretas e a pós-descarga secundária indicada pelas setas vermelhas, indicando um aumento e redução da duração da pós descarga primária, entre $1^{\circ}$ e $20^{\circ}$ estímulos, e $20^{\circ}$ e $21^{\circ}$ estímulos, respectivamente. 
Influência da estimulação olfatória com TMT no modelo de abrasamento elétrico rápido da amígdala

\subsubsection{MORTE NEURONAL INDUZIDA PELO ABRASAMENTo ElÉTrico RÁPIDO}

Durante o desenvolvimento e também na vida adulta, os circuitos neurais passam por constantes alterações estruturais e funcionais em resposta à atividade neural (SAYIN et al., 2003). Caso essa atividade seja sincrônica, como nas descargas epileptiformes, ocorre uma reorganização neuronal anormal imediatamente e tardiamente, resultando no aumento da susceptibilidade às crises de forma cumulativa e progressiva (GODDARD, 1967; LÖSCHER; BRANDT, 2010; LÖSCHER; EBERT, 1996; NOEBELS et al., 2012; PITKÄNEN, 2010; SAYIN et al., 2003; TEJADA et al., 2013).

Essa plasticidade presente nos circuitos de crise epiléptica (FISHER et al., 2005; LÖSCHER; BRANDT, 2010; LÖSCHER; EBERT, 1996; NOEBELS et al., 2012; SAYIN et al., 2003), recebe o nome de epileptogênese. Este termo refere-se a todos os processos dinâmicos que ocorrem progressivamente, e que aumentam a susceptibilidade do cérebro epiléptico a gerar crises periódicas e imprevisíveis, aumentando assim a frequência das crises (LÖSCHER; BRANDT, 2010; NOEBELS et al., 2012; PITKÄNEN, 2010; SAYIN et al., 2003; TEJADA et al., 2013), e tornando-as mais refratárias as intervenções terapêuticas (LÖSCHER; BRANDT, 2010).

Assim o período livre de crises compreendido entre o insulto inicial (causador) e o início das crises espontâneas foi descrito há cerca de 130 anos, e recebe o nome de período latente (intervalo que cursa com o processo de epileptogênese). Esse período tem um comprimento variável, e em pacientes com ELT desenvolve-se em média após 7,5 anos (LÖSCHER; BRANDT, 2010).

Desta forma, o estudo da plasticidade tem uma importância clínica fundamental, por possibilitar entender o que por algum motivo, o cérebro ineficientemente não faz após uma lesão (por exemplo), o de tentar reparar os danos e recuperar suas funções, resultando na fração de pacientes em que esse reparo não é efetivo, mantendo as funções cerebrais alteradas, contribuindo, portanto para o desenvolvimento da epilepsia (LÖSCHER; BRANDT, 2010).

Logo, entender quais são os mecanismos que facilitam o surgimento das crises representa um desafio (BERTRAM, 2007; LÖSCHER; BRANDT, 2010; SAYIN et al., 2003), principalmente quando há possibilidade de isolar as alterações celulares e moleculares, ou mesmo combiná-las. Outra dificuldade para os modelos experimentais é integrar os diferentes parâmetros moduladores de tais alterações como: gravidade do insulto gerador, localização, extensão da lesão, fatores ambientais e genéticos (LÖSCHER; BRANDT, 2010). Ademais a etiologia da epilepsia é muito vasta (BERTRAM, 2007; LÖSCHER; BRANDT, 
Influência da estimulação olfatória com TMT no modelo de abrasamento elétrico rápido da amígdala

2010; TEJADA et al., 2013), e o diagnóstico em geral é realizado somente quando a crise está presente (BERTRAM, 2007; LÖSCHER; BRANDT, 2010), ou seja, após o início da epileptogênese.

Dessa forma, dois modelos experimentais de epilepsia apresentam vantagens com relação aos demais, segundo o National Institutes of Health/National Institute of Neurological Disorders and Stroke (NIH/NINDS, 2002), são: o SE e o abrasamento (LÖSCHER; BRANDT, 2010). Sendo recomendados com base no período de latência e incidência de CRE, para a avaliação farmacológica de novos tratamentos para crises epilépticas experimentais (GODDARD, 1983; LÖSCHER; BRANDT, 2010).

Entretanto o modelo de abrasamento apresenta algumas vantagens com relação ao SE, por ser considerado o modelo mais comumente utilizado de epilepsia parcial e secundariamente generalizada do lobo temporal (BERTRAM, 2007; FISHER, 1989; LÖSCHER; BRANDT, 2010; LÖSCHER; EBERT, 1996; SAYIN et al., 2003) com resultados frequentemente interpretados para a condição clínica, no qual um processo um estímulo inicialmente subconvulsivante torna-se, após um determinado número de estímulos, convulsivante, fornecendo portanto dados importantes sobre os substratos neurobiológicos envolvidos (BERTRAM, 2007; LÖSCHER; BRANDT, 2010; KANDRATAVICIUS et al., 2014; NOEBELS et al., 2012). Logo as alterações epileptogênicas são progressivas (BERTRAM, 2007; GODDARD, 1983; KANDRATAVICIUS et al., 2014; LÖSCHER; BRANDT, 2010; SAYIN et al., 2003), e não súbitas como no SE, o que possibilita uma melhor identificação das variáveis consideradas essenciais para a ocorrência das crises, como possíveis alvos para intervenções terapêuticas antiepilépticas (GODDARD, 1983; LÖSCHER; BRANDT, 2010; KANDRATAVICIUS et al., 2014; SAYIN et al., 2003), além das citadas no item 1.2.1.

Mas uma das desvantagens do abrasamento tradicional é o período latente que demanda um tempo maior que no SE para o surgimento de CRE (BERTRAM, 2007; LÖSCHER; BRANDT, 2010; McNAMARA et al., 1980; SAYIN et al., 2003). Entretanto, uma alternativa é o modelo de abrasamento elétrico rápido, que possibilita estabelecer crises em questão de horas ou de dias (FISHER, 1989; FORESTI et al., 2008; LÖSCHER; BRANDT, 2010; LOTHMAN et al., 1985; McNAMARA et al., 1980; NOEBELS et al., 2012), e mantê-las mesmo sem um período de estímulo (GODDARD, 1967; McNAMARA et al., 1980; NOEBELS et al., 2012).

E apesar dessa redução do tempo de realização do protocolo, o abrasamento rápido conserva características importantes quanto à progressão gradual do Índice de Gravidade para 
Influência da estimulação olfatória com TMT no modelo de abrasamento elétrico rápido da amígdala Crises, e do aumento da susceptibilidade a uma nova crise (LÖSCHER; BRANDT, 2010; LOTHMAN et al., 1985). Assim, o abrasamento rápido surge como uma ferramenta viável para o estudo de intervenções anticonvulsivantes (LÖSCHER; BRANDT, 2010; NOEBELS et al., 2012).

Dentre as alterações plásticas presentes no tecido cerebral de animais submetidos ao modelo de abrasamento elétrico rápido, pode-se incluir a morte celular por necrose, além de outras litadas na Tabela 10.

Tabela 10. Alterações celulares e moleculares presentes no tecido cerebral de animais submetidos ao modelo de abrasamento elétrico rápido.

\begin{tabular}{cc}
\hline Alterações celulares e moleculares & Referências \\
Morte neuronal - Apoptose & LÖSCHER; BRANDT, 2010; SAYIN et al., 2003 \\
Brotamento de fibras musgosas & BERTRAM, 2007; LÖSCHER; BRANDT, 2010; \\
Gliose & SAYIN et al., 2003; NOEBELS et al., 2012 \\
Inflamação & LÖSCHER; BRANDT, 2010; SAYIN et al., 2003 \\
Neurogênese & LÖSCHER; BRANDT, 2010 \\
& LÖSCHER; BRANDT, 2010; SAYIN et al., 2003 \\
Alterações em receptores e canais & BERTRAM, 2007; LÖSCHER; BRANDT, 2010; \\
& SAYIN et al., 2003 \\
\hline
\end{tabular}

A perda neuronal é descrita como uma importante alteração patológica presente em pacientes com ELT (LÖSCHER; BRANDT, 2010), o que justifica a escolha desta alteração celular, mais especificamente da morte neuronal causada por necrose, em detrimento das demais, para a análise nesse estudo. Além de ser uma técnica padronizada e adaptada em nosso laboratório, e com achados interessantes no modelo SE (CASTRO et al., 2011; FURTADO et al., 2002, 2011).

Alguns estudos evidenciam que a perda de neurônios é uma consequência das CRE, o que parece explicar o fato do achado patológico mais comum em ELT ser a esclerose hipocampal, então a perda neuronal principalmente no hipocampo parece estar envolvida na progressão fisiopatológica da epilepsia (NOEBELS et al., 2012). Assim, se a crise induz perda neuronal que aumenta a susceptibilidade a nova crise, logo, a prevenção da morte neuronal possibilita alterar o curso natural da epilepsia (NOEBELS et al., 2012; PITKÄNEN, 2010).

Embora a perda neuronal pareça estar associada ao modelo de SE (CASTRO et al., 2011; FURTADO et al., 2002, 2011; NOEBELS et al., 2012), envolvendo uma ampla variedade de regiões cerebrais como: hipocampo, amígdala, córtex entorrinal, hipotálamo e 
Influência da estimulação olfatória com TMT no modelo de abrasamento elétrico rápido da amígdala núcleos talâmicos (PITKÄNEN; LUKASIUK, 2009), esse achado é ainda controverso para os modelos de abrasamento tradicional e rápido (NOEBELS et al., 2012).

Esse processo, no seu sentido mais simples, envolve a morte neuronal patológica de neurônios jovens ou adultos (NOEBELS et al., 2012). A morte neuronal é classicamente dividida em apoptose e necrose, de acordo com as características morfológicas e bioquímicas. A apoptose é caracterizada pela morte celular programada, utilizada para eliminação de células não desejadas ou danificados de forma controlada, e está presente durante a fase de desenvolvimento do cérebro e também depois do desenvolvimento ou maturidade cerebral, quando por exemplo o indivíduo é privado de certas substâncias, ou expostos a outras, como ao etanol que desencadeia uma apoptose disseminada no cérebro do rato em desenvolvimento (NOEBELS et al., 2012). Durante a apoptose ocorre perda das aderências entre células vizinhas ou matriz extracelular, encolhimento celular, com posterior lise (KERR, 1972).

A necrose por sua vez, ocorre em resposta a um insulto que cursa com dano celular irreversível (CASTRO et al., 2011). É observada em lesões causadas pela excitotoxicidade mediada por glutamato - principal mecanismo de morte neuronal, ocasionando influxo patológico de cálcio intracelular, stress oxidativo, inchaço e ruptura de membranas intracelulares, com a consequente ativação de proteases e necrose (KERR, 1972; NOEBELS et al., 2012).

Embora os neurônios inibitórios sejam mais resistentes à excitotoxicidade, a neurodegeneração desses interneurônios é parcialmente responsável pela hipersincronização do circuito subjacente, dada a perda de inibição das células excitatórias. Por outro lado, a perda de neurônios excitatórios, como as células piramidais presentes em Corno de Ammon (CA) 1 no hipocampo, é sugerida também como parte da alteração fisiológica observada na epilepsia, repercutindo em déficits cognitivos e neurológicos (TEJADA et al., 2013).

Para presente estudo foi utilizado o protocolo de FJC (SCHMUED; ALBERTSON; SLIKKER, 1997) tradicionalmente utilizado pelo nosso grupo (CASTRO et al., 2011; FORESTI et al., 2008; FURTADO et al., 2002, 2011; ROMCY-PEREIRA \& GARCIACAIRASCO, 2003) como marcador histoquímico de morte celular, principalmente após a indução de ELT química por pilocarpina (CASTRO et al., 2011; FURTADO et al., 2002; 2011). E seu uso teve como objetivo averiguar se o grupo controle Estímulo e Água teria maior neurodegeneração, em comparação com ao grupo experimental Estímulo e TMT.

Em experiência anterior do nosso laboratório, utilizando também do modelo de abrasamento elétrico rápido, não foi observada a presença de células positivas para neurodegeneração (FORESTI et al., 2008). Nosso resultado corrobora os dados (FORESTI et 
Influência da estimulação olfatória com TMT no modelo de abrasamento elétrico rápido da amígdala al., 2008), indicando ausência de marcação cerebral para a morte neuronal por necrose, conforme observado na Figura 33.
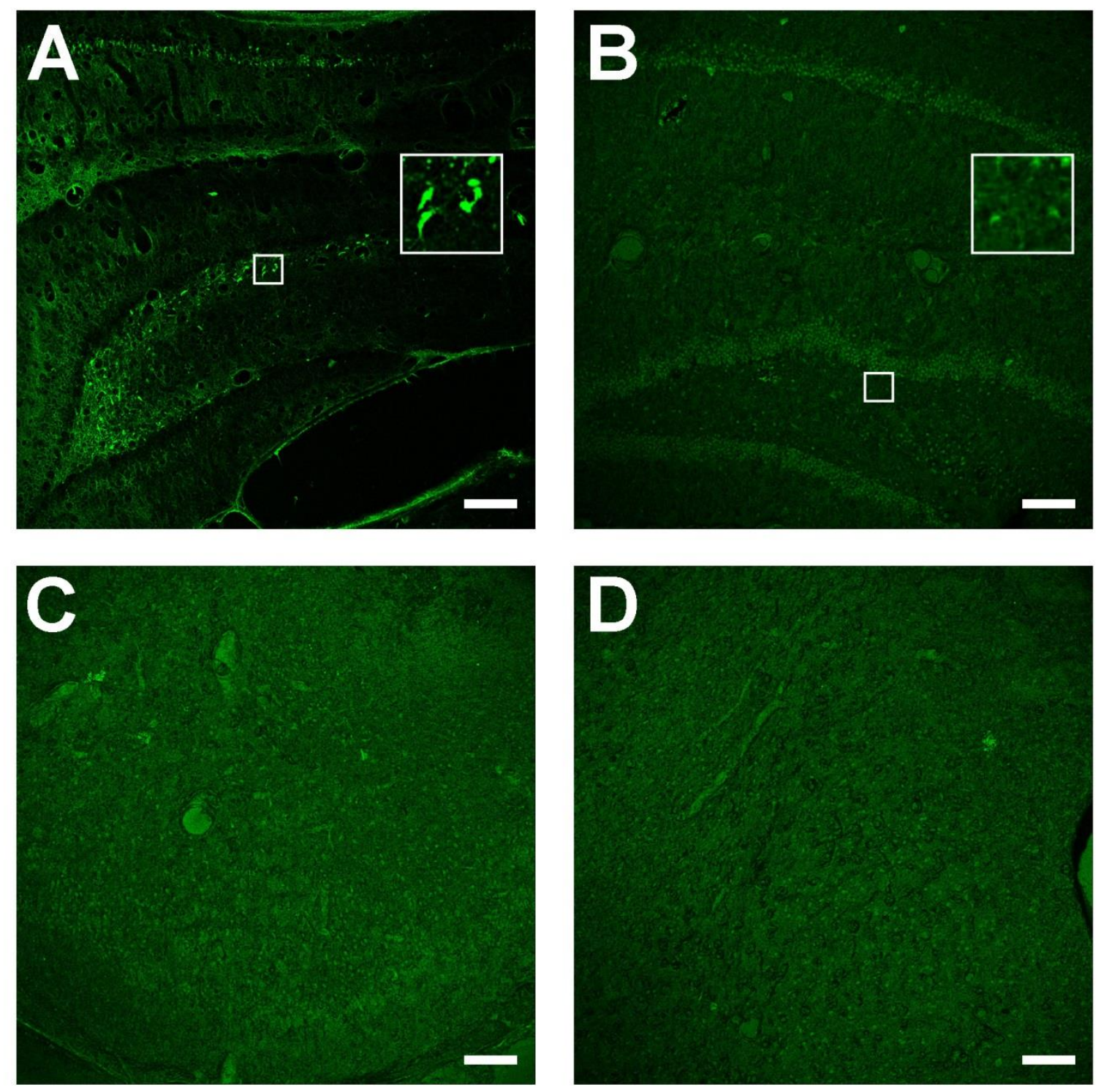

Figura 33. Histoquímica de FJC: (A) Hilus do giro denteado do controle positivo (animal submetido ao SE i.p.), (B) Hilus do giro denteado, (C) Córtex piriforme e (D) Complexo amigdalóide, sendo em (B-D) animal escolhido aleatoriamente do grupo Estímulo e TMT. Podemos notar que em (A) os animais submetidos ao SE tiveram marcação para neurodeneração no Hilus, evidenciado no inset (aumento digital de $4 \mathrm{x}$ ) pela coloração verde. E em B-D indica a ausência de marcação para essa técnica, notado pelo inset (aumento digital de $4 \mathrm{x}$ ) em B. Todos os quatro tecidos foram submetidos à mesma bateria de realização da histoquímica. Barra de calibração de $150 \mu \mathrm{m}$.

Apesar do número reduzido de animais nos grupos submetidos a essa histoquímica ( $\mathrm{N}$ total $=17$ ), provavelmente o aumento da amostra deverá confirmar a inexistência de morte celular por necrose em ratos expostos ao abrasamento elétrico rápido, ou ao TMT, e/ou ao abrasamento elétrico rápido com TMT, já que não houve célula marcada (em todo o tecido). 
Influência da estimulação olfatória com TMT no modelo de abrasamento elétrico rápido da amígdala

A explicação para esse achado apoia-se em dados descritos na literatura que indicam que a morte neuronal por necrose é detectada após repetidas estimulações, e em crises em que há a necessidade do uso de fármacos para a obtenção de controle, como no SE (DINGLEDINE; VARVEL; DUDEK, 2014).

Apesar da técnica de FJC não evidenciar a presença de necrose, há evidências que apóiam a marcação de apoptose celular após o abrasamento elétrico rápido (NOEBELS et al., 2012; SAYIN et al., 2003). Mas até o momento, a morte neuronal tanto por apoptose quanto por necrose, foi bem descrita no modelo de SE.

E ainda, estudos indicam que a perda neuronal presente na Esclerose Hipocampal pode ser uma consequência de um dano inicial, e não somente à presença de CRE (NOEBELS et al., 2012).

Logo, identificar os mecanismos que contribuem para o surgimento das CRE nos diferentes modelos representa um importante desafio evidenciando a grande variabilidade de efeitos fisiopatológicos na epilepsia. Tais achados possibilitariam a implementação de medidas terapêuticas específicas, a fim de modificar ou parar o processo de epileptogênese, representando o "Santo Graal" no estudo dessa importante desordem neurológica (NOEBELS et al., 2012; PITKÄNEN, 2010).

\subsubsection{CARACTERIZAÇÃo NeUroetológica dos EFEITOS da ExPOSiÇão AO Estímulo Olfatório COM TMT Nas Crises AUdiogêniCAS Agudas}

Os modelos genéticos em especial, permitem a análise aguda e crônica da crise, possibilitando a observação da evolução da crise. Esses modelos apresentam a vantagem de mimetizar o fenômeno real da alteração do sistema nervoso na epilepsia, permitindo estudar os mecanismos epileptogênicos presentes em uma condição experimental estabelecida geneticamente, com ou sem a presença de um estímulo adicional (MORAES, 1998).

A cepa WAR quando exposta a um único estímulo acústico apresenta crises estritamente mesencefálicas, que são caracterizadas por um período inicial chamado de fase procursiva com a presença de corrida, giros, pulos e quedas atônicas, cursando para a CVT (DORETTO et al., 2003; GARCIA-CAIRASCO, 2002; GARCIA-CAIRASCO et al., 1996; KANDRATAVICIUS et al., 2014; MORAES, 1998; ROMCY-PEREIRA, 2001; ROSSETTI et al., 2006). A estimulação acústica repetida, chamada de abrasamento audiogênico, resulta em crises gradativamente mais severas e promove o recrutamento epileptifome secundário de áreas como estruturas límbicas (DORETTO et al., 2003; GARCIA-CAIRASCO, 2002; GARCIA-CAIRASCO et al., 1996; KANDRATAVICIUS et al., 2014; MORAES, 1998; 
Influência da estimulação olfatória com TMT no modelo de abrasamento elétrico rápido da amígdala ROMCY-PEREIRA, 2001; ROSSETTI et al., 2006) culminando na presença de comportamentos descritos por Racine (1972) e modificados por Pinel \& Rovner (1978).

Para o presente experimento, realizado em colaboração ao projeto de Pós-Doutorado da Dra. Poliana Bertti Dutra, o objetivo foi verificar a influência do TMT no desenvolvimento de crises mesencefálicas, utilizando para isso o Índice de Gravidade para Crises Mesencefálicas, e as latências para a $1^{\circ}$ corrida e CVT.

Como resultado ilustrado na Figura 34 nota-se a ausência de diferenças significativas para $1^{\circ}$ Corrida (A), CVT (B) e ISc (C). Entretanto, a latência para $1^{\circ}$ corrida foi menor no grupo TMT/som (A), contrapondo a maior latência para CVT (B), ou seja, os animais correram mais cedo, porém demoraram mais para apresentar CVT, o que resultou em um menor ISc nesse grupo (C). Esse resultado permite inferir que apesar desses animais apresentarem um limiar menor para o início da crise audiogênica, eles foram mais resistentes à evolução dos comportamentos convulsivos.

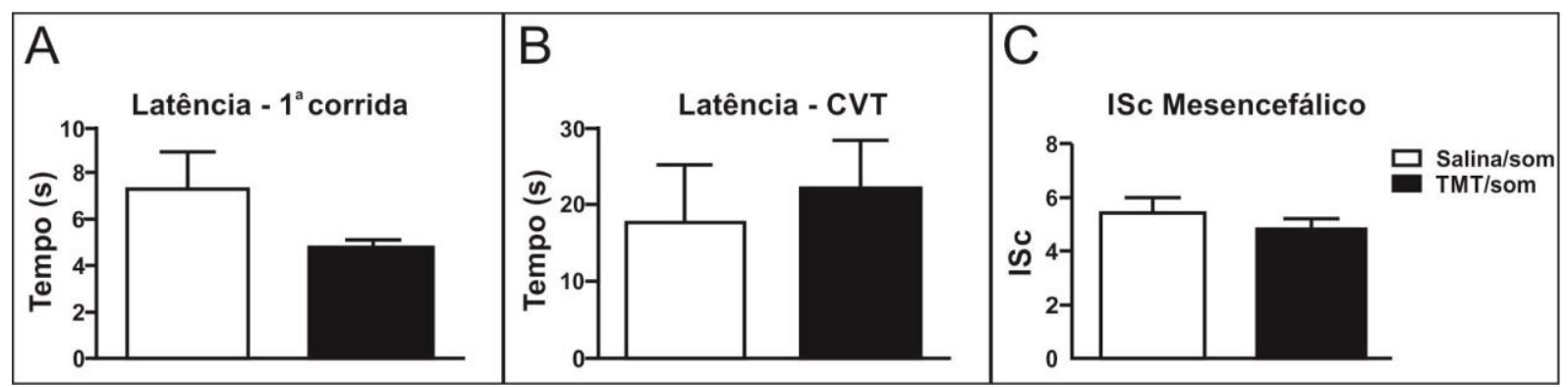

Figura 34. Influência do TMT no desenvolvimento de crises audiogênicas agudas.

Através do fluxograma da Figura 35 é possível verificar o potencial efeito anticonvulsivo do TMT, dado o aumento da frequência e das interações entre os comportamentos procursivos no grupo TMT/som (Figura 35D, itens em amarelo) em relação ao grupo SAL/som (Figura 35C), com a formação de clusters desses comportamentos. É valido ressaltar que esses comportamentos estão presentes mesmo quando separamos para fins de análise em dois subgrupos, os com (Figura 35E) ou sem (Figura 35F) CVT. Nos animais que não evoluíram com CVT (Figura 35F), a riqueza de interações entre os comportamentos procursivos demonstra a permanência num ciclo de repetição que normalmente antecede a CVT, o que pode resultar na ocorrência de crises menos severas nesses animais. 
Capítulo II:

Influência da estimulação olfatória com TMT no modelo de abrasamento elétrico rápido da amígdala

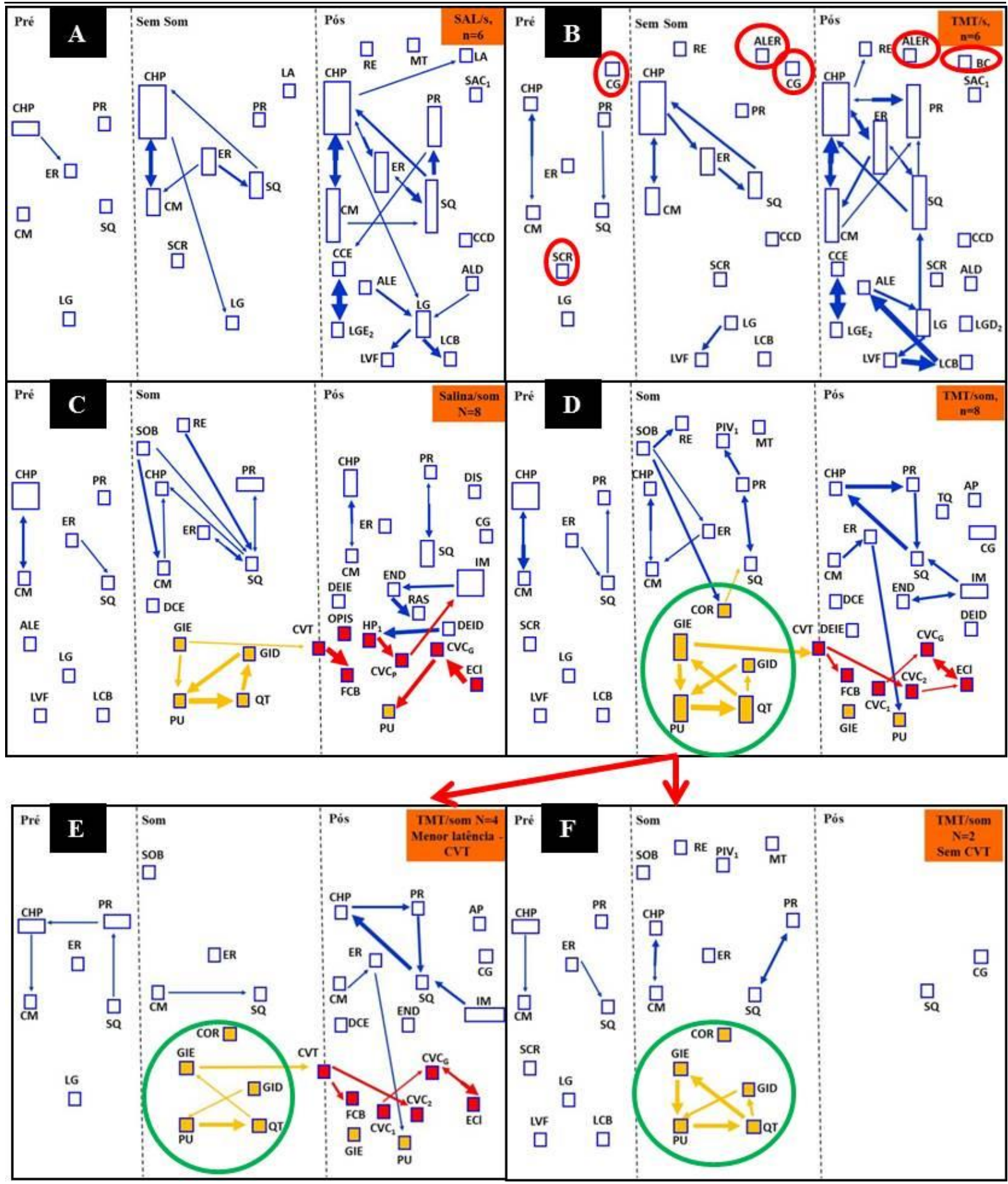

Figura 35. Evidências neuroetológicas do efeito anticonvulsivante do TMT nas crises audiogênicas agudas. Diferentes respostas comportamentais de medo foram induzidas pelo TMT/s (B) versus SAL/s (A), como: ALER, BC, CG e SCR (B, círculos vermelhos). O possível efeito anticonvulsivo é reforçado pelo aumento da frequência e das interações entre os comportamentos procursivos (corridas, COR; giros, GID e GIE; pulos, PU; e quedas, QT; em amarelo) nos TMT/som (D, círculo verde) versus $\mathrm{SAL} / \mathrm{som}(\mathrm{C})$. E e F representam os animais que tiveram um perfil diferente de crises, com (E) ou sem (F) comportamentos de CVT (círculo verde).

Assim, o TMT desencadeou reações de medo nos WAR controles (TMT/s) e modificou as sequências comportamentais das crises (TMT/som versus SAL/som), bloqueando-as $(\mathrm{N}=2)$ ou retardando a ocorrência das CVTs (N=2) (PEREIRA et al., 2014). Entretanto, são 
Influência da estimulação olfatória com TMT no modelo de abrasamento elétrico rápido da amígdala necessários novos experimentos com um maior número de animais, além da aplicação desse protocolo no grupo WAR com abrasamento, para provar o efeito anticonvulsivante do TMT. 


\section{DISCUSSÃo GERAL}

A proposta do presente estudo foi mostrar que a estimulação olfatória com TMT poderia ser capaz de ativar redes neurais que modulam a atividade de crise. Essa ativação de circuitos antagônicos, mas que convergem para as mesmas estruturas cerebrais causaria um efeito de supressão das crises (Figuras 22-24, e Figuras 26 e 27). Tal hipótese baseia-se no fato de que a ativação prévia dos neurônios das áreas estudadas pelo TMT causaria uma limitação da freqüência de potenciais de ação ao estímulo elétrico, dado o período refratário relativo, o que levaria a um comprometimento da conectividade neuronal anormal, logo a uma dessincronização.

Outra hipótese indicada pela literatura é sobre o efeito anticonvulsivante da norepinefrina (NE; FITZGERALD, 2010; GIORGI et al., 2004; JOBE; BROWNING, 2005). Esse mecanismo é ativado em resposta ao estresse agudo induzido pela apresentação do TMT, levando à rápida ativação do SNA e a consequente liberação de epinefrina e NE (rever Tabela 3 - BRANDÃO et al., 2004; HORII et al., 2010; ROSEN et al., 2008; TAKAHASHI, 2014). Tal papel anticonvulsivante da NE consiste em neutralizar o desenvolvimento do circuito epiléptico, impedindo as alterações epileptogênicas especialmente no sistema límbico, induzidas pelos modelos experimentais (FITZGERALD, 2010; GIORGI et al., 2004; JOBE; BROWNING, 2005), tal como no abrasamento elétrico rápido da amígdala. Assim a possível liberação de NE induzida pelo TMT pode ter efeito na supressão das crises nesse estudo (Figuras 22-24, e Figuras 26 e 27). Além disso, a NE sob certas condições pode ser próconvulsivante (JOBE; BROWNING, 2005).

De uma forma sucinta, o TMT pode interagir com vários receptores distintos, distribuído aleatoriamente no interior das zonas do epitélio olfatório posterior, que projetam com precisão para os glomérulos no BOP. Do bulbo partem projeções para células do córtex piriforme, considerado o córtex olfatório primário, que respondem sem uma ativação espacial/química específica. O BOP também envia projeções para diferentes áreas cerebrais, dentre elas o núcleo medial da amígdala que recebe aferências diretas e indiretas de áreas ativadas pelo TMT. Bem como para o hipocampo que recebe projeções indiretas, mas que se mostra como uma estrutura importante no comportamento emocional, especialmente no processamento do medo contextual, mas que possui sua região ventral envolvida no processamento do medo inato induzido pelo TMT (maiores informações das áreas ativadas, ver Tabela 11 e 12). Dessa forma a percepção olfatória, com o reconhecimento do odorante 
requer ativação de áreas olfatórias periféricas, que projetam para estruturas centrais que participam do processamento da informação e discriminação do odorante, permitindo reconhecer o TMT como "cheiro de predador", e gerar a resposta defensiva apropriada.

Tabela 11. Efeitos do TMT na modulação do sistema olfatório principal.

\begin{tabular}{cc}
$\begin{array}{c}\text { Sistema Olfatório } \\
\text { Principal }\end{array}$ & Referências \\
EOP & $\begin{array}{r}\text { Perfusão intranasal de sulfato de zinco induz anosmia temporária do EOP, } \\
\text { reduzindo CG (HACQUEMAND; JACQUOT; BRAND, 2010). } \\
\end{array}$ \\
Aumento na expressão de Fos, em camadas do BOP (DAY; MASINI; \\
BOP \\
Ablação do BOP reduz o CG (AYERS et al., 2013). \\
\hline
\end{tabular}


Tabela 12. Efeitos do TMT na modulação de diferentes estruturas cerebrais centrais.

Estruturas cerebrais

Amígdala

BLA

Central

Estria terminal

Ventral

Ventral

Hipocampo

Hipotálamo

Córtex pré frontal

Dorsal

\section{Referências}

Lesões prejudicam drasticamente o comportamento de CG (FENDT; ENDRES; APFELBACH, 2003).

Inativação ou lesões não induziu prejuízos robustos no $\mathrm{CG}$

(WALLACE; ROSEN, 2001).

Lesão ou inativação temporária não demonstram resultado após exposição ao TMT (FENDT; ENDRES;

APFELBACH, 2003).

Inativação reduz CG (FENDT;

ENDRES; APFELBACH, 2003).

TMT ativa células no giro dentado

(DAY; MASINI; CAMPEAU, 2004).

Processamento do odor de predador no medo condicionado e incondicionado (TAKAHASHI, 2014)

Processamento de medo contextual

(Wang et al. de 2012; e apud

TAKAHASHI, 2014).

Sistema de defesa envolvido por ativação de pistas olfatórias (GROSS;

CANTERAS, 2012).

Estrutura envolvida na avaliação defensiva (TAKAHASHI, 2014).

Entre as principais áreas ativadas nas crises límbicas encontram-se o complexo amigdalóide, a formação hipocampal, o córtex piriforme e neocórtices adjacentes. A amígdala, por exemplo, está amplamente relacionada com a geração de crises, por apresentar baixo limiar à estimulação elétrica (EBERT; LÖSCHER, 1995, 2000; FISHER, 1989; FORESTI et al., 2008; GODDARD; MCINTYRE; LEECH, 1969; GODDARD, 1967; LÖSCHER; BRANDT, 2010; LÖSCHER; EBERT, 1996; LOTHMAN et al., 1985; McNAMARA et al., 1980; PINEL; ROVNER, 1978) e posteriormente propagar o estímulo para outras regiões do sistema límbico bem como para outras estruturas cerebrais (PITKÄNEN et al., 1998). 
A formação hipocampal por sua vez inclui: giro denteado, o hipocampo (áreas: CA1, CA2 e CA3) e o subiculum, está amplamente envolvida na epilepsia seja na geração (BERTRAM, 2007; LÖSCHER; EBERT, 1996; NOEBELS et al., 2012; SAYIN et al., 2003) manutenção e/ou propagação de crises (BERTRAM, 2007; LÖSCHER; BRANDT, 2010; LÖSCHER; EBERT, 1996; NOEBELS et al., 2012; SAYIN et al., 2003).

O córtex piriforme participa de maneira importante no desenvolvimento da crise, por conter na região anterior a área tempestas, descrita pela alta sensibilidade e responsividade a estímulos (em especial elétricos; EBERT; LÖSCHER, 1995, 2000; GHORBANI et al., 2007; LÖSCHER; EBERT, 1996; PIREDDA; LIM; GALE, 1985). Além disso, essa área possui papel importante na propagação (EBERT; LÖSCHER, 2000; GHORBANI et al., 2007; LÖSCHER; EBERT, 1996; PIREDDA; LIM; GALE, 1985), bem como na amplificação da atividade epileptiforme (LÖSCHER; EBERT, 1996).

Assim as três áreas de interesse nesse estudo, são áreas que estão envolvidas no processamento do TMT, e são criticamente envolvidas na expressão de crises límbicas.

O envolvimento de estruturas olfatórias com a ELT, não é recente, data de mais de 100 anos, quando Jackson e colaboradores (apud LÖSCHER; EBERT, 1996) deram os primeiros indícios que mais tarde seriam confirmados, do envolvimento do córtex piriforme como foco primário para crise epiléptica. Em geral, pacientes com ZE nessa área apresentam auras olfatórias, e para tais pessoas, o uso de estímulo olfatório que iniba uma eventual crise, pode ser mais efetivo. Enquanto para aqueles com ZE em outras áreas do Lobo Temporal, as crises possivelmente sejam suprimidas com o estímulo olfatório, já que o córtex piriforme estaria funcionando como propagador e amplificador, e não como um gerador da crise.

Assim, estudos indicam que a estimulação sensorial periférica, como um estímulo olfatório, é capaz de suprimir ou inibir a ocorrência de uma crise. Gowers (1881, apud LÖSCHER; EBERT, 1996) descreveu que o uso de amônia foi eficaz para a contenção de crises, em especial naquelas precedidas por auras. Mais tarde seria relatado por Efron (1956, 1957), o caso de uma paciente que apresentava crise precedidadas de auras olfatórias, e que exposição ao odor semelhante ao descrito pela paciente, desde que aplicado durante a aura, era capaz de inibir tal expressão. Posteriormente a simples evocação da memória olfatória criada por condicionamento impedia a expressão de crises. Além disso, na Índia é descrito desde tempos remotos a exótica utilização de "shoe-smell", ou seja, chulé no controle das crises (JASEJA, 2008), E ainda, a terapia com odores tem-se mostrado como uma alternativa eficaz na supressão ou inibição de crises (BETTS, 2003). 
No modelo experimental o pré tratamento com Tolueno em crises induzidas por PTZ, dependendo da dose administrada, aumentou a latência para comportamentos convulsivos. Enquanto a inalação do Tolueno reduziu a mortalidade dos animais após a injeção de PTZ (WOOD et al., 1984).

Ebert \& Löscher (2000) descrevem de maneira elegante, o bloqueio de crises em animais submetidos ao abrasamento da amígdala, no qual a estimulação olfatória com Tolueno reduziu a atividade epileptiforme no córtex piriforme, aumentando o limiar convulsivo na maioria dos ratos, mesmo com estímulo elétrico $20 \%$ acima do necessário para deflagrar uma crise. Segundo os autores, o córtex piriforme estaria "ocupado" processando a informação olfatória enquanto que a propagação da atividade epileptiforme, via conexões amígdala-pirifome estaria bloqueada.

E finalmente animais da cepa WAR submetidos ao modelo audiogênico com estimulação olfatória com Tolueno, tiveram uma redução da gravidade das crises comportamentais (BERTTI et al., 2010, 2011, 2013;).

Todas essas evidências clínicas e experimentais fornecem um escopo científico para os resultados obtidos nesse estudo, demonstrando que a estimulação olfatória especificamente com o TMT pode influenciar no processo de crise, interferindo na resposta comportamental. A possível explicação para esses efeitos baseia numa combinação de fatores que incluem potencial antagonismo de circuitos e período refratário, o que dificultaria a expressão da ictogênese. Outra hipótese seria o efeito anticonvulsivante da NE.

Por outro lado, a estimulação olfatória também tem sido relatada como um fator precipitante agindo, portanto, como estímulo pró-convulsivante - desencadeadora de crises de ausência, por exemplo (KOMAREK, 1994 apud LÖSCHER; EBERT, 1996). Nesse sentido Restrepo e colaboradores (2013) descreveram que o odor forte, se inspirado rapidamente, pode provocar crise. Dado que o córtex piriforme anterior possui déficit na sua rede inibitória, favorecendo o fenômeno da ictogênese, o que em suma, justifica o uso do método de hiperventilação como deflagrador de crises na clínica (MEDEIROS; MORAES, 2014; SAKAMOTO et al., 2002).

Assim, Lunardi e colaboradores (2011) indicaram que o mesmo estímulo exógeno pode facilitar ou inibir uma crise dependendo da condição da membrana neuronal e da ativação cortical no momento da exposição a tal estímulo. Logo, os chamados fatores facilitadores são aqueles capazes de deflagrar uma crise por possivelmente estimular as ZE. Enquanto que a eventual inibição das crises requer a ativação de áreas ao redor das ZE, o que resulta no bloqueio ou supressão da propagação epileptiforme, dessincronizando-as. 
Uma importante observação quanto à ativação pelo TMT, é que estudo indicou que altas concentrações dessa substância poderiam ativar o sistema trigeminal por suas propriedades irritantes (HACQUEMAND; JACQUOT; BRAND, 2010) (Hacquemand et al., 2010) resultando portanto, em um efeito anticonvulsivante por mecanismo trigeminal (FANSELOW; REID; NICOLELIS, 2000). Entretanto Ayers e colaboradores (2013) indicaram que a transecção desse nervo prejudicaria efetivamente a resposta ao ácido butírico, mas que o CG descrito como um dos principais comportamentos de medo (Tabela 3) é mantido em ratos expostos ao TMT.

Nessa linha, uma possível hipótese para o efeito anticonvulsivante do Tolueno em animais da cepa WAR submetidos ao abrasamento audiogênico (BERTTI et al., 2010, 2011, 2013;) é por ativação do nervo trigeminal, devido as suas propriedades irritativas e nociceptivas, semelhantes aos do ácido butírico. Entretanto esse estudo necessita de uma análise específica para confirmar tal hipótese.

É sabido que a estimulação elétrica de estruturas do sistema nervoso periférico (por exemplo, nervo trigeminal e vago) ou central (núcleo anterior do tálamo e estruturas corticais, por exemplo) têm resultados interessantes nas crises epilépticas refratárias, através do controle da hiperexcitabilade e/ou dessincronização das redes neurais epileptiformes, possibilitando importantes alternativas terapêuticas para a epilepsia refratária (FANSELOW; REID; NICOLELIS, 2000; JOBE; BROWNING, 2005; MEDEIROS; MORAES, 2014).

Outro ponto que merece destaque é que a eficácia da estimulação olfatória no controle de crises pode ser favorecida se aplicado no início da crise. Assim, a previsibilidade das crises representa um critério positivo para a eficácia desse paradigma, impedindo se não a geração, mas a limitação da propagação em uma rede neural. Dessa forma, tornam-se necessários estudos de predição, que se associados a diferentes terapêuticas conduziria a melhores resultados.

Uma limitação do presente estudo refere-se aos dados inconclusivos da duração da pós descarga primária no $21^{\circ}$ estímulo. Logo, reafirma a necessidade de novas análises empregando diferentes métodos quantitativos e analíticos, por exemplo, de energia e amplitude, além do cálculo de coerência de sinais -. análise em andamento, com a colaboração entre o LNNE e a Universidade Federal de Minas Gerais (UFMG) e outros Laboratórios.

O mecanismo de ação pelo qual o TMT pode ter surtido efeito supressor (comportamento) nas crises epiléticas não está claro. No entanto, faz necessário estudar mais profundamente o papel da estimulação olfatória na epilepsia, o motivo pelo qual em alguns 
casos tal aplicação pode ser vantajoso (anticonvulsivante), mas em outros prejudicial (próconvulsivante). E ainda testar o papel da NE como potencial anticonvulsivante nesse modelo.

Assim, uma sugestão para estudo futuro seria avaliar o papel do TMT na resposta de medo, especificamente na ativação do SNA, através da concentração central de NE (BRANDÃO et al., 2004; HORII et al., 2010; ROSEN et al., 2008; TAKAHASHI, 2014), o que em caso positivo destacaria a hipótese do seu controle sobre as crises (FITZGERALD, 2010; GIORGI et al., 2004; JOBE; BROWNING, 2005).

Finalmente, a literatura ainda não identificou os mecanismos que causam a epilepsia e que em suma parecem diferir em cada modelo, logo a análise do efeito de possíveis drogas anticonvulsivantes deve ser realizada em diferentes abordagens. Além disso, é necessária uma melhor compreensão das variáveis ambientais e genéticas que possivelmente interferem nos resultados dessas terapias (LÖSCHER; BRANDT, 2010).

Assim, um dos objetivos da comunidade científica é identificar uma substância (droga) que tenha efeito antiepileptogênico (cura; LÖSCHER; BRANDT, 2010; PITKÄNEN, 2010). Entretanto a busca por tratamentos anticonvulsivantes mostram mais factível, possibilitando suprimir ou inibir crises, ou seja, modificar o curso natural da epilepsia, o que interfere no desenvolvimento de CRE. Que no cenário positivo, as crises tornariam menos frequentes, com menor duração e/ou menos graves, impactando positivamente na qualidade de vida dos pacientes com epilepsia (LÖSCHER; BRANDT, 2010; PITKÄNEN, 2010).

É inquestionável que a construção do conhecimento se dá pela busca e união dos estudos científicos. A transdisciplinaridade tão em voga nos últimos anos é extremamente necessária no estudo da epilepsia, por se tratar de uma desordem multifacetada, portanto complexa e que, apesar dos esforços da comunidade científica, muitas questões permanecem sem respostas. Assim é extremamente necessário que os conhecimentos e desconhecimentos da pesquisa básica e clínica sejam compartilhados, e que o resultado esperado seja o conhecimento comum para o controle de crises. Nesse sentido, esse estudo tenta através de uma visão inicialmente panorâmica buscar as bases científicas do conhecimento clínico.

Entretanto muita coisa deve ser feita para que se possa confirmar o papel do TMT no controle de crise (citados na discussão, rever item 7). Só então poderemos confirmar tal efeito anticonvulsivante, como demonstrado com o Tolueno no abrasamento elétrico (EBERT; LÖSCHER, 2000) e nas crises audiogênicas de WARs (BERTTI et al., 2010, 2011, 2013;). 



\section{CONCLUSÃ̃o}

1. O TMT desencadeou reações de medo, e modificou as sequências comportamentais, reduziu a atividade motora e os comportamentos de autolimpeza em ratos Wistar.

2. A estimulação olfatória com TMT puro foi escolhida como potencial concentração para induzir efeito anticonvulsivante em estudo envolvendo abrasamento elétrico rápido da amígdala em ratos Wistar.

3. Dados qualitativos da cromatografia gasosa e algoritmos matemáticos possibilitaram estabelecer as concentrações na câmara para as diferentes doses de TMT. Além disso, a cromatografia gasosa identificou que 30 minutos é o tempo necessário para saturação e dessaturação da câmara ao TMT, e indicou uma saturação homogênea do interior dessa câmara.

4. O TMT foi capaz de reduzir significativamente Índice de Gravidade para Crises Límbicas, comparado ao controle.

5. Dados neuroetológicos indicam o aumento do recrutamento de áreas cerebrais, do $1^{\circ}$ ao $20^{\circ}$ estímulos, e demonstram efeito supressor do TMT nas crises, evidenciado no $21^{\circ}$ Estímulo.

6. Resultados da duração da pós descarga primária no $21^{\circ}$ estímulo foram inconclusivos, sendo necessárias outras análises empregando diferentes métodos analíticos.

7. A técnica de FJC indicou ausência de marcação cerebral para a morte neuronal por necrose em qualquer região cerebral avaliada, de animais expostos ao abrasamento elétrico rápido, ou ao TMT, e/ou ao abrasamento elétrico rápido com TMT.

8. Em estudo comparativo, o TMT desencadeou reações de medo e modificou as sequências comportamentais das crises, bloqueando-as ou retardando a ocorrência das CVTs nas crises audiogênicas agudas com a cepa WAR. 

TABELA COMPLEMENTAR 1. Dicionário de alguns dos itens comportamentais e suas correspondentes siglas, observados no presente estudo (Garcia-Cairasco et al., 1992).

\begin{tabular}{|c|c|c|c|c|c|}
\hline Port & Descrição & Port & Descrição & Port & Descrição \\
\hline $\mathrm{AL}$ & $\begin{array}{l}\text { Autolimpeza } \\
\text { frontal }\end{array}$ & DEID & Deitar & OPIS & Opistotonus \\
\hline ALD & $\begin{array}{l}\text { Autolimpeza } \\
\text { direita }\end{array}$ & EL & Elevação & POHL & Piscar os olhos \\
\hline ALE & $\begin{array}{l}\text { Autolimpeza } \\
\text { esquerda }\end{array}$ & ER & Ereto & $\mathrm{PIV}_{1}$ & Pivotear \\
\hline ALER & Alerta & ECL & $\begin{array}{l}\text { Espasmo } \\
\text { clônico }\end{array}$ & PR & Parar \\
\hline ALG & $\begin{array}{l}\text { Autolimpeza de } \\
\text { genitais }\end{array}$ & FCB & $\begin{array}{l}\text { Flexão } \\
\text { cabeça }\end{array}$ & PU & Pular \\
\hline AP & Apnéia & GID & Girar à direita & QT & Queda atônica \\
\hline $\mathrm{BC}$ & Bocejar & GIE & $\begin{array}{l}\text { Girar à esquerda } \\
\text { Hiperextensão }\end{array}$ & $\mathrm{RE}$ & Recuar \\
\hline СBC & Cabeceio & $\mathrm{HP}_{1}$ & $\begin{array}{l}\text { de patas } \\
\text { anteriores }\end{array}$ & RO & Roer \\
\hline CCD & Coçar à direita & IMO & $\begin{array}{l}\text { Imobilidade } \\
\text { pós-ictal }\end{array}$ & $\mathrm{SAC}_{1}$ & $\begin{array}{l}\text { Sacudir } \\
\text { cabeça }\end{array}$ \\
\hline CCE & $\begin{array}{ll}\text { Coçar } & \text { à } \\
\text { esquerda }\end{array}$ & LA & Lamber & $\mathrm{SAC}_{2}$ & Sacudir o corpo \\
\hline $\mathrm{CG}$ & Congelar & LCB & Lavar a cabeça & SAL & Salivação \\
\hline CHP & $\begin{array}{l}\text { Cheirar } \\
\text { exploratório }\end{array}$ & LG & $\begin{array}{l}\text { Limpeza de } \\
\text { garra }\end{array}$ & SCR & Defecar \\
\hline $\mathrm{CM}$ & Caminhar & LGD1 & $\begin{array}{l}\text { Limpar a garra } \\
\text { anterior direita }\end{array}$ & SOB & Sobressalto \\
\hline COR & Correr & LGD2 & $\begin{array}{l}\text { Limpar a garra } \\
\text { posterior direita }\end{array}$ & SQ & Esquadrinhar \\
\hline CVCg & $\begin{array}{l}\text { Convulsão } \\
\text { clônica } \\
\text { generalizada }\end{array}$ & LGE1 & $\begin{array}{l}\text { Limpar a garra } \\
\text { anterior } \\
\text { esquerda }\end{array}$ & STN & Estendido \\
\hline CVCp & $\begin{array}{l}\text { Convulsão } \\
\text { clônica parcial }\end{array}$ & LGE2 & $\begin{array}{l}\text { Limpar a garra } \\
\text { posterior } \\
\text { esquerda }\end{array}$ & TQ & Taquipnéia \\
\hline CVC1 & $\begin{array}{l}\text { Conv. } \quad \mathrm{Cl} \text {. } \\
\text { Sincrônicas pata } \\
\text { anterior }\end{array}$ & LVF & Lavar o focinho & & \\
\hline CVC2 & $\begin{array}{l}\text { Conv. Cl. } \\
\text { Sincrônicas pata } \\
\text { posterior }\end{array}$ & $\mathrm{MIO}_{1}$ & $\begin{array}{l}\text { Mioclonia de } \\
\text { patas anteriores }\end{array}$ & & \\
\hline CVT & $\begin{array}{l}\text { Convulsão } \\
\text { tônica-clônica }\end{array}$ & MIOc & $\begin{array}{l}\text { Mioclonia de } \\
\text { cabeça }\end{array}$ & & \\
\hline DCE & $\begin{array}{l}\text { Dobramento } \\
\text { corporal à } \\
\text { esquerda }\end{array}$ & MAST & Mastigar & & \\
\hline
\end{tabular}





\section{REFERÊNCIAS BIBLIOGRÁFICAS}

APFELBACH, R. et al. The effects of predator odors in mammalian prey species: a review of field and laboratory studies. Neuroscience and biobehavioral reviews, v. 29, n. 8, p. 1123-44, jan. 2005.

ARISI, G. M. et al. The role of olfactory stimulus in adult mammalian neurogenesis. Behavioural brain research, v. 227, n. 2, p. 356-62, 14 fev. 2012.

AYERS, L. W. et al. Freezing to the predator odor 2,4,5 dihydro 2,5 trimethylthiazoline (TMT) is disrupted by olfactory bulb removal but not trigeminal deafferentation. Behavioural brain research, v. 253, p. 54-9, 15 set. 2013.

BEN-ARI, Y. et al. Diazepam pretreatment reduces distant hippocampal damage induced by intra-amygdaloid injections of kainic acid. European journal of pharmacology, v. 52, n. 3-4, p. 41920, 1 dez. 1978.

BERG, A. T. et al. Revised terminology and concepts for organization of seizures and epilepsies: report of the ILAE Commission on Classification and Terminology, 2005-2009. Epilepsia, v. 51 , n. 4 , p. $676-85$, abr. 2010.

BERTRAM, E. The Relevance of Kindling for Human Epilepsy. Epilepsia, v. 48, n. s2, p. 6574, abr. 2007.

BERTTI, P. et al. Estímulo olfatório intenso bloqueia crises num modelo experimental de epilepsia. In: XXXIII Congresso da Liga Brasileira de Epilepsia, 2010, Brasília - DF. Journal of Epilepsy and Clinical Neurophysiology (Impresso), 2010. v. 16. p. 64-65.

BERTTI, P. et al. The neurobiological substrates of behavioral manifestations during temporal lobe seizures: a neuroethological and ictal SPECT correlation study. Epilepsy \& behavior : E\&B, v. 17, n. 3, p. 344-53, mar. 2010.

BERTTI P, et al. Odorant and sound can be antagonistic sensory stimuli in an audiogenic model of epilepsy? In: Society for Neuroscience Meeting 2013, San Diego. 2013.

BERTTI, P. et al. Intense olfactory stimulation blocks seizures in an experimental model of epilepsy. In: 29th International Epilepsy Congress, 2011, Roma. Epilepsia (Copenhagen. Online), 2011. v. 52. p. 41-41.

BERTTI, P. et al. Looking for complexity in quantitative semiology of frontal and temporal lobe seizures using neuroethology and graph theory. Epilepsy \& behavior : E\&B, v. Epub ahed, 9 set. 2014.

BETTS, T. Use of aromatherapy (with or without hypnosis) in the treatment of intractable epilepsy - a two-year follow-up study. Seizure, v. 12, n. 8, p. 534-538, dez. 2003. 
BLANCHARD, D. C. et al. Failure to produce conditioning with low-dose trimethylthiazoline or cat feces as unconditioned stimuli. Behavioral Neuroscience, v. 117, n. 2, p. 360-368, 2003.

BLANCHARD, D. C.; BLANCHARD, R. J.; ROSEN, J. Olfaction and defense. Neuroscience and biobehavioral reviews, v. 32, n. 7, p. 1207-8, set. 2008.

BLANCHARD, R. J. et al. Cue and context conditioning of defensive behaviors to cat odor stimuli. v. 25, p. 587-595, 2001.

BRANDÃO, ML; et al. As bases biológicas do comportamento: Introdução à

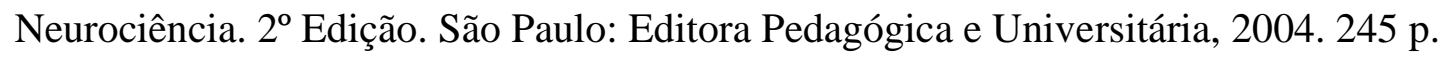

BUCK, L.; AXEL, R. A novel multigene family may encode odorant receptors: a molecular basis for odor recognition. Cell, v. 65, n. 1, p. 175-87, 5 abr. 1991.

CASTRO, O. W. et al. Comparative neuroanatomical and temporal characterization of FluoroJade-positive neurodegeneration after status epilepticus induced by systemic and intrahippocampal pilocarpine in Wistar rats. Brain research, v. 1374, p. 43-55, 16 fev. 2011.

CAVALHEIRO, E. A. The pilocarpine model of epilepsy. Ital J Neurol Sci., v. 1, p. 33-7, 1995.

CHAUVEL, P.; MCGONIGAL, A. Emergence of semiology in epileptic seizures. Epilepsy \& behavior : E\&B, 11 jan. 2014.

COLlinS, C. H; BRAGA, G. L; BONATO P. S. Introdução a métodos cromatográficos. $5^{\text {a }}$ edição. Campinas: Editora da Unicamp, 2006. 453 p.

Commission on classification and terminology of the International League Against Epilepsy. Proposal for revised clinical and electroencephalographic classification of epileptic seizures. Epilepsia. 1981;22:489-501.

DAL-CÓL, M. L. C. et al. Neuroethology application for the study of human temporal lobe epilepsy: from basic to applied sciences. Epilepsy \& behavior : E\&B, v. 8, n. 1, p. 14960, mar. 2006.

DAL-CÓL, M. L. C. et al. Is dystonic posturing during temporal lobe epileptic seizures the expression of an endogenous anticonvulsant system? Epilepsy \& behavior : E\&B, v. 12, n. 1, p. 39-48, jan. 2008.

DANTAS, F. G. et al. Clinical and EEG analysis of mesial and lateral temporal lobe seizures. Arquivos de neuro-psiquiatria, v. 56, n. 3A, p. 341-9, out. 1998.

DAY, H. E. W.; MASINI, C. V; CAMPEAU, S. The pattern of brain c-fos mRNA induced by a component of fox odor, 2,5-dihydro-2,4,5-trimethylthiazoline (TMT), in rats, suggests both systemic and processive stress characteristics. Brain research, v. 1025, n. 1-2, p. 139-51, 29 out. 2004. 
DIAS SOARES, D. et al. Fox odour affects corticosterone release but not hippocampal serotonin reuptake and open field behaviour in rats. Brain research, v. 961, n. 1, p. 166-70, 24 jan. 2003.

DINGLEDINE, R.; VARVEL, N. H.; DUDEK, F. E. When and how do seizures kill neurons, and is cell death relevant to epileptogenesis? Advances in experimental medicine and biology, $v$. 813, p. 109-22, jan. 2014.

DORETTO, M. C. et al. Quantitative study of the response to genetic selection of the Wistar audiogenic rat strain (WAR). Behavior genetics, v. 33, n. 1, p. 33-42, jan. 2003.

EBERT, U.; LÖSCHER, W. Differences in mossy fibre sprouting during conventional and rapid amygdala kindling of the rat. Neuroscience letters, v. 190, n. 3, p. 199-202, 12 maio 1995.

EBERT, U.; LÖSCHER, W. Strong olfactory stimulation reduces seizure susceptibility in amygdala-kindled rats. Neuroscience letters, v. 287, n. 3, p. 199-202, 30 jun. 2000.

EFRON, R. The effect of olfactory stimuli in arresting uncinate fits. Brain : a journal of neurology, v. 79, n. 2, p. 267-81, jun. 1956.

EFRON, R. The conditioned inhibition of uncinate fits. Brain : a journal of neurology, v. 80, n. 2, p. 251-62, jun. 1957.

ENDRES, T.; APFELBACH, R.; FENDT, M. Behavioral Changes Induced in Rats by Exposure to Trimethylthiazoline, a Component of Fox Odor. Behavioral neuroscience, v. 119, n. 4, p. 1004-1010, ago. 2005.

ENGEL, J. Concepts of epilepsy. Epilepsia, v. 36 Suppl 1, p. S23-9, jan. 1995.

ENGEL, J. A proposed diagnostic scheme for people with epileptic seizures and with epilepsy: report of the ILAE Task Force on Classification and Terminology. Epilepsia, v. 42, n. 6, p. 796-803, jun. 2001.

FANSELOW, E. E.; REID, A. P.; NICOLELIS, M. A. Reduction of pentylenetetrazoleinduced seizure activity in awake rats by seizure-triggered trigeminal nerve stimulation. The Journal of neuroscience : the official journal of the Society for Neuroscience, v. 20, n. 21, p. 8160-8, 1 nov. 2000.

FENDT, M. et al. TMT-induced autonomic and behavioral changes and the neural basis of its processing. Neuroscience and biobehavioral reviews, v. 29, n. 8, p. 1145-56, jan. 2005.

FENDT, M.; ENDRES, T. 2,3,5-Trimethyl-3-thiazoline (TMT), a component of fox odor just repugnant or really fear-inducing? Neuroscience and biobehavioral reviews, v. 32, n. 7, p. 125966, set. 2008.

FENDT, M.; ENDRES, T.; APFELBACH, R. Temporary Inactivation of the Bed Nucleus of the Stria Terminalis But Not of the Amygdala Blocks Freezing Induced by Trimethylthiazoline, a Component of Fox Feces. v. 23, n. 1, p. 23-28, 2003.

FERNANDES, RMF. O Eletrencefalograma na Caracterização das Síndromes Epilépticas. 
http://www.lasse.med.br/mat_didatico/lasse1/textos/regina01.html. Acesso em: 29 de out. 2014.

FISHER, R. S. Animal models of the epilepsies. Brain research. Brain research reviews, v. 14, n. 3, p. 245-78, 1989.

FISHER, R. S. et al. Epileptic seizures and epilepsy: definitions proposed by the International League Against Epilepsy (ILAE) and the International Bureau for Epilepsy (IBE). Epilepsia, v. 46, n. 4, p. 470-2, abr. 2005.

FITZGERALD, P. J. Is elevated norepinephrine an etiological factor in some cases of epilepsy? Seizure, v. 19, n. 6, p. 311-8, jul. 2010.

FONG, J. S. et al. Seizure outcome and its predictors after temporal lobe epilepsy surgery in patients with normal MRI. Epilepsia, v. 52, n. 8, p. 1393-401, ago. 2011.

FORESTI, ML. Efeito da quelação de zinco no desenvolvimento de crises epilépticas límbicas no modelo de abrasamento elétrico rápido da amígdala. 2008. Tese (Doutorado em Ciências Médicas) - Universidade de São Paulo, Ribeirão Preto. 2008.

FORESTI, M. L. et al. Chelatable zinc modulates excitability and seizure duration in the amygdala rapid kindling model. Epilepsy research, v. 79, n. 2-3, p. 166-72, maio 2008.

FURTADO, M. A. et al. Study of spontaneous recurrent seizures and morphological alterations after status epilepticus induced by intrahippocampal injection of pilocarpine. Epilepsy \& behavior: $\mathbf{E} \& \mathbf{B}$, v. 20, n. 2, p. 257-66, mar. 2011.

FURTADO, M. DE A. et al. Behavioral, morphologic, and electroencephalographic evaluation of seizures induced by intrahippocampal microinjection of pilocarpine. Epilepsia, v. 43 Suppl 5, p. 37-9, jan. 2002.

GARCIA-CAIRASCO, N. et al. New insights into behavioral evaluation of audiogenic seizures. A comparison of two ethological methods. Behavioural brain research, v. 48, n. 1, p. 4956, 8 maio 1992.

GARCIA-CAIRASCO, N. et al. Neuroethological and morphological (Neo-Timm staining) correlates of limbic recruitment during the development of audiogenic kindling in seizure susceptible Wistar rats. Epilepsy research, v. 26, n. 1, p. 177-92, dez. 1996.

GARCIA-CAIRASCO, N. A critical review on the participation of inferior colliculus in acoustic-motor and acoustic-limbic networks involved in the expression of acute and kindled audiogenic. Hearing research, v. 168, p. 208-222, 2002.

GARCIA-CAIRASCO, N.; SABBATINI, R. M. Role of the substantia nigra in audiogenic seizures: a neuroethological analysis in the rat. Brazilian journal of medical and biological research = Revista brasileira de pesquisas médicas e biológicas / Sociedade Brasileira de Biofísica [et al.], v. 16, n. 2, p. 171-83, jul. 1983. 
GHORBANI, P. et al. Effect of different patterns of low-frequency stimulation on piriform cortex kindled seizures. Neuroscience letters, v. 425, n. 3, p. 162-6, 2 out. 2007.

GIORGI, F. S. et al. The role of norepinephrine in epilepsy: from the bench to the bedside. Neuroscience and biobehavioral reviews, v. 28, n. 5, p. 507-24, set. 2004.

GODDARD, G. V. Development of epileptic seizures through brain stimulation at low intensity. Nature, v. 214, n. 5092, p. 1020-1, 3 jun. 1967.

GODDARD, G. V; MCINTYRE, D. C.; LEECH, C. K. A permanent change in brain function resulting from daily electrical stimulation. Experimental neurology, v. 25, n. 3, p. 295-330, nov. 1969.

GODDARD, G. V. The kindling model of epilepsy. Trends in Neurosciences, v. 6, n. July, p. 275-279, 1983.

GROSS, C. T.; CANTERAS, N. S. The many paths to fear. Nature reviews. Neuroscience, v. 13, n. 9, p. 651-8, set. 2012.

GUTIYAMA, L. M. RIC-8B, um fator trocador de nucleotídeo guanina (GEF), é essencial para a embriogênese.2013. 146 f. Tese (Doutorado em Bioquímica), - Universidade de São Paulo, São Paulo. 2013.

HACQUEMAND, R. et al. Comparison between low doses of TMT and cat odor exposure in anxiety- and fear-related behaviors in mice. Behavioural brain research, v. 238, p. 227-31, 1 fev. 2013.

HACQUEMAND, R.; JACQUOT, L.; BRAND, G. Comparative Fear-Related Behaviors to Predator Odors (TMT and Natural Fox Feces) before and after Intranasal ZnSO(4) Treatment in Mice. Frontiers in behavioral neuroscience, v. 4, p. 188, jan. 2010.

HEGAB, I. M.; WEI, W. Neuroendocrine changes upon exposure to predator odors. Physiology \& behavior, v. 131, p. 149-55, 28 maio 2014.

HOLMES, M. M.; GALEA, L. A. M. Defensive behavior and hippocampal cell proliferation: differential modulation by naltrexone during stress. Behavioral neuroscience, v. 116, n. 1, p. 160-8, fev. 2002.

HORII, Y. et al. Exposure to TMT odor affects adrenal sympathetic nerve activity and behavioral consequences in rats. Behavioural brain research, v. 214, n. 2, p. 317-22, 25 dez. 2010.

ISAACSON, J. S. Odor representations in mammalian cortical circuits. Current opinion in neurobiology, v. 20, n. 3, p. 328-31, jun. 2010.

JASEJA, H. Scientific basis behind traditional practice of application of "shoe-smell" in controlling epileptic seizures in the eastern countries. Clinical Neurology and Neurosurgery, v. 110, n. 6, p. 535-538, jun. 2008. 
JOBE, P. C.; BROWNING, R. A. The serotonergic and noradrenergic effects of antidepressant drugs are anticonvulsant, not proconvulsant. Epilepsy \& behavior : E\&B, v. 7, n. 4, p. 602-19, dez. 2005.

KANDRATAVICIUS, L. et al. Animal models of epilepsy: use and limitations. p. 1693-1705, 2014.

KERR, J. F. Shrinkage necrosis of adrenal cortical cells. The Journal of pathology, v. 107, n. 3, p. 217-9, jul. 1972.

LASKA, M. et al. Detecting danger--or just another odorant? Olfactory sensitivity for the fox odor component 2,4,5-trimethylthiazoline in four species of mammals. Physiology \& behavior, v. 84, n. 2, p. 211-5, 15 fev. 2005.

LÖSCHER, W. et al. Susceptibility of different cell layers of the anterior and posterior part of the piriform cortex to electrical stimulation and kindling: comparison with the basolateral amygdala and "area tempestas". Neuroscience, v. 66, n. 2, p. 265-76, maio 1995.

LÖSCHER, W.; BRANDT, C. Prevention or modification of epileptogenesis after brain insults: experimental approaches and translational research. Pharmacological reviews, v. 62, n. 4, p. 668-700, dez. 2010.

LÖSCHER, W.; EBERT, U. The role of the piriform cortex in kindling. Progress in neurobiology, v. 50, n. 5-6, p. 427-81, dez. 1996.

LOTHMAN, E. W. et al. Kindling with rapidly recurring hippocampal seizures. Brain research, v. 360, n. 1-2, p. 83-91, 23 dez. 1985.

LÜDERS, H. et al. Semiological seizure classification. Epilepsia, v. 39, n. 9, p. 1006-13, out. 1998.

LUNARDI, M. D. S. et al. Seizure precipitants and inhibiting factors in mesial temporal lobe epilepsy. Journal of the neurological sciences, v. 308, n. 1-2, p. 21-4, 15 set. 2011.

MALNIC, B. Searching for the ligands of odorant receptors. Molecular neurobiology, v. 35, n. 2, p. 175-81, maio 2007.

MALNIC, B. O cheiro das coisas: o sentido do olfato: paladar, emoções e comportamentos. Vieira \& Lent. Rio de Janeiro, 2008.

MARRONI, S. S. et al. Neuroanatomical and cellular substrates of hypergrooming induced by microinjection of oxytocin in central nucleus of amygdala, an experimental model of compulsive behavior. Molecular psychiatry, v. 12, n. 12, p. 1103-17, dez. 2007.

MASINI, C. V et al. Accessory and main olfactory systems influences on predator odorinduced behavioral and endocrine stress responses in rats. Behavioural brain research, v. 207, n. 1, p. 70-7, 11 fev. 2010.

MCGREGOR, I. S. et al. Not all "predator odours" are equal: cat odour but not 2,4,5 trimethylthiazoline (TMT; fox odour) elicits specific defensive behaviours in rats. Behavioural brain research, v. 129, n. 1-2, p. 1-16, 1 fev. 2002. 
MCNAMARA, J. O. et al. The kindling model of epilepsy: a review. Progress in neurobiology, v. 15, n. 2, p. 139-59, jan. 1980.

MCNAMARA, J. O. Emerging insights into the genesis of epilepsy. Nature, v. 399, n. 6738 Suppl, p. A15-22, 24 jun. 1999.

MEDEIROS, D. D. C.; MORAES, M. F. D. Focus on desynchronization rather than excitability: A new strategy for intraencephalic electrical stimulation. Epilepsy \& behavior : E\&B, 25 jan. 2014.

MORAES, MFD. Epilepsia Experimental: estudos eletrofisiológicos $e$ comportamentais em modelos de animais de crises convulsivas audiogênicas. 1998. Tese (Doutorado em Ciências Básicas) - Universidade de São Paulo, Ribeirão Preto. 1998.

MORICEAU, S. et al. Corticosterone controls the developmental emergence of fear and amygdala function to predator odors in infant rat pups. International journal of developmental neuroscience : the official journal of the International Society for Developmental Neuroscience, v. 22, n. 5-6, p. 415-22, 2004.

MORROW, B. A. et al. The predator odor, TMT, displays a unique, stress-like pattern of dopaminergic and endocrinological activation in the rat. Brain Research, v. 864, n. 1, p. 146-151, 2000 .

MORROW, B. A.; ELSWORTH, J. D.; ROTH, R. H. Fear-like biochemical and behavioral responses in rats to the predator odor, TMT, are dependent on the exposure environment. Synapse (New York, N.Y.), v. 46, n. 1, p. 11-8, out. 2002.

MORROW, B. A.; ROTH, R. H.; ELSWORTH, J. D. TMT, a predator odor, elevates mesoprefrontal dopamine metabolic activity and disrupts short-term working memory in the rat. Brain research bulletin, v. 52, n. 6, p. 519-23, ago. 2000.

NIKAIDO, Y.; NAKASHIMA, T. Effects of environmental novelty on fear-related behavior and stress responses of rats to emotionally relevant odors. Behavioural brain research, v. 199, n. 2, p. 241-6, 16 maio 2009.

NOEBELS, J. L. et al. Jasper's Basic Mechanisms of the Epilepsies, Fourth Edition. by Oxford University Press. 2012.

PAXINOS, G; WATSON, C. The rat brain in stereotaxic coordinates, Fourth Edition.. San Diego: Paxinos G, Watson C (Eds). 1997.

PEREIRA, P. D. et al. Caracterização neuroetológica dos efeitos da exposição ao estímulo olfatório com TMT nas crises audiogênicas aguda. In: $35^{\circ}$ Congresso da Liga Brasileira de Epilepsia, 2014, Foz do Iguaçu. Journal of Epilepsy and Clinical Neurophysiology, 2014.

PINEL, J. P.; ROVNER, L. I. Experimental epileptogenesis: kindling-induced epilepsy in rats. Experimental neurology, v. 58, n. 2, p. 190-202, 15 jan. 1978a. 
PINEL, J. P.; ROVNER, L. I. Experimental epileptogenesis: kindling-induced epilepsy in rats.

Experimental neurology, v. 58, n. 2, p. 190-202, 15 jan. 1978b.

PIREDDA, S.; LIM, C. R.; GALE, K. No Title. v. 36, n. c, p. 1295-1298, 1985.

PITKÄNEN, A. et al. Amygdala damage in experimental and human temporal lobe epilepsy. Epilepsy research, v. 32, n. 1-2, p. 233-53, set. 1998.

PITKÄNEN, A. Therapeutic approaches to epileptogenesis--hope on the horizon. Epilepsia, v. 51 Suppl 3, p. 2-17, jul. 2010.

PITKÄNEN, A.; LUKASIUK, K. Molecular and cellular basis of epileptogenesis in symptomatic epilepsy. Epilepsy \& behavior : E\&B, v. 14 Suppl 1, p. 16-25, jan. 2009.

RACINE, R. J. Modification of seizure activity by electrical stimulation. II. Motor seizure. Electroencephalography and clinical neurophysiology, v. 32, n. 3, p. 281-94, mar. 1972.

RACINE, R. J. et al. Rates of motor seizure development in rats subjected to electrical brain stimulation: strain and inter-stimulation interval effects. Electroencephalography and Clinical Neurophysiology, v. 35, n. 5, p. 553-556, nov. 1973.

REDMOND, A. J. et al. Selective activation of the A10, but not A9, dopamine neurons in the rat by the predator odor, 2,5-dihydro-2,4,5-trimethylthiazoline. Neuroscience letters, v. 328, n. 3, p. 209-12, 16 ago. 2002.

RESTREPO, D.; HELLIER, J. L.; SALCEDO, E. Complex metabolically demanding sensory processing in the olfactory system: Implications for epilepsy. Epilepsy and Behavior, p. 6-11, 7 out. 2013.

RODRIGUES, M. C. A. et al. Correlation between shaking behaviors and seizure severity in five animal models of convulsive seizures. Epilepsy \& behavior : E\&B, v. 6, n. 3, p. 328-36, maio 2005.

ROMCY-PEREIRA, RN. Plasticidade Límbica em Ratos Submetidos a Crise Audiogênicas Crônicas: Análise de EEG, Proliferação e Morte Neuronal. 2001. Tese (Doutorado em Ciências Básicas) - Universidade de São Paulo, Ribeirão Preto. 2001.

ROMCY-PEREIRA, R. N. et al. A semi-automated algorithm for studying neuronal oscillatory patterns: a wavelet-based time frequency and coherence analysis. Journal of neuroscience methods, v. 167, n. 2, p. 384-92, 30 jan. 2008.

ROMCY-PEREIRA, R. N.; GARCIA-CAIRASCO, N. Hippocampal cell proliferation and epileptogenesis after audiogenic kindling are not accompanied by mossy fiber sprouting or FluoroJade staining. Neuroscience, v. 119, n. 2, p. 533-46, jan. 2003.

ROSEN, J. B. The neurobiology of conditioned and unconditioned fear: a neurobehavioral system analysis of the amygdala. Behavioral and cognitive neuroscience reviews, v. 3, n. 1, p. 2341, mar. 2004. 
ROSEN, J. B. et al. Analysis of behavioral constraints and the neuroanatomy of fear to the predator odor trimethylthiazoline: a model for animal phobias. Neuroscience and biobehavioral reviews, v. 32, n. 7, p. 1267-76, set. 2008.

ROSEN, J. B.; WEST, E. A.; DONLEY, M. P. Not all rat strains are equal: differential unconditioned fear responses to the synthetic fox odor 2,4,5-trimethylthiazoline in three outbred rat strains. Behavioral neuroscience, v. 120, n. 2, p. 290-7, abr. 2006.

ROSSETTI, F. et al. EEG wavelet analyses of the striatum-substantia nigra pars reticulatasuperior colliculus circuitry: audiogenic seizures and anticonvulsant drug administration in Wistar audiogenic rats (War strain). Epilepsy research, v. 72, n. 2-3, p. 192-208, dez. 2006.

SAKAMOTO, AC; et al. Atualizações no tratamento cirúrgico das Epilepsias. São Paulo: Câmara Brasileira do Livro, 2002. 253 p.

SAYIN, U. et al. Spontaneous seizures and loss of axo-axonic and axo-somatic inhibition induced by repeated brief seizures in kindled rats. The Journal of neuroscience : the official journal of the Society for Neuroscience, v. 23, n. 7, p. 2759-68, 1 abr. 2003.

SCHMUED, L. C.; ALBERTSON, C.; SLIKKER, W. Fluoro-Jade: a novel fluorochrome for the sensitive and reliable histochemical localization of neuronal degeneration. Brain research, v. 751, n. 1, p. 37-46, 14 mar. 1997.

STAPLES, L. G.; MCGREGOR, I. S. Defensive responses of Wistar and Sprague-Dawley rats to cat odour and TMT. v. 172, p. 351-354, 2006.

SU, C.-Y.; MENUZ, K.; CARLSON, J. R. Olfactory perception: receptors, cells, and circuits. Cell, v. 139, n. 1, p. 45-59, 2 out. 2009.

TAKAHASHI, L. K. Olfactory systems and neural circuits that modulate predator odor fear. Frontiers in behavioral neuroscience, v. 8, n. March, p. 72, jan. 2014.

TEJADA, J. et al. The epilepsies: complex challenges needing complex solutions. Epilepsy $\&$ behavior : E\&B, v. 26, n. 3, p. 212-28, mar. 2013.

THOMAS, R. M.; URBAN, J. H.; PETERSON, D. A. Acute exposure to predator odor elicits a robust increase in corticosterone and a decrease in activity without altering proliferation in the adult rat hippocampus. Experimental neurology, v. 201, n. 2, p. 308-15, out. 2006.

TILELLI, C. Q. Estudo de alterações comportamentais, eletrofiológicoas e morfológicas num modelo animal para o estudo das Epilepsias. 2003. Tese (Doutorado em Ciências Básicas) - Universidade de São Paulo, Ribeirão Preto. 2003.

TILELLI, C. Q. et al. Different types of status epilepticus lead to different levels of brain damage in rats. Epilepsy \& behavior : E\&B, v. 7, n. 3, p. 401-10, nov. 2005.

TURSKI, W. A. et al. Limbic seizures produced by pilocarpine in rats: behavioural, electroencephalographic and neuropathological study. Behavioural Brain Research, v. 9, p 315-335, 1983. 
VALENTINE, P. A.; FREMIT, S. L.; TESKEY, G. C. Sensory stimulation reduces seizure severity but not afterdischarge duration of partial seizures kindled in the hippocampus at threshold intensities. Neuroscience Letters, v. 388, n. 1, p. 33-38, 4 nov. 2005.

WALLACE, K. J.; ROSEN, J. B. Neurotoxic lesions of the lateral nucleus of the amygdala decrease conditioned fear but not unconditioned fear of a predator odor: comparison with electrolytic lesions. The Journal of neuroscience : the official journal of the Society for Neuroscience, v. 21, n. 10, p. 3619-27, 15 maio 2001.

WIN-SHWE, T.-T.; FUJIMAKI, H. Neurotoxicity of toluene. Toxicology letters, v. 198, n. 2, p. $93-9,5$ out. 2010.

WOOD, R. W. et al. Anticonvulsant and antipunishment effects of toluene. The Journal of pharmacology and experimental therapeutics, v. 230, n. 2, p. 407-12, ago. 1984.

WHO EPILEPSY. Disponível em: <http://www.who.int/mediacentre/factsheets/fs999/en/index.htmL> . Acesso em: 29 de out. 2014.

YÜCEL, M. et al. Toluene misuse and long-term harms: a systematic review of the neuropsychological and neuroimaging literature. Neuroscience and biobehavioral reviews, v. 32, n. 5, p. 910-26, jul. 2008. 
10 ANOTAÇÕES 
